Document downloaded from:

http://hdl.handle.net/10251/101715

This paper must be cited as:

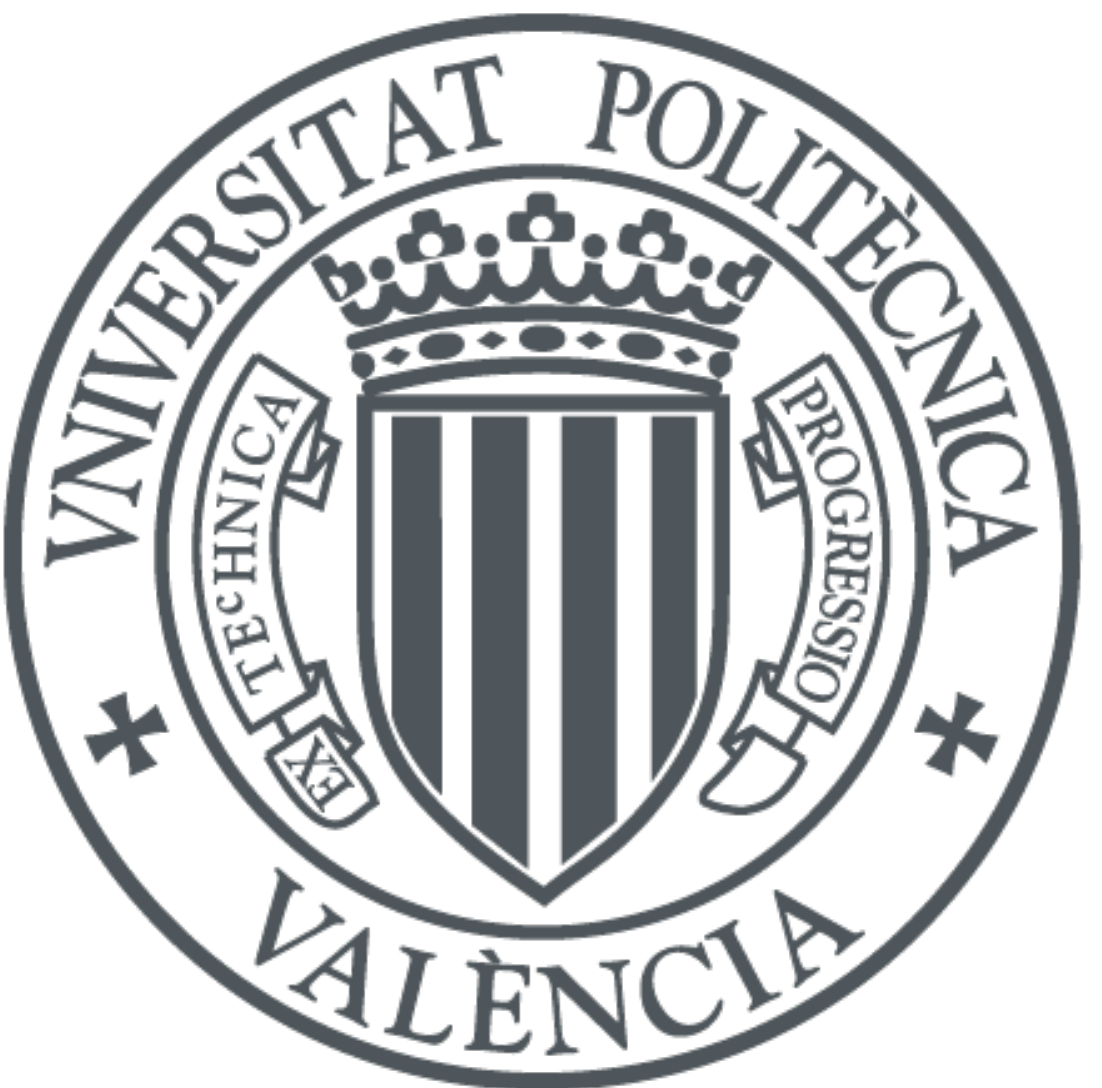

The final publication is available at

http://doi.org/10.1039/c1ra00807b

Copyright ROYAL SOC CHEMISTRY

Additional Information 


\title{
Homogeneous and Heterogeneous Catalysts for Multicomponent Reactions
}

\author{
Maria José Climent, Avelino Corma* and Sara Iborra
}

Instituto de Tecnología Química, UPV-CSIC ;

Universitat Politécnica de Valencia.

Avda. de los Naranjos s/n ; 46022 Valencia - SPAIN

Phone: + 3496 3877800, Fax: + 34963879444

${ }^{*}$ To whom correspondence should be addressed

\begin{tabular}{|c|c|c|}
\hline \multirow{3}{*}{ Avelino Corma } & E-mail & acorma@itq.upv.e \\
\hline & Fax: & (+34) 963877809 \\
\hline & Phone: & (+34) 963877800 \\
\hline
\end{tabular}




\section{Introduction}

Organic-chemical synthesis performed through one-pot, tandem, domino or cascade reactions $^{1-2}$ have become a significant area of research in organic chemistry ${ }^{3-10}$ since such processes improve atom economy. The One-pot transformations can be carried out through multi-step sequential processes where the consecutive steps take place under the same reaction conditions or, when this is not possible, they can be performed in two or more stages under different reaction conditions, with the adequate sequence of reactants addition. There are cases however, in were the desired product can be prepared in one-pot mode throught a multicomponent reaction. Multicomponent reactions (MCRs) are defined as reactions which occur in one reaction vessel and involve more than two starting reagents that form a single product which contains the essential parts of the starting materials. ${ }^{11-12}$ Thus, an ideal multicomponent reaction involves the simultaneous addition of reactants, reagents and catalyst at the beginning of the reaction and requires that all reactants couple in an exclusive ordered mode under the same reaction conditions. The success of multi-step sequential or multicomponent one-pot transformations, requires a balance of equilibria and a suitable sequence of reversible and irreversible steps. Thus, in the case of MCRs three types of reactions are known: ${ }^{13}$ a) Type I MCRs in which there is equilibrium between reactants, intermediates and final products; b) Type II MCRs in where equilibrium exists between reactants and intermediates being the final product irreversibly formed; c) Type III MCRs which involve a sequence of practically irreversible steps that proceed from the reactants to the products. Type III MCRs is usual in biochemicals transformations, but rarely occurs in preparative chemistry. ${ }^{13}$

MCRs have been known for over 150 years and it is generally considered that this chemistry began in 1850 when Strecker ${ }^{14}$ reported the general formation of $\alpha$ aminocyanides from amonia, carbonyl compounds and hydrogen cyanide. Since then, many multicomponent reactions have been developed, some of the first examples are the Hantzsch dihydropyridine synthesis $(1882)^{15}$ the Biginelli ${ }^{16}$ 3CR (1893) (Scheme 1). The first isocyanide-based 3CRs was introduced by Passerini in 1921 while in 1959 Ugi introduced the four component reaction of the isocyanides ${ }^{17}$ which involves the one-pot reaction of amines, carbonyl compounds, acid and isocyanides. The Ugi 
reaction has been the most extensively studied and applied MCRs in the drug discovery process.

Scheme 1 Preparation of privileged scaffolds by a) Biginelli reaction, b) Hantzsch synthesis and c) Ugi deBoc/cyclize methodology

One key aspect of the multicomponent reactions is that they are an important source of molecular diversity. ${ }^{18}$ For instance, a three component coupling reaction will provide 1000 compounds when 10 variants of each component are employed. This aspect together with its inherent simple experimental procedures and its one-pot character, make MCRs highly suitable for automated synthesis. They are powerful tools in modern drug discovery processes allowing rapid, automated and high throughput generation of organic compounds. ${ }^{19-22}$ Additionally the one-pot character, deliver less by-products compared to classical stepwise synthetic routes, with lower costs, time and energy.

Although most of the established MCRs do not require a catalyst, the search of new MCR products has resulted in an intensified effort to find catalysts and new catalyzed MCRs. We will show that while a variety of homogeneous and heterogeneous catalysts have been reported to perform MCRs, the advantages inherent to the use of heterogeneous catalysts, undoubtedly would reinforce the environmental benefits of these interesting reactions.

In this work we will review a large variety of MCRs, particularly three-component coupling reactions $\left(\mathrm{A}^{3}\right.$ coupling) performed with acid, base and metal heterogeneous catalysts as well as with bifunctional catalytic systems. We will present within each type of MCR, relevant products that can be obtained and their interest for industrial applications.

\section{Solid catalysts of interest for MCR}

The simplest approximation to heterogeneous catalysis starting from homogeneous mineral and organic acids has been to support them on porous solids. For instance, perchloric, sulphuric and phosphoric acids are normally supported on silica either by simple pore filling and/or by interacting with the surface of the solid. In the case of the sulfonic acids an heterogenization procedure involves the synthesis of organic polymers bearing sulphonic groups. In this case organic resins can be excellent catalysts, especially when their pore structure is adapted to the nature and dimensions of reactants. ${ }^{23-24}$ 
Inorganic solid acids can be prepared with acidity that ranges from weak to strong, going through solids with controlled intermediate acidities. One type of inorganic solid acids is the family of silicates. In high surface area silica, the silicon atoms are tetrahedrally coordinated and the system is charge neutral (Figure 1a). However the silica nanoparticles terminate at the surface with silanol groups (Fig 1b). In this silanol groups the density of positive charge on the hydrogen of the hydroxyl group is very small and they can be considered as very weak Bronsted acid sites. Nevertheless they could be used for acid catalyzed reactions that require weak acidity, provided that the silica has relatively high surface area. With this type of catalyst the reactants become activated by surface adsorption, being the heat of adsorption the sumatory of the small Van der Waals and hydrogen bridging type of interactions.

\section{Figure 1 Structure of silicates}

Larger $\mathrm{O}-\mathrm{H}$ polarizations are achieved when an isomorphic substitution of $\mathrm{Al}$ by Si occurs. In this case, the tetrahedrally coordinated $\mathrm{Al}$ generates a negative charge that is compensated by the positive charge associated to the hydrogen of the bridging hydroxyl groups (Fig. 1c). These Bronsted acid sites are clearly stronger than the silanol groups and they exist in well prepared amorphous and long range structured silica aluminas and in crystalline aluminosilicates. ${ }^{25-27}$ When the $\mathrm{T}-\mathrm{O}-\mathrm{T}^{\prime}$ bond in aluminosilicates is not constrained, as it occurs in amorphous silica alumina, the tendency to release the proton and to relax the structure is lower and consequently the Bronsted acidity is mild. However, in the case of crystalline aluminosilicates such as zeolites the bridging T-O-T' bond is constrained and the Bronsted acidity of these materials is higher than in amorphous silica alumina. If one takes into account that it is possible to synthesize zeolites with different $\mathrm{Al}$ contents and with pores within a wide range of diameters, ${ }^{28-30}$ it is not surprising that zeolites have found and still find a large number of applications as solid acid catalysts. ${ }^{31}$ Their applications can be even enlarged through the synthesis of acid zeolites with pores of different dimensions within the same structure. Thus, structures with pores formed by 12 and 10 ring, $^{32} 18 \times 10,{ }^{33} 14 \times 12^{34}$ $17 \times 12^{30,} 35$ and the recently discovered ITQ-43 with $24 \times 12^{36}$ rings, with pores in the mesoporous range have been presented.

If one takes into account that other metal atoms such as $\mathrm{Ti}, \mathrm{Sn}, \mathrm{Fe}, \mathrm{Cr}$, with catalytic activity for oxidations can be incorporated in the structure of the crystalline 
microporous silicates or aluminosilicates ${ }^{37-39}$ enlarging the reactivity of the zeolites and allowing to prepare bifunctional acid-oxidations catalysts. When metal nanoparticles are formed on the internal and/or external surface of acid zeolites, bifunctional hydrogenation/dehydrogenation-acid solid catalysts are obtained ${ }^{40-43}$ allowing zeolites to catalyze multistep multistep reactions. ${ }^{44-45}$

There are reactions that require sites with acid strength stronger than that of zeolites. Then, solid catalysts containing sulfonic groups can be used. For instance, acidic resins with sulfonic acid groups are strong solid acid catalysts that can be useful for acid catalysis, provided that the reaction temperature does not surpass their thermal stability limit. ${ }^{46}$ Along this line, Nafion is a strong solid acid catalysts but its surface area is too low. To avoid this limitation, Harmer et al. have shown that it is possible to partially depolymerize Nafion and to disperse it in silica. ${ }^{47-48}$ The resultant high surface solid catalysts can be used in a relatively larger number of acid catalyzed reactions. ${ }^{49-52}$ Nevertheless, the acidity of this hybrid material is some lower than Nafion, owing to the interaction of sulfonic groups with silanols of the silica. ${ }^{53-54}$ In any case it should be considered that polymer derived catalysts may be difficult to regenerate if poisoned by deposition of organic compounds. Indeed, regeneration by calcination with air will be limited because of thermal stability, and washing out the adsorbed products with solvents can not always restore the initial activity.

Looking for strong acid catalysts, heteropolyacids such as for instance $\mathrm{H}_{3} \mathrm{PW}_{12} \mathrm{O}_{40}\left(\mathrm{H}_{3} \mathrm{PW}\right)$ are able to catalyze at low temperatures a wide range of homogeneous catalytic processes. ${ }^{55}$ Heteropolyacids can be heterogeneized by either supporting them on a high surface area carrier such a silica ${ }^{56}$ or by forming their cesium or potassium salts $\left(\mathrm{Cs}_{2.5} \mathrm{H}_{0.5} \mathrm{PW}\right.$ or $\left.\mathrm{K}_{2.5} \mathrm{H}_{0.5} \mathrm{PW}\right)$ that are solids with micro and mesoporosity and are insoluble for organic reactions. ${ }^{57}$

Other solid acids such as metal organic frameworks bearing sulfonic groups or metal Lewis acids, ${ }^{58}$ sulphated zirconia ${ }^{59-60}$ and metal phosphates have also been used as catalysts. ${ }^{61-62}$

With respect to solid bases, basic resins, amines and alkyl ammonium hydroxides grafted on silicas, or amines bearing part of MOF estructures, KF on $\mathrm{Al}_{2} \mathrm{O}_{3}$, alkaline metal oxides on alumina and zeolites, zeolites exchanged with alkaline cations, alkaline earth oxides and anionic clays such as hydrotalcites and their corresponding mixed oxides are useful catalysts and their basic properties and catalytic acivity have been very well described in a series of reviews. ${ }^{31,63-68}$ 
The solid acid and base catalysts named above will account for the majority of the catalysts required for the MCRs presented in this review. In those cases in where significantly different catalyst will be required, we will briefly describe their nature.

\section{Heterogeneous catalyzed multicomponent reactions}

\subsection{Synthesis of propargylamines}

The Mannich reaction is a classic example of a three component condensation $\left(\mathrm{A}^{3}\right.$ coupling). In general, an aldehyde, an amine and an active hydrogen compound such as an enolyzable ketone or terminal alkyne, react affording the corresponding $\beta$ aminoketone or $\beta$-aminoalkyne (propargylamine) (Scheme 2).

\section{Scheme 2 Mannich type reactions}

Propargylamines are important synthetic intermediates for potential therapeutic agents and polyfunctional amino derivatives. ${ }^{69-71}$ Traditionally these compounds have been synthesized by nucleophilic attack of lithium acetylides or Grignard reagents to imines or their derivatives. However these reagents must be used in stoichiometric amounts, are highly moisture sensitive, and sensitive functionalities such as esters are not tolerated. Therefore, the most convenient synthetic method for preparing propargylamines has been the Mannich one pot three component coupling reaction of an aldehyde, a secondary amine and a terminal alkyne. The reactions are usually performed in polar solvents (mostly dioxane) and in the presence of a catalytic amounts of a copper salt $\left(\mathrm{CuCl}, \mathrm{Cu}(\mathrm{OAc})_{2}\right)^{72}$ which increases the nucleophilicity of the acetylenic substrate towards the Mannich reaction. Mechanistic studies indicate that the reaction involves the formation of an iminium intermediate from the starting aldehyde and amine. The C$\mathrm{H}$ bond of the alkyne is activated by the metal to form a metal acetylide intermediate which subsequently reacts with the iminium ion leading to the corresponding propargylamine (Scheme 3).

Scheme 3 Propossed mechanism for the Mannich reaction 
A variety of transition metals such as $\mathrm{Ag}^{\mathrm{I}}$ salts, ${ }^{73} \mathrm{Au}^{\mathrm{I}} / \mathrm{Au}^{\mathrm{III}}$ salts, ${ }^{74-75} \mathrm{Au}^{\mathrm{III}}$ salen complexes, ${ }^{76} \mathrm{Cu}^{1}$ salts, ${ }^{77-78}$ Ir complexes, ${ }^{79} \mathrm{InCl}_{3},{ }^{80} \mathrm{Hg}_{2} \mathrm{Cl}_{2}{ }^{81}$ and $\mathrm{Cu} / \mathrm{Ru}^{\mathrm{II}}$ bimetallic system $^{82}$ have been employed as catalysts under homogeneous conditions. In addition, alternative energy sources like microwave ${ }^{83}$ and ultrasonic ${ }^{84}$ radiations have been used in the presence of $\mathrm{Cu}^{\mathrm{I}}$ salts. Considering that chiral propargylamines are widely present in many important bioactive compounds, enantioselective synthesis of propargylamines throught this protocol have been recently developed using chiral $\mathrm{Cu}(\mathrm{I})$ complexes. ${ }^{85-86}$

However, operating under homogenous media two main drawbacks must be considered: the difficulty to recover and reuse the catalyst and the possible absorption of some of the metal catalyst on the final product (fine chemical). Currently the upper tolerance limit for the contamination of drugs or other compounds set aside for human consumption by transition metals is $5 \mathrm{ppm}$ and future regulations is expected to lower this threshold to the ppb range.

In order to achieve the recyclability of transition metal catalysts, gold, silver and copper salts in ionic liquids, [Bmim] $\mathrm{PF}_{6}{ }^{87,72}$ as well as heterogeneous catalysts have been used to obtain propargylamines. Thus, different metal exchanged hydroxyapatites (metal-HAP) are able to cataliyze the condensation of benzaldehyde, piperidine and phenylacetylene in acetonitrile under reflux temperature. ${ }^{88}$ The results showed that the order of efficiency was $\mathrm{Cu}-\mathrm{HAP}>\mathrm{Cu}(\mathrm{OAc})_{2}>\mathrm{Ru}-\mathrm{HAP}>\mathrm{Fe}-\mathrm{HAP}$ achieving yields of the corresponding propargylamine of $85 \%, 80 \%, 60 \%$, and $25 \%$ respectively. A variety of structurally different aldehydes, amines and acetylenes in the presence of $\mathrm{Cu}$ HAP were converted into the corresponding propargylamines with 55-92 \% yield. CuHAP was reused several times showing consistent activity even after the fourth cycle. Silica gel anchored copper chloride has been described by Sreedhar et al. ${ }^{89}$ as an efficient catalyst for the synthesis of propargylamines via C-H activation. Both aromatic and aliphatic aldehydes and amines and phenylacetylene have been used to generate a diverse range of acetylenic amines in good to moderate yields (52-98 \%) using water as a solvent and without any organic solvent or co-catalyst. A stable and efficient catalyst for the three component coupling Mannich reaction of aldehydes, amines and alkynes was prepared by $\mathrm{Li}$ et al. ${ }^{90}$ by immobilizing $\mathrm{Cu}(\mathrm{I})$ on organic-inorganic hybrid materials. Thus, Silica-CHDA-CuI catalyst was prepared from benzylchloride functionalized silica gel which was subsequently reacted with 1,2-diaminecyclohexane. This organic-inorganic hybride material was reacted with couprous iodide to generate Silica-CHDA-CuI catalyst with $1.6 \mathrm{wt} \%$ of $\mathrm{Cu}$. Reactions performed in absence of 
solvent afforded the corresponding propargylamines in excellent yields (82-96 \%). No catalyst leaching was observed in the reaction media, and the catalyst remained active through at least 15 consecutive runs. Others immobilized metals such a $\mathrm{Ag}(\mathrm{I})$ and $\mathrm{Au}(\mathrm{I})$ exhibited lower activity than $\mathrm{Cu}$ catalysts while silica supported $\mathrm{Pd}(\mathrm{II})$ failed in this reaction.

Recently Wang et al. ${ }^{91}$ have reported a novel silica-immobilized N-heterocyclic carbene metal complex (Si-NHC-Cu${ }^{\mathrm{I}}$ ) as efficient and reusable catalyst for the synthesis of propargylamines. Reacting different combinations of aldehydes, amines and alkynes at room temperature under solvent free conditions, produces the corresponding propargylamines in moderate to good yields (43-96 \%) after $24 \mathrm{~h}$ reaction time (see Table 1). Higher yields were obtained when the MCR was carried out at $70{ }^{\circ} \mathrm{C}$ in $4 \mathrm{~h}$, while no metal leaching in the liquid media was observed.

$\mathrm{Cu}(0)$ nanoparticles have also been used by Kidway and co-workers ${ }^{92}$ as active and recyclable catalysts in the synthesis of propargylamines following the Mannich protocol. The $\mathrm{Cu}$ nanoparticles prepared in a reverse micelar system (with size of $18+/-$ $2 \mathrm{~nm}$ ) gave a diverse range of propargylamines in excellent yields (65-98 \%).

Different metals supported zeolites such as Cu-modified zeolites (H-USY, HY, H-Beta, Mordenite and ZSM-5), have been successfully used for the synthesis of propargylamines. ${ }^{93}$ The MCR between piperidine, benzaldehyde and phenylacetylene performed at $80{ }^{\circ} \mathrm{C}$ in absence of solvent, showed tha the order of activity was: $\mathrm{Cu}^{\mathrm{I}}$ USY $>\mathrm{Cu}^{\mathrm{I}}-\mathrm{Y}>\mathrm{Cu}^{\mathrm{I}}-\mathrm{Beta}>\mathrm{Cu}^{\mathrm{I}}-\mathrm{ZSM}-5>\mathrm{Cu}^{\mathrm{I}}$-Mordenite, indicating that the pore topology of the zeolites have a marked influence on the reaction efficiency (Table 2). The authors suggest that the formation of the iminium intermediate assisted by the zeolite is combined with the formation of the acetylide within the micropores leading to an efficient reaction. The scope of the $\mathrm{Cu}^{\mathrm{I}}$-USY catalyst was examined using different reagents, including bulky amines, and in all cases propargylamines were obtained in good to moderate yields (55-90 \%), though long reaction time (15 h) were required. Furthermore, $\mathrm{Cu}^{\mathrm{I}}$-USY could be recycled up to four times without loss of activity. Cu exchanged $\mathrm{NaY}$ zeolite has also been used as catalysts in the synthesis of substituted propargylamines. ${ }^{94}$ Different metal exchanged zeolites (Cu-NaY, Ag-NaY and Au$\mathrm{NaY}$ ) were prepared by conventional ion exchange method by treating $\mathrm{NaY}$ zeolite with aqueous solution of different salts. When an equimolar mixture of benzaldehyde, piperidine and phenylacetylene were reacted at $100{ }^{\circ} \mathrm{C}$ for $5 \mathrm{~h}$ in the presence of $\mathrm{Au}-$ $\mathrm{NaY}$ zeolite the corresponding propargylamine was obtained in low yield (32\%) 
whereas both $\mathrm{Cu}-\mathrm{NaY}$ and Ag-NaY catalyst give the propargylamine in moderate yields (43\% and $52 \%$ respectively). Metal leaching of $\mathrm{Cu}-\mathrm{NaY}$ and Au-NaY catalyst was observed in the reaction media, but Ag-NaY was stable and metal leaching was not detected. Several substituted propargylamines were prepared with Ag-NaY affording the corresponding propargylamines in moderate to good yields (42-97\%) and high selectivities (90-99 \%) after $15 \mathrm{~h}$. Very recently Namitharan et al. ${ }^{95}$ have reported that Ni-exchanged $\mathrm{Y}$ zeolite (Ni-Y) exhibits excellent activity for the $\mathrm{A}^{3}$ coupling of cyclohexanecarbaldehyde, morpholine and phenylacetylene giving the corresponding propargylamine in $97 \%$ yield under solvent free conditions at $80{ }^{\circ} \mathrm{C}$. No leaching of metal ions provides strong support for the heterogeneous nature of the catalyst. In Table 3 the activity of Ni-Y zeolite is compared with other homogeneous and heterogeneous based catalysts. The Ni-Y zeolite could be recycled at least, four times retaining yield and selectivity. A variety of aliphatic, aromatic, cyclic and heterocyclic alkynes were coupled using this catalyst, and yields between 84-97 \% were achevied. The authors claim that $\mathrm{Ni}^{\mathrm{II}}$ is the catalytic site for the coupling reaction. In the mechanism proposed, the $\mathrm{Ni}^{\mathrm{II}}$ species in $\mathrm{Ni}^{\mathrm{II}}-\mathrm{Y}$ zeolite react with the terminal alkyne and the subsequent cleavage of one of the oxo bridges in the zeolite generates the nickel (II) acetylide intermediate. Then, the acetylide reacts with the iminium ion generated in situ from aldehyde and amine to give the propargylamine while the $\mathrm{Ni}^{\mathrm{II}}-\mathrm{Y}$ zeolite is ready for a subsequent reaction cycle (Scheme 4).

Scheme 4 Possible mechanism of $\mathrm{Ni}^{\mathrm{II}}$-Y-catalyzed three component coupling

Silver salt of 12-tungstophosphoric acid (AgTPA) has been reported by Reddy and coworkers ${ }^{96}$ as heterogeneous catalyst to prepare different propargylamines via a three component coupling reaction in very good yields (70-98 \%).

We have recently found that $\mathrm{Cu}-\mathrm{MOFs}^{97}$ were active and selective solid catalysts for the $\mathrm{A}^{3}$ coupling of a large variety of aldehydes, amines and alkines. The Cu-MOF catalyst deactivates because a loss of crystallinity, but the original activity was fully restored by treating with DMF at reflux and regenerating the the initial MOF structure.

While homogeneous gold complex were reasonable active catalysts for the three component reaction,, it has now been presented that gold supported catalysts can also catalize the $\mathrm{A}^{3}$ coupling for preparation of propargylamines with excellent success. For instance, Kantam et al. ${ }^{98}$ reported the use of gold supported onto a layered double 
hydroxide ( $\mathrm{LDH}-\mathrm{AuCl}_{4}$ ) for the Mannich reaction. A range of propargylamines was obtained in excellent yields (89-93 \%) at reflux of THF. However a significant

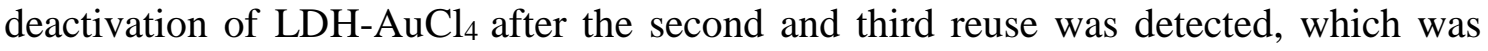
attributed to the formation of $\mathrm{Au}(0)$ and $\mathrm{Au}(\mathrm{I})$ as revealed by XPS studies. Au nanoparticles (Au-np) prepared in a reverse micelar system, has also been used as catalyst for the MCR of aldehydes, amines and alkynes. ${ }^{99}$ It was found that the nature of reaction media has an important role in the MCR reaction. Among the different solvents investigated, the acetonitrile was the best for carrying out the coupling reaction. This was attributed to its high polarity that may result in the stabilization of the acetylide-Au intermediate which reacted with the iminium ion generated in situ, to give the corresponding propargylamine. A variety of structural aldehydes and amines with a wide range of functional groups were coupled affording the propargylamines in excellent yields (67-96 \%). Maximum reaction rate was observed for an average particle size of about $20 \mathrm{~nm}$. In addition, Au-np catalyst was reused without further purification for seven runs with only slight drop in activity. Recently, Datta et al. ${ }^{100}$ have reported that $\mathrm{Au}$ nanoparticles $(7 \mathrm{~nm})$ encapsulated with highly ordered mesoporous carbon nitride $(\mathrm{Au} / \mathrm{MCN})$ is an active and recyclable catalyst for coupling benzaldehyde, piperidine and phenylacetylene. However, better yields (>95 \%) were obtained by Corma et al. for the same reaction using Au nanoparticles supported on nanocrystalline $\mathrm{ZrO}_{2}$ and $\mathrm{CeO}_{2}{ }^{101}$ (Table 4). Different studies and theoretical calculations have evidenced that cationic gold species can be stabilized on $\mathrm{ZrO}_{2}$ and $\mathrm{CeO}_{2}$ but not on other supports as showed in the Table 4. The proposed mechanism involves the activation of $\mathrm{C}_{\mathrm{sp}}-\mathrm{H}$ bond by $\mathrm{Au}$ (III) species stabilised by nanocristalline of $\mathrm{ZrO}_{2}$ or $\mathrm{CeO}_{2}$ to give a gold acetylide intermediate (A), which reacts with the immonium ion formed in situ (B) to give the corresponding propargylamine (Scheme 5). The catalytic activity TON (turn-over number) and TOF (turn-over frequency) is the highest reported up to now (see Table 4). The reaction was extended to different combinations of aldehydes, amines and alkynes giving excellent yields to the corresponding propargylamines. Besides, when a chiral amine was used in the presence of $\mathrm{Au} / \mathrm{ZrO}_{2}$ and $\mathrm{Au} / \mathrm{CeO}_{2}$ the corresponding chiral propargylamine was obtained with high yields (>97 \%) and excellent diasteroselectivities (99:1). Table 5 summarizes the results obtained in the MCR of benzaldehyde, piperidine, and phenylacetylene using different solid catalysts. 
Scheme 5 Mechanism proposed in the presence of gold suppoted on $\mathrm{CeO}_{2}$ or $\mathrm{ZrO}_{2}$.

\subsection{Synthesis of indole derivatives}

Functionalized indols are biologically active compounds ${ }^{102}$ that can be obtained using a variety of approaches. ${ }^{103}$ Recently, following the Mannich approach functionalized indols have been obtained by three component coupling and cyclization of $\mathrm{N}$-tosyl protected ethynylaniline, paraformaldehyde and piperidine in the presence of $\mathrm{Au} / \mathrm{ZrO}_{2}{ }^{101}$ (Scheme 6).

Scheme 6. Three component coupling and cyclization of an aldehyde, amine, and Nprotected ethynylaniline.

It was found that only a fraction of the total gold species i.e. only the Au(III) are active for this reaction. Thus, the MCR of paraformaldehyde, piperidine and Nprotected ethynylaniline in the presence of $\mathrm{Au} / \mathrm{ZrO}_{2}$ in dioxane at $100{ }^{\circ} \mathrm{C}$ and after $5 \mathrm{~h}$, yielded $95 \%$ of 2-(aminomethyl) indole. No propargylamines were detected in the reaction media. The reaction was also extended to different combination of aldehydes and amines giving the corresponding indols in good yields.

More recently the same authors ${ }^{104}$ have prepared a metal organic frameworks (IRMOF3-Si-Au) containing Au(III) Shiff base complex lining the pore walls. This material was obtained by reacting the $-\mathrm{NH}_{2}$ groups of IRMOF-3 with salicilaldehyde to form the corresponding imine. The final step consists in reacting a gold precursor $\left(\mathrm{NaAuCl}_{4}\right)$ with the imine. A maximum funtionalization of about $3 \%$ of the total amino groups was produced which allows to introduce up to $2 \mathrm{wt} \%$ of gold using this method. IRMOF-3$\mathrm{Si}-\mathrm{Au}$ catalyst was tested for the condensation reaction of $\mathrm{N}$-tosyl protected ethynylaniline, piperidine and paraformaldehyde in dioxane at $40{ }^{\circ} \mathrm{C}$ (see Table 6). It was found that IRMOF-3-Si-Au gives much higher catalytic performance than other gold catalysts such as $\mathrm{Au} / \mathrm{ZrO}_{2}$ and homogeneous gold/salt complexes (Au(III) Schiff base complex) and $\mathrm{AuCl}_{3}$. The results showed that the cationic gold $\mathrm{Au}(\mathrm{III})$ species are the active sites in this reaction which are more stabilized in the heterogeneous than in homogeneous media, while the higher activity of IRMOF-3-Si-Au catalyst should be attributed to the existence of well defined, isolated $\mathrm{Au}(\mathrm{III})$ stable and accessible active 
sites on this material. Good yields of indole derivatives (70-95 \%) were obtained from N-protected ethynylanilines, and different aldehydes and amines (Table 6). The IRMOF-3-Si-Au catalyst can be successfully reused and not gold leaching from the solid to the liquid media was detected. However, the reaction should be carried out with freshly prepared catalyst since catalyst amorphization occurs upon catalyst storage for long time.

\subsection{Substituted benzo[b]furans}

Benzo[b]furans derivatives are compounds of relevance because of their natural occurrence associated with their biological properties. ${ }^{70,105}$ The most general methods to prepare benzo[b]furans involve reductive cyclization of ketoesters by low valent titanium, ${ }^{106}$ photochemical rearrangement of phosphate esters, ${ }^{107}$ Suzuki coupling of boronic acids with organic halides or triflates catalyzed by palladium, ${ }^{108}$ Sonogashira cross coupling reaction of $o$-halophenols with terminal alkynes in the presence of palladium and/or copper as catalysts. ${ }^{109}$

Recently, following the Mannich protocol Kabalka et al. ${ }^{110}$ have reported the synthesis of a variety of propargylamines in good yields from different alkynes, primary or secondary amines and paraformaldehyde using cuprous iodide doped alumina as catalyst under microwave irradiation. The reaction was extended to the synthesis of 2substituted benzo[b]furans derivatives when ethynylphenol was condensed with secondary amines (such as piperidine, morpholine, 1-phenylpiperazine etc.) and paraformaldehyde (see Table 7). In this case the Mannich adduct resulting from the $\mathrm{A}^{3}$ coupling undergoes a subsequent cyclization into the benzofurane ring (Scheme 7). The reaction is highly efficient and moderated to good yields of 2-substituted benzo[b]furans (52-70 \%) were obtained in short reaction time, but high amount of catalyst was required.

Scheme 7. Synthesis of substituted benzo[b]furans through a MC Mannich reaction followed by ciclyzation

\subsection{Synthesis of $\beta$-aminocarbonyl compounds}

$\mathrm{N}$-substituted aminocarbonyl compounds can be synthesised by the versatile Mannich type reaction (see Scheme 2). The MCR between an aldehyde, amine and ketones using Lewis ${ }^{111}$ or Bronsted acids ${ }^{112}$ and Lewis bases ${ }^{113}$ as catalysts produces $\beta$ - 
aminocarbonyl compounds (Scheme 8). $\beta$-Aminocarbonyl compounds are important building blocks for the synthesis of biologically active nitrogen-containing compounds such as $\beta$-amino alcohols, $\beta$ amino acids and $\beta$-lactams and pharmaceuticals. ${ }^{114-115}$

Scheme 8. Mannich reaction of aromatic aldehyde, ketones and amines

Mechanistically the reaction proceeds typically via imine formation through the condensation of aldehyde and amine followed by the attack of the enol form of ketone on imine to afford the desired product.

Recently, the synthesis of $\beta$-amino ketones by a three component Mannich reaction in liquid phase under solvent free and at room temperature, have been carried out using tungstated zirconia $\left(\mathrm{WOx}-\mathrm{ZrO}_{2}\right) .{ }^{116}$ WOx from ammonium metatungstate was incorporated into the hydrous zirconia and calcined at $923 \mathrm{~K}$ to give a solid, which exhibits strong acidity. Different aromatic aldehydes, anilines and cyclohexanone give the corresponding $\beta$-amino ketones in good yields (66-90 \%) as a mixture of syn and anti stereoisomers. In most of the examples studied the syn selectivity was higher as compared to anti selectivity (Scheme 9).

Scheme 9. Three component reaction between aromatic aldehyde, aniline and ciclohexanone catalyzed by tungstated zirconia

Also, the sulphated ceria-zirconia $\left(\mathrm{SO}_{4}{ }^{2-} / \mathrm{Ce}_{\mathrm{x}} \mathrm{Zr}_{1-\mathrm{x}} \mathrm{O}_{2}\right)$ reported by Reddy et al. ${ }^{117}$ was an efficient catalyst for the synthesis of $\beta$-amino ketones via Mannich reaction. The reaction between benzaldehyde, aniline and cyclohexanone proceeded smoothly to afford $82 \%$ of 2-[1-phenyl-1- $N$-phenylamino]methylcyclohexanone, with a anti/syn ratio of 18:82. The catalyst could be recycled and no appreciable change in activity was observed for 2-3 runs.

It is known that fluorine containing compounds produce an enhancement of biological activity as well as a decrease in toxicity. ${ }^{118}$ Xia and co-workers ${ }^{119}$ reported that fluorinated $\beta$-aminobutanones can be obtained through one pot three-component Mannich type reaction of unmodified acetone with aldehydes and fluorinated anilines in good to excellent yields (81-96 \%) catalysed by sulfamic acid $\left(\mathrm{H}_{2} \mathrm{NSO}_{3} \mathrm{H}, \mathrm{SA}\right)$ at room 
temperature (Scheme 10). Due to its zwitter-ionic property this heterogeneous catalyst can be recycled and reused through simple filtration and washing.

Scheme 10. Synthesis 4-(3-fluorophenylamino)-4-(furan-2yl)butan-2-one

SA is also an efficient and recyclable heterogeneous catalyst for the ultrasound assisted one pot reaction of aldehydes with amines and ketones. Different aromatic aldehydes, anilines and acetophenone in ethanol at room temperature gave the corresponding $\beta$-amino ketone in 88-95 \% yield after 90-120 minutes. Also, $\beta$ aminocarbonyl compounds with ortho substituted aromatic amines are obtained in acceptable to good yields (53-95\%) after 2-8 hours in the presence of sulfamic acid catalyst under ultrasound irradiation $(600 \mathrm{~W}){ }^{120}$ The authors claimed that the accelerating effect of ultrasound can be an important tool for the one pot Mannich reaction of sterically hindered arylamines. A recyclable $\mathrm{Cu}$ nanoparticles for the one pot reaction to obtain $\beta$-amino ketones has been proposed by Kidwai and co-workers. ${ }^{121}$ For comparative purposes various metal nanoparticles such as $\mathrm{Au}$ and $\mathrm{Ni}$ were selected for the Mannich reaction. The authors found that Cu-np (particle diameter of about $20 \mathrm{~nm}$ ), was the most active catalyst. The catalyst was recovered and reused in four consecutive runs showing a gradual loss of activity. A variety of aromatic aldehydes, aromatic amines and acetophenone or cyclohexanone were coupled giving the corresponding $\beta$ amino ketones in good yields (Table 8) Optimum yields of $\beta$-amino ketones were achieved using a concentration of $10 \mathrm{~mol} \%$ of $\mathrm{Cu}-\mathrm{np}$ while increasing the $\mathrm{Cu}-\mathrm{np}$ concentration, their oxidation to form $\mathrm{CuO}$ occurs, producing agglomeration and reducing the surface area of the nanoparticles and hence decreasing the catalytic activity.

\subsection{Synthesis of Dihydropyrimidinones}

The synthesis of functionalized dihydropyrimidinones (DHPM) represents an excellent example of the utility of one pot multiple component condensation reactions.

Aryl substituted 3,4-dihydropyrimidinones are important heterocyclic compounds in organic synthesis and medicinal chemistry due to their therapeutic and pharmacological properties. The DHPM and their derivatives exhibit a broad spectrum of biological effects such as antitumor, antiviral, antibacterial and antiinflammatory activities and antioxidative properties $^{122}$. Furthermore, appropriately functionalized 3,4- 
dihydropyridimidones can act as calcium channel modulators, antihypertensive agents, $\alpha_{1 \mathrm{a}}$-adrenergic antagonists and neuropeptide antagonists. ${ }^{123}$

Apart from non natural DHPM, several marine alkaloids isolated from the Sponge Batzella as batzelladine compounds are potential new leads for drug development for AIDS therapy. ${ }^{124}$ More recently Monastrol, a 3,4-dihydropyrimidin-2(1H)-thione derivative has been identified and inhibits the mitotic kinesin Eg5 motor protein and can be considered as a new lead for the development of anticancer drugs. ${ }^{125}$ In Scheme 11 are presented different 3,4-dihydropyrimidinones, (Monastrol, SQ 32926 and SQ 32547) reported to be effective as orally active antihypertensive agents. ${ }^{126}$

Scheme 11. Different 3,4-Dihydropyrimidinones with pharmaceutical interest.

The simplest method for synthesising 3,4-dihydropyrimidin-2(1H)-one was reported first by Biginelli ${ }^{16}$ and involves a three component one-pot cyclocondensation reaction of an aldehyde, an open chain $\beta$-ketoester and urea or thiourea in presence of acid catalysts such as hydrochloric acid in ethanol at reflux temperature ${ }^{127-128}$ (Scheme 12).

Scheme 12. Three component Biginelli reaction

The plausible mechanism (Scheme 13) of the acid catalyzed Biginelli condensation postulated by Kappe, ${ }^{129}$ involves the formation of an $\mathrm{N}$-acyliminium ion intermediate from the aldehyde and urea precursors. Interception of the iminium ion by ethyl acetoacetate, presumably trough its enol tautomer, produces an open chain ureide, which undergoes cyclization and subsequent dehydratation to yield the dihydropyrimidinones.

Scheme 13. Proposed mechanism of the acid catalyzed Biginelli reaction

In recent years, many synthetic methods for preparing DHPM based on the Biginelli reaction have been reported which include classical conditions and microwave and ultrasound irradiation in the presence of Bronsted ${ }^{130}$ and Lewis acids as catalysts. For instance, lanthanide triflates, ${ }^{131}$ phase transfer catalyst (tetra-n-butyl ammonium bromide), ${ }^{132}$ and $\mathrm{NaCl}$ in DMF. ${ }^{133}$ However some of the reported methods suffer from drawbacks derived from product isolation procedure and environmental pollution. 
Moreover, in the case of substituted aromatic and aliphatic aldehydes bearing sensitive functional groups the original Biginelli reaction is unsuitable and afford DHPM compounds in low yields (20-40 \%) due to the strongly acidic conditions and prolonged time of heating required.

In the last years, replacement of conventional toxic and polluting Bronsted and Lewis acid catalysts by eco-friendly reusable solid acid heterogeneous catalysts, has achieved considerable importance in the synthesis of 3,4-dihydropyrimidinones. Thus, a wide variety of solid acid catalysts including supported Bronsted and Lewis acids, heteropolyacids, zeolites and metal complexes have been reported in literature for performing Biginelli reaction with variable success. ${ }^{134-157}$ As an example, in Table 9 are summarized results corresponding to the Biginelli reaction between benzaldehyde, ethyl acetoacetate and urea to synthesize 5-(ethoxycarbonyl)-6-methyl-4-phenyl-3,4dihydropyridin-2(1H)-one over different heterogeneous catalysts using both conventional heating or microwaves. For instance, excellent yields of DHPM derivatives (85-98\%) were reported using $\mathrm{ZrO}_{2}$-pillared clay (Zr-Pilc) under microwave irradiation. ${ }^{158}$ The efficacy of the procedure was exemplified by the synthesis of biologically active racemic mixture of monastrol (a potent anticancer drug) and nitractin (an antibacterial and antiviral drug) which were obtained in high yields (90\% and $87 \%$ respectively). The catalyst was recycled three times without any loss of activity. Also ion exchange resins such as the perflorinated resin sulfonic acid Nafion NR-50, resulted very active and reusable catalyst ${ }^{143}$ for the synthesis of DHPM derivatives with acceptable yields (74-96\%). While the catalytic activity of metallophthalocyanines complexes $^{142}$ strongly depends on the metal, being the order of activity: Co(II)phthalocyanine $>$ tetraphenoxyvanadyl(II)-phthalocyanine $>\mathrm{Fe}(\mathrm{II})$ phthalocyanine $>\mathrm{Cu}(\mathrm{II})-$ phthalocyanine $>\mathrm{Ru}(\mathrm{II})$-phthalocyanine. Particularly, Co(II) phthalocyanine complex was an efficient and recyclable heterogeneous catalyst giving good yields of different DHPM (82-98 \%).

Recently Shaabani et al. ${ }^{152}$ have reported Biginell-like reaction which combines an aldehyde, a cyclic $\beta$-dicarbonyl compound (5,5-dimethyl-1,3-cyclohexanedione) and a urea derivative such as $\mathrm{N}$-methylurea or thiourea, using silica supported sulphuric acid (SSA) as solid acid catalyst and in the presence of a ionic liquid (1-butyl-1,3methylimidazonium bromide ([bmim]Br)). The reactions performed at $100{ }^{\circ} \mathrm{C}$, yielded 4-aryl-7,7-dimethyl-1,7,7-trimethyl-1,2,3,4,5,6,7,8-octahydroquinazoline-2,5-diones derivatives (46-86 \% yield)(Scheme 14) in less than two hours. The authors found that 
the combination of the ionic liquid with SSA, decreases the reaction time and produces an increase of the yield of the target compound with respect to the classical conditions using $\mathrm{HCl}$ and conventional solvents. The acceleration of the multicomponent reaction was associated to the existence of solvophobic interactions in the ionic liquid media that generate an internal pressure which promotes the association of the reactants in a solvent cavity during the activation process.

Scheme 14. Synthesis of 4-aryl-7,7-dimethyl-1,7,7-trimethyl-1,2,3,4,5,6,7,8octahydroquinazoline-2,5-diones derivatives.

Finally, it is interesting to notice that DHPM obtained from the Biginelly type reaction are inherently asymmetric molecules and the influence of the absolute configuration at the sterogeneic centre at C4 on biological activity is well documented, ${ }^{159}$. Thus for instance the 1,4-DHPM known as SQ32926 (see Scheme 11 ) is exclusively the $(R)$-enantiomer that carries the therapheutical desired antihypertensive effect. However no general asymmetric synthesis for this heterocyclic system have been reported up to now and resolution strategies have been so far the method of choice to obtain enantiomerically pure DHPM.

\subsection{Synthesis of Tetrahydroquinoline derivatives}

Quinolines and their derivatives are achieving increasing importance due to their wide range of biological activity. Tetrahydroquinolines are an important class of natural products and exhibit diverse biological properties such as antiallergic, antiinflammatory, estrogenic and psychotropic activity. ${ }^{160-161}$ The classical method for the synthesis of tetrahydroquinolines involves the aza Diels-Alder reaction between $\mathrm{N}$-aryl-imines and nucleophilic olefins in the presence of Lewis acids, such as $\mathrm{FeCl}_{3}$ in $\mathrm{Et}_{2} \mathrm{O} / \mathrm{t}-\mathrm{BuOH}$, $\mathrm{BF}_{3} . \mathrm{Et}_{2} \mathrm{O}, \mathrm{AlCl}_{3} / \mathrm{Et}_{3} \mathrm{~N}^{162}$ which are frequently used in stoichiometric amounts. Moreover, many imines are unstable, hygroscopic and difficult to purify, and so the one-pot approach that involves the condensation of aldehydes with anilines and alkenes in the presence of Lewis acid catalysts where the imine is in situ formed, is much more efficient and economic process to produce this type of compounds. We will describe here some examples of dihydroquinoline derivatives synthesis through MCR using heterogeneous catalysts. 


\subsubsection{Synthesis of Aryl-3a,4,5,9b-tetrahydro-3H-cyclopenta[c]quinoline derivatives}

Cyclopentatetrahydroquinolines derivatives can be obtained by one pot three component reaction from aromatic aldehydes, aromatic amines, and cyclopentadiene in the presence of acid catalysts. Sartori et al. ${ }^{163}$ have reported the synthesis of cyclopentatetrahydroquinolines derivatives by one pot three component reactions from aromatic aldehydes, aromatic amines, and cyclopentadiene in the presence of acid clays as catalysts (Scheme 15). Montmorillonite KSF, acid Bentonite Bieliaca, and Hectorite are efficient catalysts to carry out this one-pot approach, being Bentonite Bieliaca the most efficient catalyst. Reactions performed in aqueous or polar solvents at $40{ }^{\circ} \mathrm{C}$ afforded the corresponding cyclopentatetrahydroquinoline derivatives in good yields (85-98\%) and selectivities (97-99\%) independently of the electronic effect of substituents. In all cases the reaction was regiospecific and stereospecific yielding exclusively the endo adduct (all cis product). The Bentonite catalyst could be reused five times without reducing its efficiency.

Scheme 15. Synthesis of Aryl-3a,4,5,9b-tetrahydro-3H-cyclopenta[c]quinoline derivatives through three component reaction.

The authors propose that the aza-Diels-Alder cycloaddition may proceed through a concerted polar $\left[4 \pi^{+}+2 \pi\right]$ cycloaddition with subsequent tautomerization (via a, Scheme 16) or by an intermolecular $1,2 \mathrm{C}=\mathrm{N}^{+}$addition-intramolecular cationic cyclisation sequence (via $b$, Scheme 16). The active species are produced by H-bond activation or by nitrogen protonation of the imine by the strong acid sites of the catalyst.

Scheme 16. Proposed mechanism of formation of cyclopentatetrahydroquinolines.

Kobayashi et al. ${ }^{164}$ have prepared diverse tetrahydroquinoline derivatives (Scheme 17) using a polymer supported Scandium ((polyallyl)scandium trifylamide ditriflate, (PA-Sc-TAD)) as catalyst. Thus, diverse quinoline derivatives have been efficiently obtained (99-65 \%) from aldehydes (aromatic, aliphatic, heterocycic, and glyoxals and glyoxylates), aromatic amines and different olefins, at $40{ }^{\circ} \mathrm{C}$ in $\mathrm{CH}_{2} \mathrm{Cl}_{2}: \mathrm{CH}_{3} \mathrm{CN}$ (2:1) as solvent and $15 \mathrm{~h}$ reaction time. The method is especially useful 
for construction of a quinoline library due to the efficiency and simplicity of the process.

Scheme 17. MC synthesis of tetrahydroquinoline derivatives

\subsubsection{Synthesis of Aryl 1,2,3,4-tetrahydrospiro(3,1'-cyclopropyl)quinolines derivatives}

Quinolines derivatives having a spyrocyclopropyl ring can be synthesised by one pot three component reaction using Montmorillonite KSF clay ${ }^{165}$ under mild reaction conditions (Scheme 18). The aza-Diels-Alder reaction of methylenecyclopropanes, arenecarbaldehydes and arylamines were carried out in various solvents at room temperature under ambient atmosphere.The results indicate that in acetonitrile and dichloromethane the corresponding adduct was obtained in good yields (100 and $90 \%$ respectively), whereas in acetone, ether or THF very low yield was achieved due to the coordination of the oxygen atom of the solvent to the active site. The recovered Montmorillonite catalyst was reused in several consecutive cycles giving similar results. Other solid catalyst such as silica gel, neutral alumina and zeolites showed no catalytic activity for this reaction.

Scheme 18. Synthesis of aryl 1,2,3,4-tetrahydrospiro(3,1'-cyclopropyl)quinolines derivatives through MCR.

\subsubsection{Synthesis of Aryl pyran[3,2-c] and furan[3,2-c]quinolines}

Pyranoquinolines (pyran[3,2-c]quinolines) are present in several bioactive alkaloids and it is found to possess a wide spectrum of biological activities such as antiallergenic, psychotropic, anti-inflammatory, inmmunosupresssive and strogenic activity. ${ }^{160}$ The most common method for preparing pyranoquinolines is by aza-Diels-Alder reaction of imines (derived from aromatic amines and aldehydes) with 3,4-dihydro-2H-pyran in the presence of Lewis acids such as $\mathrm{GdCl}_{3},{ }^{166} \mathrm{ZrCl}_{4},{ }^{167} \mathrm{KHSO}_{4}{ }^{168}$ etc. Recently, it has been reported that Bronsted and Lewis solid acids such as antimony chloride doped on hydroxyapatite ( $\left.\mathrm{SbCl}_{3}-\mathrm{HAP}\right),{ }^{169}$ perchloric acid adsorbed on silica gel $\left(\mathrm{HClO}_{4}-\mathrm{SiO}_{2}\right),{ }^{170}$ $\mathrm{Fe}^{3+}-\mathrm{K} 10$ Montmorillonite clay and $\mathrm{HY}$ zeolite ${ }^{171}$ are highly efficient and diastereoselective solid acid catalysts for one pot synthesis of pyrano and furoquinolines 
by coupling the three components, benzaldehydes, anilines and 3,4-dihydro-2H-pyran or 3,4-dihydro-2H-furan. (Scheme 19).

Scheme 19. Multicomponent synthesis of pyran- and furandihydroquinolines ( $\mathrm{n}=2$ and 1 respectively).

As in the case of spyrocyclopropyldihydroquinolines, the imines formed in situ by the condensation of benzaldehyde and aniline derivatives acts as heterodienes which subsequently undergo the aza-Diels-Alder reaction with 3,4-dihydro-2H-pyran or 3,4dihydro- $2 \mathrm{H}$-furan to form pyran and furanquinolines.

Different benzaldehyde derivatives and anilines were reacted with 3,4-dihydro$2 \mathrm{H}$-pyran or 3,4-dihydro- $2 \mathrm{H}$-furan giving the corresponding pyran and furanquinolines in good yields. In all cases a mixture of trans and cis isomers were detected being the trans isomer the major product (Scheme 19). The $\mathrm{Fe}^{3+}-\mathrm{K} 10$ Montmorillonite clay and HY catalysts were recovered and recycled in three consecutive reactions without lost of activity. In Table 10 are compared the results obtained with different homogeneous and heterogeneous acid catalysts in the synthesis of 5-phenyl-3,4,4a,5,6,10b-hexahydro- $2 \mathrm{H}$ pyran-[3,2-c]quinoline.

\subsection{Synthesis of $\alpha$-amino nitrile derivatives}

$\alpha$-Amino nitriles are a very useful intermediate compounds for the synthesis of versatile $\alpha$-amino acids, various nitrogen-containing heterocyclic compounds (imidazoles, thiadiazoles etc.) and biologically useful molecules (such as for instance Saframycin A, a highly potent antitumor drug from Streptomyces lavendulae). ${ }^{173-174}$

The most important route for the synthesis of $\alpha$-amino acids via the formation of $\alpha$ amino nitriles is the well known Strecker reaction (1850). ${ }^{14}$ The classical Strecker reaction involves a direct multi-component reaction of an aldehyde or a ketone, an ammonium salt and alkaline cyanides in aqueous solution to form $\alpha$-amino nitriles, which can be subsequently converted to $\alpha$-amino acids (Scheme 20).

\section{Scheme 20. 3MC Strecker reaction}

The reaction involving aldehydes is tipically catalyzed by Lewis acids such as $\mathrm{BiCl}_{3}, \mathrm{NiCl}_{2}, \mathrm{InCl}_{3}, \mathrm{LiClO}_{4}, \mathrm{RuCl}_{3}{ }^{175}$ However, in the case of ketones, the reaction is more difficult and other acid catalysts such as gallium triflate $\left(\mathrm{Ga}\left(\mathrm{SO}_{3} \mathrm{CF}_{3}\right)\right.$ or the 
related metal triflates, trimethylsilyltriflate and $\mathrm{Fe}(\mathrm{Cp})_{2} \mathrm{PF}_{6}$ are required. ${ }^{176}$ Some of these Lewis acid catalysts are strong and expensive and their use involves harsh conditions, long reaction time and tedious aqueous work-up, leading to the generation of large amounts of toxic metal-containing waste.

Several modifications of the Strecker reaction have been reported using a variety of cyanating agents in the presence of solid or supported acids as heterogeneous catalysts. For instance, polyoxometalate salts $\left(\mathrm{K}_{5} \mathrm{CoW}_{12} \mathrm{O}_{40} \cdot 3 \mathrm{H}_{2} \mathrm{O}\right)$ have been used as efficient and recyclable heterogeneous catalysts in the three-component condensation of aldehydes, amines, and KCN. The reaction is performed at ambient temperature in acetonitrile giving the corresponding $\alpha$-amino nitriles in good to moderate yields (51-98 \%) and excellent selectivity. ${ }^{177}$ Yadav and co-workers ${ }^{178}$ prepared 2-anilino-2phenylacetonitrile in $90 \%$ yield by treatment of benzaldehyde, aniline and trimethylsilyl cyanide (TMSCN) in dichloromethane at room temperature with Montmorillonite KSF clay as catalyst (Scheme 21). No cyanohydrin trimethylsilyl eter (an adduct obtained from the aldehyde and TMSCN) was obtained under these reaction conditions. A variety of aldehydes were reacted with a range of amines and TMSCN in a one pot procedure to produce aminonitriles in 85-94 \% yields.

Scheme 21. Three component Strecker reaction of aldehyde, amine and TMSCN.

The mechanism of the process involves the formation of imines or iminium ions and the subsequent nucleophilic attack of cyanide ion of TMSCN to provide the final product.

Using the same approach, Heydari et al. ${ }^{179}$ performed the synthesis of several $\alpha$ amino nitriles using sulfamic acid $\left(\mathrm{NH}_{2} \mathrm{SO}_{3} \mathrm{H}\right.$, SA), a stable, non corrosive acid, as heterogeneous catalyst. The three-component coupling reaction involving an aldehyde (aliphatic, aromatic, heterocyclic and conjugated aldehyde) an amine (aliphatic and aromatic) and TMSCN in the presence of $5 \mathrm{~mol} \%$ of sulfamic acid at room temperature under solvent free conditions afforded the corresponding $\alpha$-amino nitriles in excellent yields (82-98\%) and selectivities in short reaction times (see Table 11). No undesired side products such as cyanohydrins were obtained under these conditions due to the rapid formation and activation of the imine intermediates catalyzed by sulfamic acid. The catalyst was recovered by simple filtration and recycled in subsequent three cycles giving similar yields. 
A polymer, poly(4-vinylpyridine (PVP-SO $\mathrm{SO}_{2}$ complex) with mild acidity, has been prepared by Olah et al. ${ }^{180}$ and used in the multicomponent synthesis of $\alpha$-amino nitriles. The catalyst was prepared by passing $\mathrm{SO}_{2}$ gas through $2 \%$ cross linked poly(4vynilpyridine) at $-78{ }^{\circ} \mathrm{C}$. The Strecker reaction of aromatic and conjugated aldehydes, aliphatic, benzylic and aromatic amines and TMSCN was performed in dichloromethane at $50{ }^{\circ} \mathrm{C}$ giving excellent yields (81-98\%) of the corrresponding $\alpha$ aminonitriles. No differences in yield were found using aromatic aldehydes with electron donating or electron withdrawing groups, but attempts to perform the reaction with ketones failed. The PVP could be recycled to form the $\mathrm{PVP}-\mathrm{SO}_{2} \mathrm{complex}$.

Bio-supported catalyst as cellulose sulphuric acid ${ }^{181}$ (CSA) has been also used as highly efficient, selective and recyclable catalyst for performing the MC condensation of aldehydes, amines and TMSCN. Reactions performed at room temperature in acetonitrile as a solvent, gave excellent yields (85-97 \%) in rather short reaction times (45-80 min). Lower yields were achieved with others solvents such as water, methanol, ethanol, dichloromethane, toluene or under solvent-free conditions. No undesired side products, such as cyanidrin trimethylsilyl ether, were observed owing to the rapid formation of the imine intermediate.

Fluorinated amino acids are important building blocks in pharmaceuticals for anticancer drugs for the control of tumor growth, antihypertensive and anti allergic applications. ${ }^{173}$ Following the Strecker route, efficient synthesis of $\alpha$-amino nitriles using aldehydes, ketones and fluorinated ketones has been achieved with Nafion- $\mathrm{H}$, Nafion SAC-13 (10-20 \% Nafion-H polymer on amorphous silica porous nanocomposite) silica gel and fumed silica. ${ }^{182}$ When the reaction was carried out with aldehydes or ketones, primary amines and TMSCN at $60{ }^{\circ} \mathrm{C}$ in dichloromethane as a solvent in the presence of Nafion, yields between $75-97 \%$ of the corresponding $\alpha$ amino nitriles were obtained after 6 h reaction time. A similar result was obtained using Nafion SAC-13. When the Strecker reaction was performed with monofluoroacetone, $p$ toluidine and TMSCN, it was found that though silica and fumed silica showed catalytic activity, Nafion and Nafion SAC-13 gave the best yields (86\%) (Scheme 22). It is worth mentioning that these catalysts gave comparable results to those obtained in the case of metal triflates $\left(\mathrm{Ga}(\mathrm{OTf})_{3}\right)$ and trimethylsilyl triflate (TMSOTf) with 96 and $74 \%$ yield respectively. Nafion catalyst was reused for five consecutive runs and the catalytic activity remains practically unchanged. It is interesting to notice that when ketones are involved in the reaction the nature of the solvent plays an important role. Acetonitrile, 
THF, and toluene are not suitable for the direct Strecker reaction of ketones, since they are more basic and interact with the acidic sites, thus reducing the catalytic activity. ${ }^{183}$ However, dichloromethane minimizes such interaction enhancing the catalytic activity.

Scheme 22. Strecker reaction was of monofluoroacetone, $p$-toluidine and TMSCN

\subsection{Synthesis of multi-substituted imidazole derivatives}

Multi-substituted imidazole derivatives are an important class of compounds which exhibit a wide spectrum of biological activities as for instance antiinflammatory and antithrombotic activities. ${ }^{184}$ The well known microtubule stabilizing agents such as Eleutherobin and Sarcodictyn, among other marine and plant derived products contain imidazole. ${ }^{185}$ Also, Trifenagrel, a potent arachidonate cyclooxygenasa inhibitor that reduces platelet aggregation is structurally a 2,4,5-triarylimidazole ${ }^{186}$ (Scheme 23). Furthermore 2,4,5-trisubstituted imidazole moieties are common structures in numerous synthetic compounds used in agriculture, for plant growth regulators, herbicides and fungicides. ${ }^{187}$ In addition 2,4,5-triarylimidazole have received great attention for the development of fluorescence labelling agents for biological imaging applications ${ }^{188}$ or chromophores for non linear optics systems. ${ }^{189}$ Among them Lophine is one of the few long-lasting chemiluminescent molecules and its dimmers have piezochromic and photochromic properties. ${ }^{190}$

Scheme 23. Different 2,4,5-trisubstituted imidazole derivatives with pharmaceutical interest

Numerous classical methods for the synthesis of multisubstituted imidazoles have been developed. Among these methods a typical procedure is the multicomponent reaction approach involving the cyclocondensation of a 1,2-diketone (or $\alpha$-hydroxy ketones), an aldehyde and ammonia or ammonium acetate in the presence of a homogeneous strong protic acid catalysts (such as phosphoric acid, sulphuric acid, acetic acid), ${ }^{191}$ Lewis acids ${ }^{192}$ or oxidant agents such as ceric ammonium nitrate. ${ }^{193}$ The reactions are usually performed under reflux of a polar organic solvent (acetic acid, methanol, ethanol, DMF and DMSO) under inert atmosphere. More recently, 
microwave irradiation in absence of any catalyst ${ }^{194}$ have been used to produce multisubstituted imidazole derivatives with good success, however high reaction temperatures $\left(180-210^{\circ} \mathrm{C}\right)$ are required.

Some research groups have reported the one pot condensation of 1,2-diketone, (or $\alpha$ hydroxy ketone or $\alpha$-keto-oxime), aldehydes and ammonium acetate under microwave irradiation using acetic acid as a solvent ${ }^{195-196}$ or solid supports impregnated with ammonium acetate. Thus, $\mathrm{Xu}$ et al. ${ }^{197}$ have reported the condensation of $\alpha$-hydroxy ketone (benzoin) (instead of benzyl) with an aldehyde over silicagel or alumina impregnated with ammonium acetate. Reactions performed under solvent free conditions and microwave irradiation gave the corresponding trisubstituted imidazoles in good yields. Contrarely to conventional condensation of $\alpha$-hydroxy ketones, no oxidizing reagents such as $\mathrm{Cu}(\mathrm{II})$ was required and an air oxidation mechanism of the hydroxyl to carbonyl group was proposed. In Scheme 24 the proposed mechanism starting from an aldehyde, an $\alpha$-hydroxyketone, and ammonium acetate is displayed. The process involves the formation of an imine intermediate from the aldehyde and ammonia which undergoes the nucleophilic addition of the imine intermediate coming from a $\alpha$-hydroxyketone and ammonia. Subsequent cyclocondensation and oxidation steps lead to the substituted pyrazole derivative.

Scheme 24. Proposed mechanism for the formation of multi-substituted imidazole derivatives

Bentonite, Montmorillonite K-10 and KSF, and acid alumina impregnated with ammonium acetate have been used as solid acid catalysts to prepare 2,4,5-trisubtituted imidazole derivatives from 1,2-dicarbonyl compounds and aldehydes under microwave irradiation. Also 1,2,4,5-substituted imidazoles from 1,2-dicarbonyl compounds, aldehydes and primary amines were also obtained in good yields (Scheme 25). Comparison of the different supports show that acidic alumina was the most suitable support yielding imidazoles in 75-85 \% yield. ${ }^{198}$

Scheme 25. MC synthesis of 2,4,5-trisubtituted and 1,2,4,5- tetrasubstituted imidazole derivatives. 
HY zeolite and silica gel ${ }^{199}$ have also been used as heterogeneous acid catalysts for the synthesis of triarylimidazoles by condensation of benzyl, benzaldehyde derivatives and ammonium acetate under solvent free conditions and microwave irradiation (Scheme 26). The corresponding triarylimidazoles were obtained in good yields (80-90 \%) after six minutes reaction times.

Scheme 26. MC synthesis of 2,4,5- triarylimidazoles.

Shaabani et al. ${ }^{200}$ have reported that silica supported sulphuric acid (SSA) is an excellent and recyclable catalyst for the synthesis of trisubstituted imidazoles under reflux of water or solvent free conditions. When the reactions were performed with different aldehydes, 1,2-diketone, (or $\alpha$-hydroxy ketone or $\alpha$-keto oxime), ammonium acetate at reflux of water, the corresponding imidazoles were obtained in yields between 59-81 \% for 45-90 min. Under microwave irradiation similar yields were achieved after 10 min (Scheme 27). Sulphuric acid on silica catalyst could be reused in four consecutive runs maintaining its catalytic activity.

Scheme 27. Synthesis of 2,4,5-triarylimidazol from benzil or benzoin or benzylmonoxime, aldehyde and ammonium acetate in the presence of silica sulphuric acid (SSA) catalyst

Recently Wang et al. ${ }^{201}$ have prepared a polymer supported zinc chloride which was found to be extremely efficient as Lewis acid catalyst for the preparation of 2,4,5trisubstituted imidazoles. The polymer supported zinc was prepared from chloroacetylated polystyrene resin which reacted with diethanolamine and then zinc chloride was anchored to the polymer matrix (PSZC). The condensation of benzyl, benzaldehyde and ammonium acetate at reflux of ethanol in the presence of $15 \mathrm{~mol} \%$ of catalyst give $96 \%$ yield of 2,4,5-triphenylimidazole after 1.5 h. For comparison purposes the reaction was carried out using different conventional Lewis acids such as $\mathrm{AlCl}_{3}, \mathrm{FeCl}_{3} 6 \mathrm{H}_{2} \mathrm{O}, \mathrm{NiCl}_{2} 6 \mathrm{H}_{2} \mathrm{O}$, and $\mathrm{ZnCl}_{2}$ in $20 \mathrm{~mol} \%$ of catalyst which afforded lower yields of the 2,4,5-triphenylimidazole that the $\mathrm{ZnCl}_{2}$ supported catalyst (52, 47, 71 , and $83 \%$ respectively after $3 \mathrm{~h}$ ). The condensation was extended to different substituted benzaldehydes achieving excellent yields of the corresponding imidazoles (85-95 \%). The immobilized catalyst was very stable and could be reused at least four 
times without further purification. Shelke et al. ${ }^{202}$ have been prepared cellulose sulphuric acid (CSA) as a bio-supported and recyclable solid acid catalyst for the one pot synthesis of 2,4,5-triarylimidazoles. Condensation reaction of benzil or benzoin, aldehydes and ammonium acetate under microwave irradiation gave excellent yields (90-95 \%) with rather short reaction times (1-3 min). In Table 12 comparative results obtained with different catalyst in the coupling of benzyl (or benzoin), benzaldehyde and ammonium acetate are summarized.

\subsection{Synthesis of Quinazolin-4-(3H)-one derivatives}

4-(3H)-Quinazolinone derivatives were reported to possess analgesical, antibacterial, antifungical, antihelmentics, antiparkinson, anticancer, anti-HIV, MAO inhibitory, central nervous system and antiaggregating activity ${ }^{203-204,205}$ (some examples are displayed in Scheme 28).

Scheme 28. 4(3H) quinazolinones with different pharmacological activities.

The most simple procedure for the synthesis of 4-(3H)-quinazolinones was reported by Niementowski in $1895^{206}$ and involves de condensation of 2-aminobenzoic acid (anthranilic acid) or aminobenzoic acid derivatives with amides (Scheme 29). Other methods include cycloaddition reactions of anthranilic acid derivatives with diverse range of substrates including imidates and imino halides.

Scheme 29. Niementowski reaction

Recently, it has been reported that silica gel-supported ferric chloride ${ }^{207}$ catalyzes efficiently the three component reaction of anthralinic acid, orthoesters and amines to afford 4-(3H)-quinazolinones in one pot reaction (Scheme 30).

Scheme 30. MC synthesis of 2,3-disusbtituted-4-(3H)-quinazolinones from anthranilic acid or isatoic anhydride, orthoesters and amines.

Total conversion and good yields (84-98 \%) in short reaction time (5-10 min) were obtained when the reaction was performed at reflux temperature under solvent free conditions. The silica gel-supported ferric chloride catalyst could be recovered and 
recycled without loss of activity. Nafion has also been used as efficient catalyst in this multicomponent reaction to obtain 2,3-disubstituted 4-(3H)-quinazolinones under solvent free microwave irradiation. ${ }^{208}$ An equimolar mixture of isatoic anhydride or anthranilic acid, triethyl orthoester, aromatic aniline and a catalytic amount of Nafion was subjected to microwave irradiation (2-6 $\mathrm{min}$ ) affording the corresponding quinazolin-4-(3H)-ones in good yields (71-94\%). Anilines having an electron donating group (methyl) gave higher yields (89 \%) than anilines with electron withdrawing groups $\left(\mathrm{CF}_{3}\right.$ and $\left.\mathrm{NO}_{2}\right)(77 \%)$. Substituents on the orthoester did not result in much variation in yield. On the other hand, the recovered catalysts can be reused and did not show any reduced activity after six consecutive runs.

\subsection{Synthesis of 4-Arylaminoquinazoline derivatives}

Natural and synthetic compounds possessing the quinazoline structural motif, particularly 4-arylaminoquinazoline derivatives, display a wide range of biological activities. For instance, 6,7-dimethoxy-4-(3-bromophenylamino) quinazoline (PD 153035) (Scheme 31) and its analogues exhibit high tyrosine kinase inhibitor activity. ${ }^{209}$

\section{Scheme 31 PD 153035}

4-Arylaminoquinazolines can be obtained by reactions of $4(3 \mathrm{H})$-quinazolones with aromatic amine hydrochlorides and dimethylcyclohexylamine in the presence of phosphorous pentoxide. ${ }^{210}$ Other methods to obtain 4-arylaminoquinazolines involve the reaction of 2-aminobenzonitrile and different anilines in the presence of $\mathrm{AlCl}_{3}$ and subsequent condensation of the products with formic acid. ${ }^{211}$ A new multi-component synthesis of 4-arylaminoquinazolines has been reported by Heravi et al. ${ }^{212}$ The protocol involves the reaction of 2-aminobenzamide, orthoesters, and substituted anilines in the presence of acid catalysts such as different Keggin-type heteropolyacids (Scheme 32).

Scheme 32. Multicomponent synthesis of 4-arylaminoquinazolines from reaction of 2aminobenzamide, aniline derivative and orthoesters.

Various anilines and orthoesters were reacted with 2-aminobenzamide in the presence of different heteropolyacids $\left(\mathrm{H}_{6}\left[\mathrm{PMog}_{9} \mathrm{~V}_{3} \mathrm{O}_{40}\right], \mathrm{H}_{5}\left[\mathrm{PMo}_{10} \mathrm{~V}_{2} \mathrm{O}_{40}\right]\right.$, $\left.\mathrm{H}_{4}\left[\mathrm{PMo}_{11} \mathrm{VO}_{40}\right], \mathrm{H}_{3}\left[\mathrm{PMo}_{12} \mathrm{O}_{40}\right]\right)$ in acetonitrile under refluxing conditions. The order of 
activity of different heteropolyacids was $\mathrm{H}_{6}\left[\mathrm{PMog}_{3} \mathrm{~V}_{3} \mathrm{O}_{40}\right]>\mathrm{H}_{5}\left[\mathrm{PMo}_{10} \mathrm{~V}_{2} \mathrm{O}_{40}\right]>$ $\mathrm{H}_{4}\left[\mathrm{PMo}_{11} \mathrm{VO}_{40}\right]>\mathrm{H}_{3}\left[\mathrm{PMo}_{12} \mathrm{O}_{40}\right]$. Using $\mathrm{H}_{6}\left[\mathrm{PMog}_{9} \mathrm{~V}_{3} \mathrm{O}_{40}\right]$ as a catalyst, different 4benzylaminoquinazolines were obtained in good yields (80 -90 \%) within 2-3 hours. In all cases, 3-quinazolin-4-one was also obtained as a by-product in low yield. Studies to recyclability of the catalyst showed that using the catalyst over three runs only a slight loss of activity was observed.

\subsection{Synthesis of Homoallylic amine derivatives}

Homoallylic amines are excellent building blocks in the synthesis of $\beta$-amino acids, gamma amino alchohols, $\beta$-lactams antibiotics, aziridines, amino sugars HIVprotease inhibitors and other compounds (Scheme 33). ${ }^{213}$

Scheme 33. Different tansformations of homoallylic amines.

The homoallylic amines moiety is not widely present in natural products, however compounds like Eponemycin, ${ }^{214}$ which exhibits strong activity against B16 melanoma cells, or a depsipeptide Cryptophycin 337, which is analog of a potent antitumor compound Criptophycin, ${ }^{215}$ contain this subunits (Scheme 34$)$.

Scheme 34 Natural products containing homoallylic amines moiety

Generally, homoallylic amines are prepared either by addition of organometallic reagents to imines or by nucleophilic addition of allylstannane, allylsilane, allyltin, allylboron or allylgermanium reagents to imines in the presence of Lewis acid catalysts ${ }^{216}$ such as $\mathrm{BF}_{3}-\mathrm{OEt}_{2}, \mathrm{TiCl}_{4}$ and $\mathrm{PdCl}_{2}\left(\mathrm{Ph}_{3} \mathrm{P}\right)_{2}$ or $\mathrm{PtCl}_{2}\left(\mathrm{Ph}_{3} \mathrm{P}\right)_{2}$, Lithium perchlorate. ${ }^{217}$ The first addition of allylstannane with imine was catalized by $\operatorname{Ln}(\mathrm{OTf})_{3}$ affording moderate yields in $24 \mathrm{~h}^{218}$ One of the main disadvantages using Lewis acid catalysts is that the catalyst are deactivated or sometimes decomposed by the amine and water that is formed during the imine formation.

In order to circumvent some of the problems derived from the use of homogeneous catalysts, a one-pot $\mathrm{A}^{3}$ protocol involving aldehydes, aromatic amines and allyltributylstannane has been developed recently (Scheme 35). The one-pot process involves the in situ formation of imine followed by the nucleophilic addition of the organometallic reagent. 
Scheme 35 Three component coupling condensation to obtain homoallylic amines.

Ionic liquids such as 1-butyl-3-methylimidazolium tetrafluoroborate([bmim] $\mathrm{BF}_{4}$ ), have been used as solvent and catalysts with success in this transformation. ${ }^{219}$ However, similar yields were achieved with heterogeneous catalysts such as Montmorillonite $\mathrm{KSF}^{220}$ clay. Using this catalyst, different aldehydes, anilines and allyltributylstannane were coupled at room temperature in acetonitrile producing the corresponding homoallylic amines in high yields (73-90 \%) and in short times (3-5.5 h)(see Table 13). ${ }^{220}$ The Montmorillonite catalyst was reused showing a gradual decrease in activity. Thus when benzaldehyde, aniline and allyltributylstannane was reacted afforded $90 \%$, $85 \%$ and $80 \%$ yield over three cycles.

In all cases, the homoallylic alcohol coming from reaction between aldehyde and allyltributylstannane as well as decomposition or polymerization of sensitive aldehydes was not observed. On the other hand, ketones did not react under similar reaction conditions.

Under the same reaction conditions, analogous selective preparation of homoallylic amines have also been performed using silica supported sodium hydrogen sulphate $\left(\mathrm{NaHSO}_{4} \mathrm{SiO}_{2}\right)$ as acid catalyst. ${ }^{221}$ The one pot coupling between aldehydes (aromatic, heteroaromatic or aliphatic), aniline derivatives and allyltributylstannane in the presence of $\mathrm{NaHSO}_{4}-\mathrm{SiO}_{2}$ in acetonitrile at room temperature afforded the corresponding homoallylic amines in high yields (82-93 \%) within 1.5-3 h. Recently Yadav et al. ${ }^{222}$ have introduced a common organic acid with mild acidity (sulphamic acid , $\mathrm{NH}_{2} \mathrm{SO}_{3} \mathrm{H}$ ) (SA) as recyclable solid catalyst for three component synthesis of homoallylic amines. When the reaction was carried out with aldehydes and anilines with different substituents a room temperature and in absence of solvent, the corresponding homoallylic amines (82-90 \% yield) were obtained. $\mathrm{HClO}_{4}$ supported on silica gel $\left(\mathrm{HClO}_{4}-\mathrm{SiO}_{2}\right)^{223}$ with low loading $(0.01 \mathrm{mmol})$ is also an efficient catalyst for the synthesis of homoallylic amines through a 3CR of various aldehydes, aniline derivatives and allyltributylstannane in acetonitrile at room temperature (yields 82-90 \%).

Yin et al. ${ }^{224}$ have synthetised polystyrene-bound super Bronsted acids and their ytterbium salts for the synthesis of homoallylic amines. The polystyrene-bound perfluoroalkyl sulfonic ytterbium (Yb-PS $-\mathrm{RF}_{6}$ ) was the most efficient and recyclable catalyst in the coupling of aldehydes, anilines and allyltributylstannane achieving 86-95 
\% yield of the corresponding homoallylic amines when benzoic acid is added as promoter in the reaction media. It has been suggested ${ }^{225}$ that the Bronsted acidity of benzoic acid acts not only regenerating the catalyst, but also that Bronsted and the Lewis acid sites are working as a combined catalyst to produce a double activation of the substrate. Using $\mathrm{Yb}-\mathrm{PS}_{2}-\mathrm{RF}_{6}$ ) and benzoic acid as co-catalyst, the authors designed a one pot four-component coupling reaction involving benzaldehyde, aniline, allyltributylstannane and acrylic chloride in order to obtain homoallylic amides. Reaction performed at room temperature in acetonitrile give N-phenyl-N-(1-phenylbut3-enyl) acryl amide in good yield (78 \%) (Scheme 36 ).

Scheme 36. Synthesis of homoallylic acrylic amide by one-pot four component coupling reaction.

To examine the scope of the $\mathrm{A}^{4}$ reaction a number of acid chlorides were reacted under the above condtions achieving different homoallylic amides (benzamides carboxamides, acryl amides, acetamides, and cinnamamides) in good to moderate yields $(32-88 \%)$.

Zhengfeng et al. ${ }^{226}$ have proposed the synthesis of homoallylic amines from aromatic aldehydes, aromatic amines and allyltributylstannane in the presence of phosphomolybdic acid (PMA). A variety of different homoallylic amines were obtained in good to excellent yields (83-99 \%) at room temperature using 10 mol\% of PMA and water as a solvent.

Table 14 summarizes the results and experimental conditions for the synthesis of $N$-(1-phenyl-3-butenyl)aniline from benzaldehyde, aniline and allyltributylstannane using different acid catalysts.

\subsection{Synthesis of amidoalkyl naphthol derivatives}

Compounds bearing 1,3-amino-oxygenated functional motifs are common in a variety of natural products and drugs including nucleoside, antibiotics and HIV protease inhibitors (such as ritonavir and and lipinavir). ${ }^{227}$ 1-Amidomethyl-2-naphthol is an important precursor of biological active 1-aminomethyl-2-naphthol derivatives. These compounds present hypotensive and bradycardiac effects. ${ }^{227}$ Also it is noteworthy that 
aminotetralin derivatives presents several biological activities as antidepressant, immunomodulator, and antitumor. ${ }^{227}$

Generally, 1-amidoalkyl-2-naphthol derivatives can be prepared through MCR (via a Ritter type reaction) of aryl aldehydes, 2-naphthol and acetonitrile or amides in the presence of Lewis or Bronsted acid catalysts (Scheme 37).

Scheme 37. MC synthesis of 1-Amidomethyl-2-naphthol derivatives

The main preparation methods involve the use of acetonitrile as reactant and solvent (Method A), or acetamide under thermal (or microwave irradiation) and solvent free conditions (Method B). The reaction involves first the alkylation of 2-naphthol with benzaldehyde in the presence of an acid catalyst to give ortho-quinone methydes (oQMs, I). These intermediate I reacts with acetonitrile (Method A) to obtain the intermediate II through a Ritter type reaction that after hydrolysis gives the desired product. Following method B the o-QMs generated in situ reacted with acetamide, which acts as nucleophile, via conjugate addition to form 1-amidoalkyl-2-naphthol derivatives (Scheme 38).

Scheme 38. Reaction phatways in the formation of 1-Amidomethyl-2-naphthol derivatives

A variety of homogeneous (such as iodine, ${ }^{228} \mathrm{Ce}\left(\mathrm{SO}_{4}\right)_{2},{ }^{229} \mathrm{p}-\mathrm{TSA},{ }^{230}$ and heterogeneous catalysts have been reported in the literature $231-237$ to perform this MCR. Thus, Montmorillonite K-10 clay, Amberlyst-15, $\mathrm{K}_{5} \mathrm{CoW}_{12} \mathrm{O}_{40} 3 \mathrm{H}_{2} \mathrm{O}, \mathrm{H}_{3} \mathrm{PW}_{12} \mathrm{O}_{40}, \mathrm{FeCl}_{3}-\mathrm{SiO}_{2}$, $\mathrm{Al}_{2} \mathrm{O}_{3}-\mathrm{SO}_{3} \mathrm{H}, \mathrm{HClO}_{4}-\mathrm{SiO}_{2}, \mathrm{Al}_{2} \mathrm{O}_{3}-\mathrm{HClO}_{4}$ catalysts have been used with different succces for the preparation of 1-amidoalkyl-2-naphthol derivatives. It was found that aromatic aldehydes with electron-withdrawing groups reacted faster than those bearing electron donating groups. In Table 15 are summarized the yields and experimental conditions for the formation of $\mathrm{N}$-[phenyl-(2-hydroxynaphthalen-1-yl)-methyl]acetamide using different acid catalysts reported in the literature.

Recently Shaterian et al. ${ }^{239}$ have introduced the synthesis of 1-carbamate-alkyl2-naphthol in the presence of silica-supported sodium hydrogen sulphate $\left(\mathrm{SiO}_{2}\right.$ $\mathrm{NaHSO}_{4}$ ) as catalyst. The benefit to use carbamates instead of amides is that the carbamates can be deprotected more easily than amides for the preparation of 1aminomethyl-2-naphthol derivatives (Scheme 39). The three component condensation 
reaction between aldehydes, 2-naphthol and cabamates in the presence of $\mathrm{SiO}_{2}-\mathrm{NaHSO}_{4}$ was carried out under thermal and solvent free conditions $\left(100{ }^{\circ} \mathrm{C}\right)$. A wide variety of substituted 1-carbamato-alkyl-2-naphthol using various aryl aldehydes, 2-naphthol, and methyl/benzyl carbamates were obtained in good to moderate yields (60-92 \%) within 20-30 min.

Scheme 39. Synthesis of 1-carbamato-alkyl-2-naphthol derivatives

Das et al. ${ }^{240}$ have found that perchloric acid supported on silica $\left(\mathrm{HClO}_{4}-\mathrm{SiO}_{2}\right)$ is an efficient catalyst for the synthesis of $\mathrm{N}$-[(2-hydroxynaphthalen-1-yl)methyl]amides through the condensation of 2-naphthol, aromatic aldehydes and urea (or an amide) (Scheme 40). The reaction was performed by heating the corresponding mixture at 125 ${ }^{\circ} \mathrm{C}$ during 3-7 h giving the corresponding target products in good yields (71-93 \%). The reaction proceeded similarly with amides such as acetamide, benzamide, and acrylamide. In this case, the corresponding $\mathrm{N}$-[(2-hydroxynaphthalen-1yl)methyl]amides were obtained in yields of 68-82 \% in 5.5-9 h. Interestingly, when the reaction was carried out using aliphatic aldehydes the selectivity to the target compound was very low.

Scheme 40. Synthesis of N-[(2-hydroxynaphthalen-1- yl)methyl]amides derivatives.

\subsection{Synthesis of dihydropyridine derivatives}

Dihydropyridines (DHPs) are important class of compounds which cover a variety of pharmaceutical and agrochemical activities such as insecticidal, herbicidal and acaricidal. ${ }^{241}$ Some of them have used as cardiovascular agents for the treatment of hypertension and angina pectoris ${ }^{242}$ (nifedipine, nicardipine, and amlodipine) (Scheme 41), platelet antiaggregatory bactericidal agents, and bronchodilator. ${ }^{243}$ In addition, they have been used as cerebral antischemic agent in the treatment of Alzeimer's disease ${ }^{244}$ and also as chemosensitizer in tumour therapy. ${ }^{241}$ In addition, DHP present applications in stereospecific hydrogen transfer reactions. ${ }^{245}$

Scheme 41. 1,4-dihydropyridines of pharmaceutical interest. 
The classical method to obtain DHPs is the MC Hantzsch reaction involving the condensation of and aldehyde, a $\beta$-ketoester and ammonia either in acetic acid or by refluxing in alcohol for long reaction times ${ }^{15}$ (Scheme 42).

Scheme 42. Synthesis of DHPs through the MC Hantzsch reaction

Numerous synthetic methods have been reported for the preparation of 1,4dihydropyridine derivatives ${ }^{246}$ under classical or modified conditions. For instance using microwave irradiation in absence of catalyst, ${ }^{247-248}$ ionic liquids ${ }^{249}$ or metal triflates as acid catalyst. ${ }^{250}$ However, some of them suffer from drawbacks such as long reaction times, and low yields particularly when unsaturated and aliphatic aldehydes are involved.

Recently, heterogeneous acid and acid-base catalysts have been used for the preparation of DHPs. Thus, Gupta et al. ${ }^{251}$ have reported that sulfonic acid covalently anchored onto the surface of silica gel $\left(\mathrm{SiO}_{2}-\mathrm{SO}_{3} \mathrm{H}\right)$ is an efficient and recyclable catalyst to synthesize 1,4-dihydropyridines (1,4-DHPs). Various aldehydes (aromatic, heterocyclic and unsaturated) and $\beta$-keto esters (ethyl and methyl acetoacetate) in the presence of ammonium acetate at $60{ }^{\circ} \mathrm{C}$ under solvent free conditions afforded the corresponding 1,4-DHPs in good yield (83-90 \%). For comparative purposes different supported sulfonic acid catalysts such as polystyrene and polyethylene glycol supported sulfonic acid, were also used in the coupling of 4-methoxybenzaldehyde, ethyl acetoacetate and ammonium acetate for the synthesis of diethyl 4-(4-methoxyphenyl)2,6-dimethyl-1,4-dihydropyridine-3,5-dicarboxylate (see Table 16). In Table 16 is showed that $\mathrm{SiO}_{2}-\mathrm{SO}_{3} \mathrm{H}$ was the most active catalyst followed by polystyrene- $\mathrm{SO}_{3} \mathrm{H}$ and $\mathrm{PEG}-\mathrm{SO}_{3} \mathrm{H}$. In addition it was found that $\mathrm{SiO}_{2}-\mathrm{SO}_{3} \mathrm{H}$ is a stable catalyst, and no significant change in the activity was found after eight consecutive runs.

The mechanism proposed by the authors for the acid catalyzed synthesis of 1,4DHPs is presented in Scheme 43. The first step is the formation of the Knoevenagel adduct from one equivalent of ethyl acetoacetate and benzaldehyde (intermediate A). On the other hand, a second equivalent of ethyl acetoacetate reacts with the ammonia generated by the ammonium acetate. The $\mathrm{N}$-addition of ammonia to a protonated carbonyl group which suffers dehydration gives ethyl-3-aminobut-2-enoate (intermediate B). Subsequent cyclocondensation of both intermediates and dehydration give the DHP. 
Scheme 43. Proposed mechanism for the formation of DHP in the presence of acid catalyst.

Recently Nikpassan et al. ${ }^{252}$ have developed the synthesis of fused 1,4-DHPs starting from dimedone (5,5-dimethyl-1,3-cyclohexadienone), different aldehydes and ammonium acetate in the presence of HY zeolite. The reactions were carried out at reflux temperature of ethanol giving the corresponding 1,4-DHPs in good yields (70-90 $\%)$ and in short reaction times (2.5-3.5 h) (Scheme 44). The catalyst was recovered and its activity was maintained after three consecutive runs.

Scheme 44. Synthesis of fused 1,4-DHP.

$\mathrm{N}$-aryl-1,4-dihydropyridines and other related analogues are valuable compounds since they have applications as pharmaceuticals and agrochemicals. However, it is known that the classical Hantzsch reaction is not a suitable method for the preparation of N-aryl-1,4-dihydropyridines. For that reason, a complementary route to the Hantzsch synthesis has been developed to obtain N-aryl-1,4-DHP. This involves the coupling of aromatic amines, $\alpha, \beta$-unsaturated aldehydes and ketoesters. Using sulfonic functionalized silica $\left(\mathrm{SiO}_{2}-\mathrm{SO}_{3} \mathrm{H}\right){ }^{253}$ as recyclable heterogeneous acid catalyst (Scheme 45) a series of $N$-aryl-1,4-DHPs were successfully obtained (80-89 \% yields) starting from cinnamaldehyde, different aromatic amines and methyl or ethyl acetoacetate, at room temperature within a short time (5-30 $\mathrm{min})$. However, low selectitity was obtained using aliphatic amines and cinnamaldehyde derivatives containing nitro groups in the aromatic ring.

Scheme 45. Synthesis of N-aryl-1,4-dihydropyridines.

Polyhydroquinoline derivatives, compounds containing a 1,4-DHP moiety, are a source of valuable drugs, which have been prepared efficiently through an $\mathrm{A}^{4}$ Hantzsch type coupling condensation involving 1,3-cyclohexanediones (5,5-dimethyl-1,3cyclohexadione or dimedone), ethyl acetoacetate, aldehydes and ammonium acetate in the presence of acid catalysts (Scheme 46). 
Scheme 46. Synthesis of polyhydroquinoline derivatives through an $\mathrm{A}^{4}$ coupling Hantzsch condensation

Various methods for the preparation have been reported using conventional heating, microwave and ultrasound irradiation in the presence of a wide variety of homogeneous and heterogeneous catalysts. They include trimethylsilyl chloride (TMSCl), ${ }^{254}$ iron (III) trifluoroacetate, ${ }^{255}$ metal triflates, ${ }^{250}$ PTSA acid, ${ }^{256}$ Bronsted ionic liquid, ${ }^{249}$ glycine, ${ }^{257}$ silica supported perchloric acid $\left(\mathrm{HClO}_{4}-\mathrm{SiO}_{2}\right){ }^{258}$ Montmorillonite $\mathrm{K} 10,{ }^{259}$ heteropolyacid $\left(\mathrm{K}_{7}\left[\mathrm{PW}_{11} \mathrm{CoO}_{40}\right]\right),{ }^{260} \mathrm{HY}$ zeolite ${ }^{261}$ and nickel nanoparticle. ${ }^{262}$ Using the Hantzsch protocol and catalysts referenced above, a series of polyhydroquinolines derivatives have been prepared in good yields. For comparison purposes in Table 17 are summarized some results in the synthesis of ethyl 2,7,7-trimethyl-5-oxo-4-phenyl1,4,5,6,7,8-hexahydroquinoline-3-ethylcarboxylate from the 4CR of benzaldehyde, dimedone, ethyl acetoacetate and ammonium acetate using different heterogeneous catalysts reported in the literature.

Besides heterogeneous acid catalysts, solid base catalysts have also been used to perform the MC synthesis of 1,4-DHP. Thus, Antonyraj et al. ${ }^{264}$ have reported the coupling of benzaldehyde, ethyl acetoacetate and ammonium acetate using hydrotalcites (HT) and hydrotalcites like materials as solid base catalysts. Various $\mathrm{Al} / \mathrm{Mg}$ hydrotalcites with different $\mathrm{Mg} / \mathrm{Al}$ ratios were tested in the synthesis of 1,4-DHP (Table 18). The authors found that the activity decreased when increasing the $\mathrm{Mg} / \mathrm{Al}$ atomic ratio, being the material $\mathrm{MgAl}_{2}-\mathrm{HT}$ (with a $\mathrm{Mg} / \mathrm{Al}=2.1$ ) the most active catalyst. This catalyst possesses maximum aluminium content even though possesses lesser Bronsted basicity than the other studied materials. In order to study the importance of the Bronsted basic $\mathrm{OH}$ groups present in HT-like lattice, the $\mathrm{MgAl}_{2} \mathrm{HT}$ sample was subjected to calcination and the resulting $\mathrm{Al} / \mathrm{Mg}$ mixed oxide $\left(\mathrm{MgAl}_{2} \mathrm{CHT}\right)$, which presents basic Lewis sites associated at $\mathrm{O}^{2-}$ centres, was tested in the synthesis of 1,4DHP. Low yield of the 1,4-DHP was obtained in this case, which suggest that the presence $\mathrm{OH}$ groups in the hydrotalcite catalyst is required for the reaction. It is known that the original lamellar structure of hydrotalcites can be restored by hydration of the calcined mixed oxide (memory effect) while the carbonate anions are exchanged by hydroxyl anions resulting is a material with strong Bronsted basic character. ${ }^{265-266}$ When the Hantzsch reactions were carried out over a hydrated sample ( $\left.\mathrm{MgAl}_{4} \mathrm{RHT}\right)$ and a 
$\mathrm{MgAl}_{4} \mathrm{HT}$, similar results were obtained (Table 18). From these results, the authors conclude that the high activity of $\mathrm{MgAl}_{2} \mathrm{HT}$ is due to the appropriate cooperative behaviour of acid-base sites existing in this catalyst. With this optimized catalyst, different aliphatic, cyclic and aromatic aldehydes were reacted affording the corresponding 1,4-DHP in moderated to good yields (57-75 \%). When different nitrogen sources such as liquid ammonia, ammonium carbonate and ammonium acetate were used to synthesize 1,4-DHP, maximum yield was obtained using ammonium acetate followed of ammonia and ammonium carbonate.

Finally, the synthesis of 1,4-DHP was also carried out using HT with different $\mathrm{M}$ (II) metals such as $\mathrm{NiAl}_{3}-\mathrm{HT}$ and $\mathrm{CoAl}_{3} \mathrm{HT}$, however the catalytic activity was considerably lower than those obtained with $\mathrm{MgAl}_{2}$-HT catalyst.

The mechanism involving three reactants at different stoichiometry is complex. The first step is the proton abstraction from the active methylene group of ethyl acetoacetate by the base catalyst, followed by $\mathrm{N}$-addition to a protonated carbonyl group which suffer a dehydration giving the ethyl-3-aminobut-2-enoate intermediate (A). Subsequent condensation with another molecule of ethyl acetoacetate results in the imine B (ethyl 3-(4-ethoxy-4-oxobutan-2-ylideneamino)but-2-enoate)). Tautomerisation reaction of this imine in the presence of base catalyst will form the enamine (C) which finally condensed with benzaldehyde to give the 1,4-DHP (Scheme 47).

Scheme 47. Reaction mechanism catalyzed by bases in the synthesis of 1,4-DHP

\subsection{Synthesis of pyridine derivatives}

Pyridines are interesting compounds since to their saturated and partially saturated derivatives are present in many biologically active and natural products such as for instance pyridoxol (vitamin $\mathrm{B}_{6}$ ), NAD nucleotide (Nicotin Adenosin) and pyridine alkaloids. ${ }^{267}$ The precursor compounds for the synthesis of pyridines are often 1,4-DHP, which can be prepared by the Hantzsch reaction mentioned above. Nowadays the synthesis of highly substituted pyridines by one pot three component reactions has recently attracted much attention since this methodology allows obtaining important medicinal pyridine derivatives that can act as ligand for a number of structural diverse biological receptors. Some examples are presented in Scheme 48. 
Scheme 48. Some examples of pyridine derivatives with pharmacological activity

The traditional synthesis of pyridines involves the synthesis of 1,4-DHP followed by an additional step consisting in the oxidative aromatization to obtain the corresponding pyridine (Scheme 49). Some years ago Boker et al. ${ }^{268}$ demonstrated that the metabolism of 1,4-DHP drugs involves its catalyzed oxidation in the liver by cytochrome P-450. Due to the biological importance of the oxidation step of 1,4-DHPs, a large number of studies and reagents have been utilized to mimic the "in vivo" transformations. Many efficient oxidative aromatization processes using conventional oxidants, such as potassium permanganate, ${ }^{269}$ ceric ammonic nitrate, ${ }^{270}$ ruthenium trichloride, ${ }^{271}$ as well as supported oxidants such as clayfen(iron (III) nitrate on clay), ${ }^{272}$ or $\mathrm{Mn}$ (pbdo) ${ }_{2} \mathrm{Cl}_{2} / \mathrm{MCM}-41$ in acetic acid ${ }^{273}$ and a variety of other catalyst and reagents have been reported. However the use of liquid acids in the cyclization step along with the stoichometric amount of oxidant agent required for the oxidative aromatization produce significant drawbacks. In this section we will show different 3CRs (based mainly on Hantzsch type reaction) leading to a variety of pyridine derivatives.

\subsubsection{Synthesis of 3,5-ethoxycarbonyl pyridine derivatives}

As an alternative strategy to the homogeneous acid catalyzed Hantzsch reactionoxidation, De Paolis et al. ${ }^{274}$ developed a heterogeneous bifunctional noble metal-solid acid catalyst system ( $\mathrm{Pd} / \mathrm{C} / \mathrm{K} 10$ Montmorillonite) for the one pot three component reaction to obtain pyridines under microwave irradiation. The solid acid catalyzes the condensation of an aldehyde, a $\beta$-ketoester and ammonium acetate (Hantzsch reaction) to give 1,4-dihydropyridines which undergoes dehydrogenation on the surface of the metal probably as a concerted reaction and results in pyridine derivative (Scheme 49).

Scheme 49. Pyridine derivative synthesis

The authors claimed that the presence of acidic surface favors the dehydrogenation due to the anchoring of the intermediate (1,4-DHP) via its basic nitrogen. When the reaction was performed under conventional heating, high yield was also achieved, however longer reaction time was required (Table 19). Comparatively, triflic acid and acetic acid in the presence of $\mathrm{Pd} / \mathrm{C}$ give lower yields than those obtained with Montmorillonite (Table 19). The scope of the reaction was showed by reacting a 
variety of aliphatic and aromatic aldehydes with ethyl acetoacetate and ammonium acetate affording the corresponding pyridines in good to moderate yields (45-95 \%) at $130{ }^{\circ} \mathrm{C}$ in short reaction time.

\subsubsection{Synthesis of 2,4,6-triarylpyridine derivatives}

Recently the synthesis of 2,4,6-triarylpyridines through one pot condensation of aldehydes, ketones and ammonium acetate have been carried out in the presence of perchloric acid supported on silica gel $\left(\mathrm{HClO}_{4}-\mathrm{SiO}_{2}\right)^{223}$ as heterogeneous catalyst (Scheme 50 ). It is known that the potential hazard to use perchlorates is connected with the explosive reactions when larger amounts are heated at high temperature. However recent methods indicate that the low acid loading on $\mathrm{HClO}_{4}-\mathrm{SiO}_{2}$ catalyst can be safetly and effectively used for organic transformations.

Scheme 50. MC synthesis of 2,4,6-triarylpyridine derivatives.

Then, a variety of symmetric 2,4,6-triarylpyridines were synthesized in 68-88 \% yield, by heating a mixture of aromatic aldehydes, aromatic ketones and ammonium acetate in the presence of $\mathrm{HClO}_{4}-\mathrm{SiO}_{2}$ catalyst at $120{ }^{\circ} \mathrm{C}$. In addition the catalyst could be recovered after reaction and reused seven times without significant decrease in activity.

\subsubsection{Synthesis of 3-Cyanopyridine derivatives}

Substituted 3-cyanopyridines are increasingly useful compounds since they are important intermediate in pharmaceuticals, dyes and photo industries. Recently Heravi et al. ${ }^{275}$ have prepared a series of 3-cyanopyridine derivatives through the MCR involving aldehydes, 3,4-dimethoxyacetophenone, malononitrile and ammonium acetate using different heteropolyacids as heterogeneous and recyclable acid catalysts (Scheme 51). The screening of different heteropolyacids $\left(\mathrm{H}_{14}\left[\mathrm{NaP}_{5} \mathrm{~W}_{30} \mathrm{O}_{110}\right], \mathrm{H}_{6}\left[\mathrm{P}_{2} \mathrm{~W}_{18} \mathrm{O}_{62}\right]\right.$, $\mathrm{H}_{4}\left[\mathrm{PMo}_{11} \mathrm{VO}_{40}\right], \mathrm{H}_{3}\left[\mathrm{PMo}_{12} \mathrm{O}_{40}\right]$ ), showed that the highest activity was achieved with $\mathrm{H}_{14}\left[\mathrm{NaP}_{5} \mathrm{~W}_{30} \mathrm{O}_{110}\right]$. It is known, the one of the factors that influences the oxidation capacity and activity of polyanions is the energy gap between the highest occupied molecular orbital, HOMO, and the lowest unoccupied orbital (LUMO). It is suggested that the energy and composition of the LUMO have significant effects on the redox properties and activities of the different polyanions studied. The authors sugested that the highest activity exhibited by $\mathrm{H}_{14}\left[\mathrm{NaP}_{5} \mathrm{~W}_{30} \mathrm{O}_{110}\right]$ should be attributed to the energy and composition of the LUMO and higher acidic protons. 
Scheme 51. MC synthesis of 3-cyanopyridine derivatives

Then, condensation of different aldehydes, 3,4-dimethoxyacetophenone, malononitrile and ammonium acetate in ethanol in the presence $\mathrm{H}_{14}\left[\mathrm{NaP}_{5} \mathrm{~W}_{30} \mathrm{O}_{110}\right]$ at $78{ }^{\circ} \mathrm{C}$ gave after $3 \mathrm{~h}$ the corresponding cyano-2- $(1 \mathrm{H})$-iminopyridines in good yields (90$93 \%)$. When ethyl cyanoacetate was used instead of malononitrile the corresponding cyano-2(1H)-pyridinones were also obtained in excellent yields 91-94 \%.

\subsubsection{Synthesis of 3,5-Dicyanopyridine derivatives}

3,5-Dicyanopyridine is an important heterocyclic scaffold. Different substitutions at positions C2, C4 and C6 of the pyridine core have resulted in a large number of compounds with diverse biological activities. Among them, 2-amino-4-aryl6-sulfanyl substituted compounds (Scheme 52) found different applications such as anticancer, ${ }^{276}$ and antihepatitis B virus infection ${ }^{277}$ among others. These compounds are considered as potential medicinal leads when developing first therapeutic agents for the treatment of prion-induced fatal neurodegeneration diseases such as Creutzfeldt-Jacob disease in humans, bovine spongiform encephalopathy and scrapie in sheep. Recently, it has been found that 3,5-dicyanopyridine derivatives due to its capacity for recognition of adenosine receptors, are potential targets for developing new pharmaceutical agents for the treatment of Parkinson’s disease, hypoxia-ischemia, epilepsy and asthma. ${ }^{278}$

Due to their medicinal utility, various methods to prepare these compounds have been reported. ${ }^{279}$ Some of them include Vilsmeier reactions of tertiary alcohols, ${ }^{280}$ Diels-Alder reactions of 3-siloxy-1-aza-1,3-butadienes and 6-alkyl-3,5-dichloro-2H-1,4oxazin-2-ones with different types of acetylenic compounds, ${ }^{281}$ reaction of imines with enamines or carbonyl compounds ${ }^{282}$ and [4+2] cycloadditions of oximinosulfonates. ${ }^{283}$ However these methods involve multistep sequences, low yield, expensive and toxic catalysts and lack of generality.

Scheme 52. 3,5-Dicyanopyridine derivatives

Recently, a new MCR strategy for the preparation of 3,5-dicyanopyridines pyridines has been reported by Evdokimov et al. ${ }^{278,284}$ that involve the base catalyzed coupling of aldehydes, malononitrile and thiols. Homogeneous bases such as 
triethylamine or 1,4-diazabicyclo[2,2,2]octane $\quad(\mathrm{DABCO})^{278,} \quad 284$ afford 3,5dicyanopyridines in low yields (20-48 \%) due to the formation of appreciable enaminonitrile as by-product. However, the use of other basic catalysts such as piperidine on microwave irradiation, ${ }^{285}$ and Lewis acids such as $\left(\mathrm{ZnCl}_{2}\right)$ have considerably improved the yields of 3,5-dicyanopyridines. ${ }^{286}$ Also, a basic ionic liquid such as 1-methyl-3-butylimidazolium hydroxide $([\mathrm{bmim}] \mathrm{OH})^{287}$ has been described as recyclable catalyst to produce highly substituted pyridines in high yields (65-95 \%) a room temperature. As an alternative to homogeneous base or acid catalysts, nanoparticles have attracted much attention in catalysis because their improved efficiency (high surface area) under mild an environmentally benign conditions. Recently, silica nanoparticles (silica NP) have been used as catalyst for the preparation of 2-amino-3,5-dicarbonitrile-6-sulfanylpyridines, via a single step multicomponent reaction of aldehydes, malononitrile and thiols ${ }^{288}$ (Scheme 53).

Scheme 53. One-pot three components synthesis of substituted 2-amino3,5dicyanopyridines

A series of 2-amino-3,5-dicarbonitrile-6-sulfanylpyridine derivatives was prepared in good yields (60-85 \%) starting from different aliphatic and aromatic aldehydes and thiophenol or alkyl thiols. The significant improvement in the yield of pyridines derivatives obtained using the silica NP compared to other catalysts such as $\mathrm{ZnCl}_{2}$ (yield 45-67) $\mathrm{Et}_{3} \mathrm{~N}$ or DABCO (20-48 \%), or piperidine under microwave irradiation (60-81 \%) was attributed to the presence of hydroxyl groups on the surface of the catalyst. In accordance with the mechanism proposed by Evdokimov ${ }^{278}$ the reaction starts by the formation of the Knoevenagel adduct (A) from the aldehyde and malononitrile. Subsequently a second molecule of malononitrile reacts with Knoevenagel adduct through base catalyzed Michael addition followed by simultaneos thiolate addition to nitrile group. Then cyclization process gives the dihydropyridine intermediate (B) which posterior oxidation in the presence of air leads to the pyridine (Scheme 54).

Scheme 54. Possible mechanism for the formation of substituted 3,5-dicyanopyridines 
The authors suggest that the polar amphoteric surface hydroxyl groups of the silica nanoparticles facilitate the interaction of adsorbed weak acidic and basic components due to stabilization of the corresponding transition states and intermediates by hydrogen boding. In addition, it is also speculated the participation of two proximate silanols groups (acting one as hydrogen bond donor and another one as an acceptor) in the reaction mechanism.

Singh et al. ${ }^{263}$ have recently reported the synthesis of 2-amino-3,5-dicarbonitrile6-sulfanylpyridines (Scheme 53) using FK-alumina as catalyst under microwave irradiation and conventional heating. Condensation of different aromatic aldehydes, malononitrile and thiophenols under microwave conditions give 62-93 \% yield of the corresponding pyridines in 5-10 min, whereas at refluxing of ethanol the reaction afforded the corresponding pyridines in 56-82 \% yield within 30-70 min.

Very recently Kantam et $\mathrm{al}^{289}$ have reported the one pot three component synthesis of 2-amino-3,5-dicarbonitrile-6-sulfanylpyridines from diverse aldehydes with various thiols and malonitrile in the presence of nanocrystalline magnesium oxide (NAP-MgO, with surface area of $590 \mathrm{~m}^{2} / \mathrm{g}$ ). Moderate to good yields (41-69\%) of pyridine derivative were obtained when the reaction was carried out a reflux of ethanol. A possible rationale clarification for the higher activity of NAP-MgO compared with other MgO samples (CM- MgO (30 m²/g), NA-MgO (250 $\left.\mathrm{m}^{2} / \mathrm{g}\right)$ ) is the presence of more surface Lewis acid sites (20\%) along with the $\mathrm{OH}$ groups present on the edge and corner sites on the NAP-MgO. The authors suggest a dual activation of the substrate by the catalyst, thus Lewis base sites $\left(\mathrm{O}^{-2} / \mathrm{O}^{-}\right)$activate the manolonitrile while Lewis acid sites $\left(\mathrm{Mg}^{+2} / \mathrm{Mg}^{+}\right)$activate the aldehyde and thiol. The catalyst can be recovered and reused at least up to four cycles without appreciable lost of activity.

\subsubsection{Synthesis of 3-Cyano-6-hydroxy-2(1H)-pyridinones}

3-Cyano-6-hydroxy-2(1H)-pyridinones and other 1-substituted derivatives are compounds widely used in the preparation of azo dyes, mainly as disperse dyes for polymeric materials. ${ }^{290}$ Several methods have been described for the synthesis of $2(1 \mathrm{H})$ pyridinones. Among them, the most common method involves the condensation of $\mathrm{N}$ alkylcyanoacetamides with $\beta$-ketoesters under pressure or in the presence of base. ${ }^{291}$ Balalaie et al. ${ }^{292}$ have performed the three component condensation of alkylacetoacetates, primary amines and alkyl cyanoacetates catalyzed by solid acids under microwave irradiation obtaining the corresponding 3-cyano-6-hydroxy-2(1H)- 
pyridinones in good yields (Scheme 55). Condensation of methyl acetoacetate, methyl cyanoacetate and methyl amine using different solid acids such as silica gel, Montmorillonite $\mathrm{K}-10$, HY zeolite and acidic alumina give the corresponding pyridinones in moderate to good yields (93\%, $65 \%, 60 \%$ and $55 \%$ respectively). The authors claimed that the reaction of $\beta$-ketoesters and primary amines afford the enamino- $\beta$-ketoester which react with alkylcyanoesters to give the final product. Using silica gel excellent yields of different 3-Cyano-6-hydroxy-2(1H)-pyridinones (87-94 \%) were obtained after two minutes.

Scheme 55. One-pot three component synthesis of 3-Cyano-6-hydroxy-2(1H)pyridinone derivatives

\subsection{Synthesis of $\beta$-acetamido ketone derivatives}

$\beta$-acetamido ketones are considered versatile intermediates since its basic skeleton exists in a number of pharmacologically or biologically active compounds. ${ }^{293-}$ ${ }^{294}$ Moreover they are important synthons for a variety of specialty chemicals ${ }^{295}$ and pharmaceuticals such as nikkomycine and neopolyxine antibiotics. ${ }^{296}$ The main route for the synthesis of these compounds is the Dakin-West reaction ${ }^{297}$ which involves the condensation of an $\alpha$-aminoacid with acetic anhydride in the presence of a base via an intermediate azalactone. Recently Bathia et al. ${ }^{298}$ have proposed another general route for the synthesis of $\beta$-acetamido ketones that involves the condensation of an aryl aldehyde, an enolizable ketone or ketoester, acetyl chloride and acetonitrile in the presence of Lewis acid catalysts such as $\mathrm{CoCl}_{2}$ (Scheme 56 ). The same author performed this MCR using Montmorillonite K10 as acid catalysts. ${ }^{299-300}$ The reactions were carried out at $70{ }^{\circ} \mathrm{C}$ using acetonitrile as reactant and as a solvent. Particularly for the coupling of substituted benzaldehydes, acetophenone, acetyl chloride and acetonitrile yields between 64-88 \% were achieved.

Scheme 56. MC synthesis of $\beta$-acetamido ketone derivatives

When $\alpha$-substituted ketones were used, for instance ethyl methyl ketone or propiophenone, a diastereomeric mixture of the $\beta$-acetamido ketones were obtained, 
being the anti diasteroisomer the most abundant (Scheme 57). In addition, the catalyst could be reused without considerable variation in yield and stereoselectivity.

Scheme 57. MC synthesis of $\beta$-acetamido ketone using $\alpha$-substituted ketones

Besides Montmorillonite K10, a variety of solid acid catalysts promoting this MCR have been reported. For instance, HBeta zeolite has been used as active and reusable catalyst to perform this reaction at room temperature. ${ }^{301}$ Using different substituted benzaldehydes and enolizable ketones 63-90 \% yields of the corresponding $\beta$-acetamido ketones can be achieved in 8-12 h. Also heteropolyacids, ${ }^{302-304}$ acid resins, ${ }^{305-306}$ sulfated zirconia, $^{307}$ sulfuric acid supported on silica ${ }^{308}$ or phosphomolybdic acid supported on silica $\left(\mathrm{PMA} / \mathrm{SiO}_{2}\right)^{309}$ have been used to perform this MCR using a wide variety of aromatic aldehydes and ketones or ketoesters and giving in general excellent yields of the desired product. As example, a summary of the different catalysts ad their activity performing the coupling of benzaldehyde, acetophenone, acetyl chloride and acetonitrile is presented in Table 20.

A plausible mechanism for this transformation is presented in Scheme 58. The acid catalyst activates the aldehyde which reacts with acetyl chloride and acetonirile giving an intermediate (A) which subsequently reacts with the enolisable ketone giving the intermediate (B) which hydrolysis gives the $\beta$-acetamido ketone.

Scheme 58 Mechanism in the one-pot formation of $\beta$-acetamido ketones

\subsection{Synthesis of Imidazo[1,2-a]pyridine derivatives}

Imidazo[1,2-a]pyridines (Impy) is an important pharmacophore and is widely found in many natural and synthetic biologically active compounds ${ }^{310}$ Moreover, they exhibit antiviral (antivaricella-zoster and anticytomegalo-zoster virus) anti-inflammatory, antipyretic, antifungal activities and calcium channel blockers. ${ }^{311-313}$ They have also been found to be $\alpha$-amyloid formation inhibitors, GABA and benzodiazepines receptor 
agonist. $^{314-315}$ Drugs formulations containing Imidazo[1,2-a]pyridines currently available on the market include Zolimidine (used for peptic ulcer and gastroesophageal disease), Zolpidem (hypnotic drug), and Alpidem (anxyolytic) (Scheme 59). ${ }^{316}$

Scheme 59 . Imidazopyridines of pharmacological activity

The classical route for the synthesis of Impy involves the coupling of 2-aminopyridines with lachrymatory $\alpha$-haloketones. ${ }^{317}$ However this approach does not readily lend itself to diversity oriented synthesis. In 1998 three research groups published simultaneously a new version of the Ugi reaction in which 2-aminopyridine, aldehydes and isocyanides react in the presence of an acid catalyst to give Imidazo[1,2-a]pyridines in one step (Scheme 60). ${ }^{318-320}$

Scheme 60. MC synthesis of Imidazo[1,2-a]pyridines by Ugi reaction

Reactions were performed at room temperature by combining all three reagents in methanolic solution in the presence of homogeous acids such as $\mathrm{Sc}(\mathrm{OTf})_{3}{ }^{319}$ perchloric acid ${ }^{318}$ or glacial acetic acid. ${ }^{320}$

\section{Scheme 61. Ugi and Passerine reactions}

This robust approach allows for the preparation of a diverse range of substituted imidazo[1,2-a] annulated nitrogen heterocycles. However this synthesis suffers from several drawbacks such as the acid catalyzed polymerization of isocyanides and the competitive Passerine reaction, leading to moderate yields of the target compound, with relativelly long reaction times (Scheme 61). In order to overcome those drawbacks, a variety of catalytic systems have been reported to perform this multi-component reaction under classical conditions and under microwave irradiation. For instance, Lewis acids such as $\mathrm{ZnCl}_{2}{ }^{321}$ ammonium chloride, ${ }^{322-323}$ protic acids ${ }^{324-325}$ or ionic liquids, ${ }^{326}$ have been used as catalysts, however in most cases the catalyst is required in stoichiometric amounts in order to achieve high yield of the target compound. Concerning to the use of heterogeneous catalysts, there are scarce studies. For instance, a variety of Imidazo[1,2-a]pyridines were prepared starting from 2-aminopyridine, aldehydes and isocyanides using Montmorillonite K10 clay as catalyst in a microwave 
reactor or by conventional heating at reflux of 1,4-dioxane, ${ }^{321}$ although moderate yields (61-72 \%). Improved results were achieved with Montmorillonite K10 in the condensation of amino pyridines, pyrazines and pyrimidines with different aldehydes and isocyanides under microwave irradiation and in absence of any solvent (Scheme 62). ${ }^{327}$ In this case the corresponding imidazo[1,2- $a$ ] annulated nitrogen heterocycles were obtained within 3-5 min in 56-88 \% yield.

Scheme 62. MC synthesis of imidazo -pyridine, -pyrazine and -pyrimidine using Montmorillonite K10 as catalyst.

The mechanism of formation of these heterocycles can be rationalized by the initial formation of iminium ion from the condensation of the amine with the aldehyde which is followed by the nucleophilic attack of isocyanide. Subsequently, internal nucleophilic attack of ring nitrogen leads to the bicycle adduct which upon aromatization and 1,3shift of hydrogen atom results in the formation of the imidazole ring (Scheme 63).

Scheme 63. Proposed mechanism for the MC synthesis of imidazo[1,2-a]pyrimidines

Sulphuric acid supported on silica has also been used recently as reusable acid catalyst $^{328}$ to perform the synthesis of 3-aminoimidazo[1,2-a]pyridines and -pyrazines by condensation of an aldehyde, 2-amino-5-substitutedpyridines or 2-aminopyrazine and alkyl or aryl isocyanides. Reactions performed at room temperature in methanol give good yields (77-99 \%) of the corresponding 3-aminoimidazo[1,2-a]pyridines and pyrazines.

\subsection{Synthesis of 1,2,4,5-tetrazinan-3-one derivatives}

1,2,4,5-Tetrazines are heterocyclic compounds with numerous biological activities such as bronchodilating, bactericidal, antiallergical, antiulcer, antinflammatory, pesticidal and antineoplasic activities. ${ }^{329-331}$ Moreover, some tetrazoles have recently been introduced for the treatment of type 2 diabetes. ${ }^{332}$

The formation of $\mathrm{N}-\mathrm{N}$ bonds is not easy and 1,2,4,5-tetrazines have generally been prepared from hydrazine derivatives or from nitrilimines. ${ }^{331}$ Recently Gopalakrishnan et al. ${ }^{333}$ have reported the synthesis of 6-aryl-1,2,4,5-tetrazin-3-ones or thiones through a MC reaction involving urea, various substituted benzaldehydes, and 
ammonium acetate in the presence of $\mathrm{NaHSO}_{4}$ supported on silica gel $\left(\mathrm{NaHSO}_{4}-\mathrm{SiO}_{2}\right)$ as acid catalyst (Scheme 64). Reactions performed under microwave irradiation afforded 6-aryl-1,2,4,5-tetrazin-3-ones in 68-75 \% yield within 2 or 3 min, while under thermal conditions (heating at $75^{\circ} \mathrm{C}$ ) lower yield was achieved (30-38 \%) in 35-43 min. The catalyst also resulted active when using thiourea, affording the corresponding 6aryl-1,2,4,5-tetrazin-3-thiones in similar yields.

Scheme 64. MC synthesis of 6-aryl-1,2,4,5-tetrazinane-3-one (X=O) and 6-aryl-1,2,4,5tetrazinane-3-thione $(\mathrm{X}=\mathrm{S})$ derivatives.

The proposed mechanism involves the nucleophilic addition of the aminoalcohol adduct (formed by reaction of benzaldehyde with ammonia) to the urea, followed by cyclization and dehydrogenation to the target compound (Scheme 65).

Scheme 65. Proposed mechanism for the formation of 1,2,4,5-tetrazinane-3-ones

\subsection{Synthesis of $\alpha$-aminophosphonates}

$\alpha$-Aminophosphonates is an important class of biologically active compounds. Some of them act as peptide mimics, ${ }^{334}$ antibiotics, enzyme inhibitors, ${ }^{335}$ haptens of catalytic antibodies, pharmacological agents (antithrombotic, antibacterial, antiHIV, anticancer) ${ }^{336}$ and plant-growth regulators. ${ }^{337}$ Recently the syntheses of this type of organophosphorous compounds has attracted a lot of interest due to structural analogy to the corresponding $\alpha$-amino acids and besides, they are key substrates in the synthesis of phosphonopeptides.

Several methods to obtain $\alpha$-aminophosphonates have been developed in the last decades. One conventional method is the nucleophilic addition of dialkylphosphites to imines in the presence of base or Lewis acid catalysts ${ }^{338}$ (Pudovik reaction).

However, recently the most common method to obtain $\alpha$-aminophosphonates involves a three component coupling reaction of an aldehyde, an amine, and a di- or trialkyl phosphite in the presence of acid or base catalysts (Kabachnik-Fields reaction) $)^{339}$ (Scheme 66). A variety of homogeneous Lewis acids catalysts such as metal triflates, ${ }^{340} \mathrm{ZrOCl}_{2} .8 \mathrm{H}_{2} \mathrm{O},{ }^{341} \mathrm{SbCl}_{3} / \mathrm{Al}_{2} \mathrm{O}_{3},{ }^{342}$ indium in aqueous $\mathrm{HCl},{ }^{343}$ Bronsted acids as such as $p$-Toluenesulfonic acid, $\mathrm{CF}_{3} \mathrm{CO}_{2} \mathrm{H}$, and ionic liquids, ${ }^{344}$ as well as microwave 
irradiation itself ${ }^{345}$ and ultrasonic irradiation itself or in the presence of $\mathrm{AlCl}_{3}{ }^{346}$ techniques have been used to promote this reaction.

Following this approach, recently, different heterogeneous catalysts have been used as a green alternative for the synthesis of $\alpha$-aminophosphonates by coupling carbonyl compounds, amines and diethyl phosphate.

Scheme 66. Synthesis of $\alpha$-aminophosphonates

Thus, Silica supported sulphuric acid (SSA), sodium hydrogen sulphate supported on silica gel and sulfamic acid (SA) have been selected to prepare $\alpha$-aminophosphonates under solvent free conditions and at room temperature. ${ }^{347}$ The results demonstrate the superiority of sulfamic acid compared with other catalysts. Complete conversions and good yields (76-94 \%) were obtained in the reaction between aldehydes (aromatic and heteroaromatic) and a range of amines (aliphatic, aromatic and cycloalkyl) and dimethyl phosphonate in a short reaction time (1-4 h). It is noteworthy to mention, that when the reaction was carried out using diethyl amine, different benzaldehydes (4chlorobenzaldehyde, 4-methylbenzaldehyde and 4-isopropilbenzaldehyde) and diethyl phosphite the condensation failed to form the corresponding $\alpha$-aminophosphonate. In these cases, only the $\alpha$-hydroxyphosphonates were obtained in excellent yields after 15 minutes, as a result of the competing nucleophilic addition of diethyl phosphite to the carbonyl compound.

The mechanism proposed for the synthesis of $\alpha$-aminophosphonate involves the formation of an imine promoted by the acid catalyst which is subsequently converted in to iminium ion, a more electrophilic intermediate, to facilitate the attack of dialkyl or diaryl phosphite nucleophile (Scheme 67). The authors explain that in the case of diethyl amine, the imine intermediate either being unstable or its formation being difficult, the base catalyzes the addition of diethyl phosphite to aldehyde that results in the formation of $\alpha$-hydroxyphosphonate.

Scheme 67. Proposed mechanism for the preparation of aminophosphonates

Acidic alumina has also been used as acid catalyst in the synthesis of $\alpha$ aminophosphonates under microwave irradiation. ${ }^{348}$ Different aldehydes, amines and 
diethyl phosphite reacted on alumina under solvent free conditions using microwave irradiation producing high yields of the corresponding $\alpha$-aminophosphonate (70-95 \%) in 6 min. No $\alpha$-hydroxyphosphonate was detected in the reaction mixture. The MCR was also carried out in acidic alumina supported ammonium formate at room temperature yielding the desired compounds in good yields (59-76 \%) after 4-8 $\mathrm{h}$. Neutral and basic alumina and magnesium oxide were not as effective as acidic alumina, giving $\alpha$-hydroxyphosphonate as major product. Montmorillonite KSF clay has also been used for the synthesis of $\alpha$-aminophosphonate by three component condensation of aldehydes amines and diethylphosphite under microwave irradiation under solvent free conditions. ${ }^{349}$ Various carbonyl compounds (aldehydes or ketones) and amines reacted with diethylphosphite to afford the corresponding $\alpha$ aminophosphonate. In the case of aldehydes, the target compounds were obtained in excellent yields (80-92 \%) in short reaction times, whereas ketones gave phosphonates in lower yields (65-80 \%) after longer reaction time (6-8 $\mathrm{min})$. When reactions were carried out by conventional heating in refluxing toluene, longer reaction times (5-10 h) were required to achieve good yields of the corresponding $\alpha$-aminophosphonate (70-80 \%). Other solid acid catalysts such as Amberlyst-IR 120, $\mathrm{H}_{6} \mathrm{P}_{2} \mathrm{~W}_{18} \mathrm{O}_{62}$, ,ALKIT-5 ((A mesoporous metalosilicate) and $\mathrm{SbCl}_{3} / \mathrm{Al}_{2} \mathrm{O}_{3}$ also promote this MCR. In Table 21 are compared the results obtained in the coupling reaction of benzaldehyde aniline and diethyl phosphonate using different acid catalysts.

\subsection{Tetrahydroisoquinolonic acid derivatives}

Tetrahydroisoquinolonic acid derivatives have attracted the attention of synthetic organic chemists due to their potential activity in the field of pharmaceuticals. This family of compounds exhibit a wide spectrum of biological activities including antinflammatory, antiallergenic, anti-tumor activity, psychotropic and estrogenic behaviour. ${ }^{354-355}$ Tetrahydroisoquinolonic acid derivatives have been reported as starting material for the synthesis of natural phenanthridine alkaloids such as corolyne derivatives, decumbenine B. $^{356}$ and indenoisoquinolines ${ }^{357}$ possessing significant antitumor activity. Tetrahydroisoquinolonic acid derivatives can be synthesised by cycloaddition reaction of homophthalic anhydrides with imines in the presence of conventional Bronsted and Lewis acids (such as acetic acid, $\mathrm{HCl}, \mathrm{AlCl}_{3}, \mathrm{FeCl}_{3}$ ) and bases $\left(E t_{3} \mathrm{~N}, \mathrm{Et}_{2} \mathrm{NH}\right){ }^{358}$ When reaction is performed under classical conditions, the reaction product resulting from this cycloaddition possesses two asymmetric centres and is therefore capable of existing as a mixture of cis- and trans-diastereoisomers, being 
the cis compound the main product. $\mathrm{BF}_{3}-\mathrm{Et}_{2} \mathrm{O}^{359}$ and titanium(IV)chlorideN,N.diisopropylethylamine ${ }^{360}$ have been used for the preparation of trans-isoquinolonic acid, meanwhile trimethyl orthoformate, ${ }^{361}$ ionic liquids, ${ }^{362}$ rare earth metal triflate (ytterbium(III) triflate), ${ }^{363}$ and $\mathrm{KAl}\left(\mathrm{SO}_{4}\right)_{2}{ }_{12}{ }^{2} \mathrm{H}_{2} \mathrm{O}^{364}$ have been employed for the synthesis of cis-isomers.

Using this approach Azizian et al. ${ }^{365}$ have reported the synthesis of cisisoquinolonic acid derivatives by coupling homophthalic anhydride, aldehydes and amines in the presence of $\mathrm{KAl}\left(\mathrm{SO}_{4}\right)_{2} 1_{2} \mathrm{H}_{2} \mathrm{O}$ (Alum) and silica sulphuric acid as heterogeneous catalysts (Scheme 68).

Scheme 68. MC synthesis of tetrahydroisoquinolonic acid derivatives.

When a mixture of equimolar amounts of homophthalic anhydride, benzaldehyde and aniline in acetonitrile is allowed to react in the presence of Alum catalyst at room temperature, 1-oxo-2,3-diphenyl-1,2,3,4-tetrahydro-isoquinoline-4carboxylic acid was obtained in yield of $88 \%$ after $7 \mathrm{~h}$. The reaction was extended to a range of different aldehydes and amines giving the corresponding cis-isoquinolonic acid in good yields (81-91\%). Similar results were obtained using silica sulphuric acid. It is northworthy that in all cases the reaction is steroselective in the preparation of cisisoquinolonic acid derivatives.

Recently, Karimi et al. ${ }^{366}$ have reported the use of sulphonic acid functionalized silica (SAFS) as a recyclable heterogeneous catalyst for the synthesis of isoquinolonic acids by a three component condensation of homophthalic anhydride, aldehydes and amines. When the reaction was carried out at room temperature in the presence acetonitrile, good yields of the isoquinolonic acid derivatives were obtained (78-98 \%) in 1-5 h. The reaction was highly diastereoselective and only the cis diasteromer was obtained in all cases.

The mechanism proposed proceeded via the initial formation of an intermediate from homophthalic anhydride and an amine followed by (path i) initial methylene attack on to the aldehyde followed by Michael reaction or (path ii) nitrogen attack on to the aldehyde followed by methylene attack to give the final product (Scheme 69).

Scheme 69. Plausible reaction mechanism for the formation of cis-isoquinolonic acids. 


\subsection{Synthesis of 4-amidotetrahydropyran derivatives}

The 4-amidotetrahydropyran ring system is a core structure in a variety of natural products, among them ambrucitins VS, glycamino acid, and others. ${ }^{367}$ The most general method to obtain tetrahydropyrans derivatives is via Prins cyclization reaction using acid catalysts. ${ }^{368}$ The Ritter amidation after Prins cyclacion (Prins-Ritter reaction) is a very useful methodology for natural products synthesis. Recently 4amidotetrahydropyrans have been prepared by a three component coupling of carbonyl compounds, homoallylic alcohols and nitriles using phosphomolybdic acid $\left(\mathrm{H}_{3} \mathrm{PMo}_{12} \mathrm{O}_{40}, \mathrm{PMA}\right)$ as catalyst via Prins-Ritter reaction (Scheme 70$) .{ }^{369}$ Various homoallylic alcohols and nitriles reacted at ambient temperature to produce the corresponding 4-acetoamidotetrahydropyrans in high yields (82-92\%). In all cases cis isomer was exclusively obtained.

Scheme 70 Synthesis of N-(2-cyclohexyltetrahydro-2H-4-pyranyl)-acetamide.

For comparison purposes other solid acid catalysts such as Montmorillonite KSF and Amberlyst-15 were tested, however the PMA catalyst was more efficient in terms of conversion. Spirocyclic-4-amidotetrahydropyrans were also obtained in good yields (84-88 \%) from cycloketones, homoallylic alcohols and nitriles (Scheme 71).

Scheme 71 Spirocyclic-4-amidotetrahydropyrans.

The formation of 4-amidotetrahydropyran could be explained by hemiacetal formation followed by Prins cyclization and subsequent Ritter amidation (Scheme 72).

Scheme 72 Reaction mechanism for the formation of cis-amidotetrahydropyrans via Prins- Ritter reaction sequence.

\subsection{Synthesis of DL-5-(4-hydroxyphenyl)hydantoin}

DL-5-(4-hydroxyphenyl)hydantoin is an important intermediate for the enzymatic production of $(R)$-2-(4-hydroxyphenyl)glycine a compound widely used in the preparation of semi-synthetic penicillins and cephalosporines. ${ }^{370}$ 
Various methods have been described for synthesising DL-5-(4hydroxyphenyl)hydantoin in homogeneous media. However the most common method is by amidoalkylation of phenol with urea and glyoxylic acid in the presence of larger excess of concentrated mineral acid (such as $35 \%$ hydrochloric acid) ${ }^{371}$ (Scheme 73). In this reaction a mixture of the DL-5-(4-hydroxyphenyl)hydantoin (para-isomer) and DL5-(2-hydroxyphenyl)hydantoin (ortho-isomer) is obtained being the para-isomer the major product.

Scheme 73. Synthesis of DL-5-(4-hydroxyphenyl)hydantoin from amidoalkylation of phenol with urea and glyoxylic acid.

The reaction proceeds possibly through of the coupling of glyoxylic acid with urea leading allantoin which subsequently reacts with the phenol via a Friedel-Crafts alkylation in the presence of the acid catalyst giving the ortho and para isomers (Scheme 74).

Scheme 74. Proposed mechanism in the formation of DL-5-(4-

$$
\text { hydroxyphenyl)hydantoin }
$$

Cativiela et al. ${ }^{372}$ have reported the synthesis of DL-5-(4-hydroxyphenyl)hydantoin following this approach using solid acids catalysts such as clays (KSF and K10 Montmorillonite), Beta zeolite, and sulfonic organic polymers. The condensation reaction of phenol, urea and glyoxylic acid performed in water at $70{ }^{\circ} \mathrm{C}$ in the presence of clay or Beta zeolite afforded the target product in low yields $(7.5 \%$ and $4.2 \%$ respectively, after $21 \mathrm{~h}$ ) even when they were used as co-catalyst with hydrochloric acid. The reaction was also tested with Dowex and Duolite, two sulfonic acid resins of different particle size. It was found that Dowex promotes the synthesis of the hydantoin more efficiently than Duolite due probably to the diffusion restrictions imposed by the larger particle size of the later. With Dowex, a yield of $74 \%$ of hydantoin was achieved, while with Duolite and Nafion resins the yield was sensibly lower (47 \%).

\subsection{Synthesis of $2 H$-indazolo[2,1-b]phthalazine-trione derivatives}

Among the large variety of nitrogen-containing heterocyclic compounds, heterocycles containing the phthalazine moiety are of interest because they show 
important pharmaceutical and biological activities. ${ }^{373}$ It has been reported that this type of compounds possesses anticonvulsant, ${ }^{374}$ cardiotonic $^{375}$ and vasorelaxant ${ }^{376}$ activities. Various methods have been reported for the synthesis of phthalazine derivatives. ${ }^{377}$ Recently, the multicomponent reaction of dimedone (5,5-dimethylcyclohexane-1,3dione), phthalhydrazide (2,3-dihydro-1,4-phthalazinedione) and aromatic aldehydes in the presence of $p$-TSA to give 3,4-dihydro-3,3-dimethyl-13-aryl-2H-indazolo[2,1b]phthalazine-1,6,11(13H)-trione derivatives has been reported ${ }^{378}$ (Scheme 75). Good yields (83-93 \%) were obtained when the reaction was performed at $80{ }^{\circ} \mathrm{C}$ under solvent free conditions for several minutes.

Scheme 75. Synthesis of 3,4-dihydro-3,3-dimethyl-13-phenyl-2H-indazolo[2,1b]phthalazine-1,6,11(13H)-trione

Following this protocol, Shaterian et al. ${ }^{379}$ have reported the use of silica supported sulfuric acid as an efficient heterogeneous catalyst for the preparation of $2 \mathrm{H}$ indazolo[2,1- $b]$ phthalazine-1,6,11(13H)-trione derivatives. Good yields of the corresponding products (84-93 \%) were obtained using different aromatic aldehydes, when the condensation reaction was carried out under solvent free conditions, at $100{ }^{\circ} \mathrm{C}$ within short reaction time (7-35 $\mathrm{min})$. The catalyst could be successfully recovered and recycled at leas for five runs without significant loss in activity.

A possible mechanism for the formation of $2 \mathrm{H}$-indazolo[2,1-b]phthalazinetriones is presented in Scheme 76 Initially a Knovenagel condensation between dimedone and benzaldehyde occurs to form a heterodyne intermediary (A).Then the subsequent Michael-type addition of the phthalhydrazide to the heterodyne (A) followed by cyclization affords the $2 \mathrm{H}$-indazolo[2,1-b]phthalazine-triones product.

Scheme 76. Possible mechanism for the formation of $2 \mathrm{H}$-indazolo[2,1-b]phthalazinetriones.

\subsection{Synthesis of polyfunctionalized pyran, pyranodipirimidine and chromene derivatives}

Compounds bearing $4 H$-pyran units present important biological and pharmacological activities. Its activity depends mainly on the presence of different heterocyclic ring system. Among the different pharmacological activities exhibited by these compounds are anticancer, anticoagulants, antianaphylactics, and spasmolytics 
agents. ${ }^{380-381}$ They are usually prepared by reaction between arylidenemalonolitriles and activated methylene compounds in the presence of organic bases. ${ }^{382}$ However, $4 \mathrm{H}$ pyrans rings can be also obtained through a $\mathrm{A}^{3}$ coupling reaction of an aldehyde, malononitrile and an active methylenic diketo compound. Initially the reaction proceeds by abstracting a proton from the malononitrile which subsequently reacts with the benzaldehyde forming an arylidenemalonolitrile intermediate (Knoevenagel condensation).Subsequently, the arylidenemalonolitrile intermediate reacts with methylenic diketo compound giving the $4 \mathrm{H}$-pyran unit (Scheme). Depending on the structure of the diketocompound $4 \mathrm{H}$-pyran rings bearing different heterocyclic ring systems can be obtained. In this secction some examples involving this MCR performed under heterogeneous catalysis will be presented.

\subsubsection{Synthesis of polysubstituted $4 \mathrm{H}$-pyran derivatives}

5-Substituted-2-amino-4-aryl-3-cyano-6-methyl-4H -pyrans (Scheme 77) are important drugs used in neuro degenerative diseases such as Alzheimer's disease and for the treatment of schizophrenia. ${ }^{381}$. They can be obtained by the coupling of an aromatic aldehyde, malononitrile and an active methylenic diketocompound using radiative (microwave and ultrasonic irradiation) and non radiative techniques have been reported. ${ }^{383}$ Thus, some ionic liquids under microwave irradiation ${ }^{384-385}$, as well as some organic bases such as tetrabutylammonium bromide, ${ }^{386}$ and $(S)$-proline. ${ }^{387}$ promote this transformation. Recently, Babu et al. ${ }^{388}$ have synthesized this type of compounds using $\mathrm{Mg} / \mathrm{La}$ mixed oxide as heterogeneous basic catalysts.

Scheme 77. $\mathrm{A}^{3}$ coupling process for the synthesis of $4 H$-pyran derivatives

Compared to other solids basic catalysts such as $\mathrm{MgO}$, KF-Alumina, $\mathrm{Mg} / \mathrm{Al}$ hydrotalcite, and $\mathrm{Mg}-\mathrm{Al}-\mathrm{CO}_{3}$, the $\mathrm{Mg} / \mathrm{La}$ mixed oxide catalyst was the most active promoting the coupling of benzaldehyde, ethyl acetoacetate and malononitrile in high yield (92\%) (Table 22). This result was attributed to the presence of $\mathrm{La}_{2} \mathrm{O}_{3}$ in proximity to $\mathrm{MgO}$ leads to an increased basicity. The condensation of various aromatic and aliphatic aldehydes, malononitrile and several active methylene diketo-compounds afforded the corresponding $4 H$-pyran derivatives in variable yields (15-92\%). The proposed mechanism is presented in Scheme 78. Recycling experiments showed that the 
$\mathrm{Mg} / \mathrm{La}$ mixed oxide catalyzes the reaction with consistent activity even after four cycles.

Scheme 78. Proposed mechanism for the $\mathrm{A}^{3}$ coupling synthesis of $4 H$-pyran derivatives

\subsubsection{Synthesis of dihydropyran [3,2-c]chromene derivatives}

Dihydropyran[3,2-c]chromene derivatives are important heterocyclic compounds used in the treatment of neurodegenerative diseases including Alzheimer's disease, AIDS associated dementia, for the treatment of schizophrenia, Down's syndrome, Huntington's disease. In addition, 2-amino-chromene derivatives exhibit antihypertensive and antischemia acivity.

Conventionally the synthesis of 2-amino-3-alkyl-4-aryl-5-oxo-4,5dihydropyran[3,2-c]chromene involves the MC condensation of 4-hydroxycoumarin, aldehydes and alkylnitriles (Scheme 79) in the presence of organic bases (piperidine or pyridine in organic solvents). However, recently Heravi et $\mathrm{al}^{389}$ have reported this 3CR using heterogeneous acid catalysts such as $\mathrm{H}_{6} \mathrm{P}_{2} \mathrm{~W}_{18} \mathrm{O}_{62} .18 \mathrm{H}_{2} \mathrm{O}$ as a Wells-Dawson type heteropolyacid catalyst.

Scheme 79 MCR of 4-hydroxycoumarin, aldehydes and alkylnitriles.

A study of the synthesis of 2-amino-4-(4-bromophenyl)-3-cyano-4,5dihydropyran[3,2-c]chromene-5-one from the condensation of 4-hydroxycoumarin, 4bromobenzaldehyde and malononitrile in presence of variety of solvents and catalysts was performed. As can be seen in Table 23, the best results were obtained with $\mathrm{H}_{6} \mathrm{P}_{2} \mathrm{~W}_{18} \mathrm{O}_{62} .18 \mathrm{H}_{2} \mathrm{O}$ using a mixture of ethanol: water (50:50). The authors suggest that the reaction, which occurs in pseudoliquid, is accelerated due to the participation of all bulk protons of the heteropolyanion.

Coupling different aromatic aldehydes, 4-hydroxycoumarin and malononitrile in the presence of $\mathrm{H}_{6} \mathrm{P}_{2} \mathrm{~W}_{18} \mathrm{O}_{62} .18 \mathrm{H}_{2} \mathrm{O}$, a wide variety of substituted 2-aminochromenes were obtained in high yields (80-90 \%) and selectivity (85-90 \%) in 35-80 min. When ethyl cyanoacetate was used as reactant longer reaction time (16 h) was required in order to obtain the corresponding 2-aminochromene in good yield (90 \%) and selectivity (90\%). The catalyst was recyclable and could be reused without significant loss of activity during five consecutive runs. 
Following the same protocol as above, tetrahydro-4H-benzo-[b]-pyran derivatives can be obtained by coupling aromatic aldehydes, malononitrile and cyclic $\beta$-diketones such as dimedone. Conventionally this $\mathrm{A}^{3}$ coupling is performed under refluxing in acetic acid, ${ }^{390}$ although other homogeneous catalysts such as diammonium

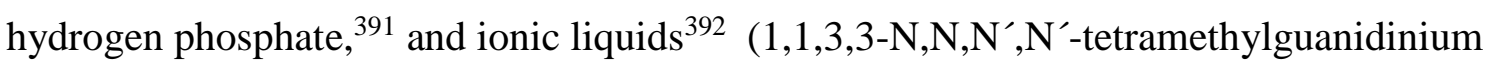
trifluoro acetate) have been reported to perform this MCR with variable success. Recently, Seifi et al. ${ }^{393}$ presented a highly efficient method for the synthesis of pyrano annulated heterocyclic system via a three component reaction of an aldehyde, malononitrile and a $\alpha$-hydroxy or an $\alpha$-amino activated $\mathrm{C}-\mathrm{H}$ acids in the presence of $\mathrm{MgO}$ as catalyst. The study of the effect of the solvent in the reaction between benzaldehyde, malononitrile and dimedone in the presence of $\mathrm{MgO}$ reveal that polar solvents such as ethanol and acetonitrile afford better yields (85 \% and $74 \%$ after 0.6 and $1.5 \mathrm{~h}$ respectively) than nonpolar solvents such as toluene (63 \% after $2.5 \mathrm{~h}$ ), being the most effective solvent a mixture of water and ethanol (40:10) yielding $94 \%$ after 0.5 h. A variety of tetrahydrobenzo[b]pyran-, [2,3-d]pyrano- and pyrido[2,3-d]pyrimidine derivatives were synthesized with this protocol in excellent yields in the presence of MgO catalyst from aryl aldehyde, malononitrile and cyclic $\beta$-diketones (A: 1,3cyclohexanedione or dimedone, B: 4-hydroxy-6-methylpyrone, 4-hydroxycoumarin, C: 1,3-dimethylbarbituric acid and D: 1,3-dimethyl-6-amino uracil) (Scheme 80).

Scheme 80 Synthesis of pyran annulated heterocyclic systems via three component reaction.

The mechanism for the formation of these products involves as first step the Knoevenagel condensation between the aromatic aldehyde and malononitrile giving the $\alpha$-cyanocinnamonitrile. Subsequently the methylene of the diketone is activated by $\mathrm{MgO}$ and reacts with the electrophilic carbon-carbon double bond (Michael addition) giving the intermediate (A) which cyclizes by nucleophilic attack of the hydroxyl group on the cyano moiety, to form the intermediate B. Finally a tautomerization process affords the desired product (Scheme 81). 
Scheme 81 Proposed mechanism for the one-pot synthesis of tetrahydrobenzopyran derivatives.

\subsubsection{Synthesis of pyranodipyrimidine derivatives}

Pyranodipyrimidines are a tryciclic important class of compounds which present a variety of biological activities such as antibacterial, HIV integrasa inhibitor, antitumor, and also are used as antiretroviral drug. ${ }^{394}$ In addition, N-alkylated pyranodipyrimidines show increased bioactivity due to its high lipophilicity which facilitates membrane transport and strengthens functional activity. ${ }^{394}$

The MCR involving benzaldehyde, malononitrile and barbituric acid or its thio analogous was performed using neutral alumina as catalyst under microwave irradiation, and yields 7-amino-6-cyano-5-aryl-5H-pyrano[2,3-d]pyrimidine2,4(1H,3H)-diones, an intermediate in the synthesis of pyranodipyrimidines ${ }^{395}$ (Scheme 82 ). This intermediate compound was allowed to react with different aromatic carboxylic acids adsorbed on Montmorillonite under microwave irradiation to give the desired product. Under these reaction conditions, a mixture of the target compound (yield 62-70 \%) along with the N-acylated pyranopyrimidines (yield 20-28\%) was obtained. However, surprisingly, using acidic alumina, the pyranodipyrimidines were obtained in good yields (55-65 \%) and $100 \%$ selectivity in 4-5 min.

Scheme 82 One-pot synthesis of pyranodipyrimidine derivatives.

For comparison purposes the reaction was performed using the conventional procedure with hydrochloride acid at reflux temperature during 6.5-8 hours. The yield of the pyranodipyrimidines was lower (35-48 \% yield) and the N-alcylated pyranopyrimidines were also obtained in considerable amount. Although the $\mathrm{N}$-acylated product is obtained in smaller quantities and is considered as by-product this compound possesses various biological activities. ${ }^{395}$

\subsubsection{Synthesis of 2-amino-4H-benzo[h]chromene derivatives}

Fused chromenes exhibit a wide spectrum of pharmacological applications as antimicrobial, ${ }^{396}$ antitumor, ${ }^{397}$ cancer therapy, ${ }^{398}$ sex pheromone ${ }^{399}$ and central nervous system activity. ${ }^{400}$ They are also widely employed as cosmetics, pigments, and potential biodegradable agrochemicals. ${ }^{401}$ 
The most straightforward synthesis for 2-aminobenzochromene derivatives involves a three-component coupling of aromatic aldehyde, malononitrile and an activated phenol in the presence of organic bases (as piperidine), which is frequently used in stoichiometric amounts using ethanol or acetonitrile as solvents ${ }^{402}$ (Scheme 83).

Scheme 83 3MC synthesis of 2-aminochromene derivatives.

As in the previous reactions presented above, benzylidenemalononitrile is formed fast and in quantitative yield by the Knoevenagel condensation between benzaldehyde and malononitrile. Subsequently ortho C-alkylation of $\alpha$-naphthol by reaction with the electrophilic $\mathrm{C}=\mathrm{C}$ double bond and the nucleophilic addition of the hydroxyl moiety to the nitrile producing the final 2-aminochromenes (Scheme 84).

Scheme 84 Mechanism in the one-pot synthesis of 2-aminochromene derivatives.

Nevertheless, diverse heterogeneous catalysts have been employed for this multicomponent reaction. Wang et al. ${ }^{403}$ synthesized a series of 2-aminochromene derivatives from aryl aldehydes, malononitrile or ethyl cyanoacetate with 1-naphtol or 1,5-naphthalenediol, in the presence of alumina coated with potassium fluoride (KFAlumina). When aryl aldehydes, malononitrile or ethyl cyanoacetate and 1-naphthol react in presence of FK-Alumina in refluxing ethanol for 5-6 hours, the 2-amino-4-aryl4H-benzo[h]chromene derivatives were obtained in slightly high yields (72-90\%). When 1,5-naphthalenediol was used instead of 1-naphthol, naphthol [1,2-b;6,5b’]dipyrans derivatives were isolated in good yields (83-94\%) (Scheme 85).

Scheme 85. Synthesis of the naphtho [1,2-b;6,5-b’]dipyrans derivatives from aryl aldehydes, malononitrile or ethyl cyanoacetate and 1,5-naphthalenediol.

Basic alumina was proposed by Maggi et al. ${ }^{404}$ as catalyst in the synthesis of substituted 2-amino-2-chromenes by coupling benzaldehyde, malononitrile and $\alpha$-naphthol using water as a solvent. Basic alumina exhibited better activity and selectivity to 2-amino-2chromenes than Montmorillonite KSF, Hydrotalcite and Silica gel. In all cases mixtures of Knoevenagel adduct (KA) and the desired product was obtained (Table 24). 
Excellent yields (83-98 \%) and selectivity to 2-aminochromene derivatives (85-99\%) were obtained on basic $\gamma$-alumina when different aldehydes, malononitrile and $\alpha$-naphthol were reacted in water for $3 \mathrm{~h}$. In addition, the reaction showed high regioselectivity affording only one of the two possible isomers than can be formed. The catalyst could be reused four times giving the same yield and excellent selectivity to chromene.

Nanosized magnesium oxide has been reported ${ }^{405}$ as efficient catalyst for the three component condensation of aldehyde, malononitrile and $\alpha$-naphthol in methanol, water or PEG-water as reaction medium. Thus, when a mixture of equimolar amounts of benzaldehyde, malononitrile and $\alpha$-naphthol, in methanol or water was refluxed for $1 \mathrm{~h}$ in the presence of $\mathrm{MgO}$, the corresponding 2-aminochromene was obtained with yields of $96 \%$ and $86 \%$ repectively. Meanwhile, using PEG-water (1:1) at room temperature $96 \%$ yield of aminochromene was obtained after 15 min reaction time. The catalytic activity of the nanosized MgO particles (100-200 nm) was superior to those exhibited by a commercial available MgO sample. The nanosized magnesium oxide was employed for the synthesis of a diverse set of 2-aminochromenes achieving yields of 70-98 \% within 15-90 minutes using PEG-water as a solvent. After the reaction the catalyst was reused in subsequent reactions with consistent activity.

More recently, $\mathrm{Mg} / \mathrm{Al}$ hydrotalcite was found to be highly effective catalyst for the synthesis of 2-aminochromenes via a multicomponent reaction in a dry state under single-mode microwave irradiation. ${ }^{406}$ Thus, under optimal conditions (molar ratio aromatic aldehyde:malononitrile: $\alpha$-naphthol 1:1:1 mmol, $\mathrm{HT}(\mathrm{Mg} / \mathrm{Al}=3)$ at $\left.140{ }^{\circ} \mathrm{C}\right)$, it is possible to obtain 2-aminochromenes in good yields (71-90 \%) in an interval of 5-34 minutes reaction time. When the reaction was carried out on calcined hydrotalcite the catalytic activity was lower than that the corresponding uncalcinated HT. On calcination at a high temperature the hydroxyl groups in the brucite layers are eliminate as water. Thus, the Bronsted basicity decreases meanwhile the Lewis basicity increases, which is indicating that Bronsted basicity is required for this reaction. The authors found that the catalyst was reusable however there was a reduction in the yield of the product after reuses (Table 25). 


\section{Conclusions and Catalytic Opportunities}

A large number of MCRs have been presented giving all of them quite good conversions and selectivities for preparing products of industrial interest. It was seen that most of the work has been performed using homogeneous catalysts ranging from Bronsted and Lewis acid to base catalyzed reactions. Mineral and organic Bronsted acids and basic amines were the most commonly used homogeneous catalysts together with organic and inorganic transition metal salts. The number of catalytic studies with solid catalysts is still limited and less sophisticated materials have been used. For instance, mineral acids impregnated on inorganic porous carriers were extensively used. With these catalysts one should be expected acid leaching to occur. Then, while they can be useful for laboratory preparative uses they will be limited for industrial use. This is more so if sustainable processes are going to be implemented.

Supported heteropolyacids on silica and supported Lewis acids such as $\mathrm{AlCl}_{3}$ and $\mathrm{SbCl}_{5}$ on alumina give excellent results for various acid catalyzed MCRs. However, polar reactants and solvents will make these catalysts to leach, while the presence of even small amounts of water could hydrolyze the supported Lewis acids. True heterogeneous catalysts such as silica and activated silica, activated alumina, montmorillonites, zeolites and organic resins with sulfonic groups have also been used successfully for Biginelli type reactions, synthesis of imidazole and quinazoline derivatives. Even hybrid materials in where organic molecules with sulfonic groups are grafted on inorganic solids (amorphous and ordered silicas) show reasonable to good activities for Hantzsch type reactions. However, it should be considered that if catalyst deactivation occurs it will be difficult in many cases to regenerate the hybrid organic-inorganic material. Metal substituted zeolites and zeolites with exchanged metal cations in where unusual metal valences are stabilized (for instance $\mathrm{Cu}(\mathrm{I})$-zeolite) are also excellent catalysts for the $\mathrm{A}^{3}$ coupling of aldehydes, amines and alkynes.

In the case of basic and bifunctional metal-base solid catalysts such as $\mathrm{MgO}$ and mixed oxides of $\mathrm{Al}, \mathrm{Mg}$ and transition metals derived from hydrotalcites good results for the synthesis of pyran and aminochromene derivatives have been obtained. These catalysts are stable and regenerable.

New possibilities are open for the preparation of catalysts containing acid and basic sites, if possible, with controlled distance and orientation ${ }^{408}$ that can work in homogeneous phase but which can be recycled, or integrated in solid catalysts. 
In conclusion MCRs present clear advantages for process intensification, avoiding costly and energy consuming intermediate separation and purification steps, and there are open possibilities for the use of mono and bifunctional catalyst for achieving fully green processes.

\section{Acknowledgements}

The authors wish to gratefully acknowledge the Generalitat Valenciana for the financial support in the project CONSOLIDER-INGENIO 2010 (CSD2009-00050)

\section{References}

1. D. E. Fogg and E. N. dos Santos, Coor. Chem. Rev., 2004, 248, 9456

2. G. Poli and G. Giambastiani, J. Org. Chem., 2002, 67, 9456

3. G. Balme, E. Bossharth and N. Monteiro, Eur. J. Org. Chem., 2003, 4101

4. M. Malacria, Chem. Rev., 1996, 96, 289

5. P. J. Parsons, C. S. Penkett and A. J. Shell, Chem. Rev., 1996, 96, 195

6. L. F. Tietze, Chem. Rev., 1996, 96, 115

7. J. M. Lee, Y. Na, H. Han and S. Chang, Chem. Soc. Rev., 2004, 33, 302

8. J. C. Wasilke, S. J. Obrey, R. T. Baker and G. C. Bazan, Chem.Rev., 2005, 105, 1001

9. M. J. Climent, A. Corma and S. Iborra, Chemsuschem, 2009, 2, 500

10. M. J. Climent, A. Corma and S. Iborra, Chem. Rev., 2011, 111, 10721072.

11. A. Dömling, Chem. Rev., 2006, 106, 17

12. C. Hulme and V. Gore, Curr. Med. Chem., 2003, 10, 51

13. I. Ugi, Journal für Praktische Chemie, 1997, 339, 499

14. A. Strecker, Liebigs Ann. Chem., 1850, 75, 27

15. A. Hantzsch, Liebigs Ann. Chem., 1882, 215, 1

16. P. Biginelli, Chim. Ital., 1893, 23, 360

17. I. Ugi, R. Meyr, R. Fetzer and C. Steinbruckner, Angew. Chem. , 1959, 71, 386

18. P. Eilbracht, Chem. Rev., 1999, 99, 3329

19. L. Weber, Curr. Med. Chem., 2002, 9, 1241

20. R. E. Dolle and K. H. Nelson, J. Com. Chem., 1996, 1, 235

21. L. A. Thompson and J. A. Ellman, Chem. Rev., 1996, 96, 555

22. I. Ugi, B. Werner and A. D”mling, Molecules, 2003, 8, 53

23. G. Gelbard, Ind. Eng. Chem. Res., 2005, 44, 8468 
24. A. Guyot, Pure Appl. Chem., 1988, 60, 365

25. A. Corma, Chem. Rev. , 1995, 95, 559

26. R. A. van Santen and G. J. Kramer, Chem. Rev. , 1995, 95, 637

27. W. E. Farneth and R. J. Gorte, Chem. Rev. , 1995, 95, 615

28. M. E. Davis, Nature, 2002, 417, 813

29. J. Jiang, J. L. Jorda, M. J. Diaz-Cabanas, J. Yu and A. Corma, Angewandte Chemie, International Edition, 2010, 49, 4986

30. J. Jiang, J. Yu and A. Corma, Angew. Chem. Int. Ed., 2010, 49, 3120

31. E. G. Derouane, ed., Catalysts for Fine Chemical Synthesis. Microporous and Mesoporous Solid Catalysts, vol 4, John Wiley and Sons, Chichester, 2006.

32. R. Simancas, D. Dari, N. Velamazan, M. T. Navarro, A. Cantin, J. L. Jorda, G. Sastre, A. Corma and F. Rey, Science, 2010, 330, 1219

33. A. Corma, M. J. Diaz-Cabanas, J. L. Jorda, C. Martinez and M. Moliner, Nature, 2006, 443, 842

34. A. Corma, M. J. Diaz-Cabanas, F. Rey, S. Nicolopoulus and K. Boulahya, Chem. Commun., 2004, 1356

35. A. Corma, M. J. Diaz-Cabanas, J. Jiang, M. Afeworki, D. L. Dorset, S. L. Soled and K. G. Strohmaierb, Proc. Natl. Acad. Sci., 2010, 107, 13997

36. J. Jiang, J. L. Jorda, J. Yu, L. A. Baumes, E. Mugnaioli, M. J. Diaz-Cabanas, U. Kolb and A. Corma, Science, 2011, 333, 1131

37. P. Ratnasamy, D. Srinivas and H. Knoezinger, Adv. Catal., 2004, 48, 1

38. M. Bejblova and J. Cejka, Zeolites, 2008, 263

39. M. Boronat, P. Concepcion, A. Corma and M. Renz, Catal. Today, 2007, 121, 39

40. F. Alvarez, A. I. Silva, F. R. Ribeiro, G. Giannetto and M. Guisnet, Stud. Surf. Sci. Catal., 1997, 108, 609

41. J. Chupin, N. S. Gnep, S. Lacombe and M. Guisnet, Appl. Catal. A Gen, 2001, 206, 43

42. M. Guisnet, F. Alvarez, G. Giannetto and G. Perot, Catal. Today, 1987, 1, 415

43. A. I. Silva, F. Alvarez, F. Ramoa Ribeiro and M. Guisnet, Catal. Today, 2000, 60, 311

44. F. Iosif, S. Coman, V. Parvulescu, P. Grange, S. Delsarte, D. De Vos and P. Jacobs, Chem. Commun., 2004, 1292 
45. F. Neatu, S. Coman, V. I. Parvulescu, G. Poncelet, D. Vos and P. Jacobs, Top. Catal., 2009, 52, 1292

46. B. R. Jermy and A. Pandurangan, Appl. Catal. A Gen, 2005, 288, 25

47. M. A. Harmer, W. E. Farneth and Q. Sun, J. Am. Chem. Soc., 1996, 118, 7708

48. M. A. Harmer, Q. Sun, A. J. Vega, W. E. Farneth, A. Heidekum and W. F. Hoelderich, Green Chem., 2000, 2, 7

49. M. C. Laufer, H. Hausmann and W. F. Hoelderich, J. Catal., 2003, 218, 315

50. T. C. Wabnitz, Y. J. Q. and J. B. Spencer, Synlett, 2003, 1070

51. P. Beltrame and G. Zuretti, Appl. Catal. A Gen, 2003, 248, 75

52. I. Ledneczki, M. Daranyi, F. Fülöp and A. Molnar, Catal. Today, 2005, 100, 437

53. M. Alvaro, A. Corma, D. Das, V. Fornes and H. Garcia, J. Catal., 2005, 231, 48

54. P. Botella, A. Corma and J. M. Lopez-Nieto, J. Catal., 1999, 185, 371

55. T. Okuhara, N. Mizuno and N. Mison, Adv. Catal., 1996, 41, 113

56. I. V. Kozhevnikov, Catal. Rev. - Sci. Eng., 1995, 37, 311

57. Y. Izumi, M. Ogawa and K. Urabe, Appl. Catal. A Gen, 1995, 132, 127

58. A. Corma, H. Garcia and F. X. Llabres i Xamena, Chem. Rev. , 2010, 110, 4606

59. R. L. White, E. C. Sikabwe, M. A. Coelho and D. E. Resasco, J.Catal., 1995, 157, 755

60. D. A. Ward and E. I. Ko, J. Catal., 1995, 157, 321

61. J. M. Campelo, J. M. Marinas, S. Mendioroz and J. A. Pajares, J. Catal., 1986, 101, 484

62. M. J. Climent, A. Corma, H. Garcia, R. Guil-Lopez, S. Iborra and V. Fornes, J. Catal., 2001, 197, 385

63. Y. Ono and T. Baba, Catal. Today, 1997, 38, 321

64. H. Hattori, Chem. Rev. , 1995, 95, 537

65. J. Gascon, U. Aktay, M. D. Hernandez-Alonso, G. P. M. van Klink and F. Kapteijn, J. Catal., 2009, 261, 75

66. J. Weitkamp, M. Hunger and U. Rymsa, Micropor. Mesopor. Mat., 2001, 48, 255

67. B. F. Sels, D. E. De Vos and P. A. Jacobs, Catal. Rev. - Sci. Eng., 2001, 43, 443

68. A. Corma and S. Iborra, Adv. Catal., 2006, 49, 239

69. B. Ringdahl, in The Muscarinic Receptors, Humana Press, Clifton, New Jersy, 1989. 
70. K. B. Sanders, A. J. Thomas, M. R. Pavia, R. E. Davis, L. L. Coughenour, S. L. Myers, S. Fisher and W. H. Moos, Bioorg. Med. Chem. Lett., 1992, 2, 803

71. P. Matyus, B. Dajka-Halasz, A. Foldi, F. Haider, D. Barlocco and K. Magyar, Curr Med Chem, 2004, 11, 1285

72. S. B. Park and H. Alper, Chem. Commun., 2005, 1315

73. C. Wei, Z. Li and C. J. Li, Org. Lett., 2003, 5, 4473.

74. C. Wei, L. Zhang and C. J. Li, Synlett., 2004, 1472.

75. C. Wei and C. J. Li, J. Am. Chem. Soc., 2003, 125, 9584.

76. V. K. Y. Lo, Y. Liu, M. K. Wong and C. M. Che, Org. Lett., 2006, 8, 1529.

77. N. Gommermann and P. Knochel, Chem-Eur J, 2006, 12, 4380.

78. A. Bisai and V. K. Singh, Org. Lett., 2006, 8, 2405.

79. S. Sakaguchi, T. Mizuta, M. Furuwan, T. Kubo and Y. Ishii, Chem. Commum., 2004, 1638.

80. Y. L. Zhang, P.; Wang, M.; Wan, L., J. Org. Chem., 2009, 74, 4364.

81. P. Li and L. Wang, Chin. J. Chem., 2005, 23, 1076.

82. C. J. Li and C. Wei, Chem. Commum., 2002, 3, 268.

83. L. Shi, Y. Q. Tu, M. Wang, F. M. Zhang and C. A. Fan, Organic Letters, 2004, 6, 1001

84. B. Sreedhar, P. S. Reddy, B. V. Prakash and A. Ravindra, Tetrahedron Lett, 2005, 46, 7019

85. A. Bisai and V. K. Singh, Organic Letters, 2006, 8, 2405

86. N. Gommermann and P. Knochel, Chem-Eur J, 2006, 12, 4380

87. Z. Li, C. C. Wei, L., R. S. Varma and C.-J. Li, Tetrahedron Lett., 2004, 45, 2443.

88. B. M. Choudary, C. Sridhar, M. L. Kantam and B. Sreedhar, Tetrahedron Lett., 2004, 45, 7319

89. B. Sreedhar, P. S. Reddy, C. S. V. Krishna and P. V. Babu, Tetrahedron Lett., 2007, 48, 7882

90. P. Li and L. Wang, Tetrahedron, 2007, 63, 5455.

91. M. Wang, P. H. Li and L. Wang, Eur J Org Chem, 2008, 2255

92. M. Kidwai, V. Bansal, N. K. Mishra, A. Kumar and S. Mazumdar, Synlett, 2007, 1581

93. M. K. Patil, M. Keller, B. M. Reddy, P. Pale and J.Sommer, Eur.J.Org.Chem., 2008, 4440 
94. R. Maggi, A. Bello, C. Oro, G. Sartori and L. Soldi, Tetrahedron, 2008, 64, 1435

95. K. Namitharan and K. Pitchumani, Eur. J. Med. Chem., 2010, 411

96. K. M. Reddy, N. S. Babu, I. Suryanarayana, P. S. S. Prasad and N. Lingaiah, Tetrahedron Lett., 2006, 47, 7563

97. A. Corma and F. X. Llabres i Xamena, J. Catal. in press, 2011,

98. M. L. Kantam, B. V. Prakash, C. R. V. Reddy and B. Sreedhar, Synlett, 2005, 2329

99. M. Kidwai, V. Bansal, A. Kumar and S. Mozumdar, Green Chem., 2007, 9, 742

100. K. K. R. Datta, B. V. Subba Reddy, K. Ariga and A. Vinu, Angew. Chem., Int. Ed. , 2010, 49, 5961

101. X. Zhang and A. Corma, Angew Chem. Int. Edit.. 2008, 47, 4358

102. S. Rivara, S. Lorenzi, M. Mor, P. V. Plazzi, G. Spadoni, A. Bedini and G. Tarzia, Journal of Medicinal Chemistry, 2005, 48, 4049

103. G. R. Humphrey and J. T. Kuethe, Chem Rev, 2006, 106, 2875

104. X. Zhang, F. X. L. I. Xamena and A. Corma, Journal of Catalysis, 2009, 265, 155

105. J. Y. Chang, C. Y. Chang, C. C. Kuo, L. T. Chen, Y. S. Wein and Y. H. Kuo, Mol Pharmacol, 2004, 65, 77

106. J. Bosch, T. Roca, J. L. Catena, C. Farrerons and I. Miquel, Synth., 2000, 721.

107. R. S. Givens, P. S. Athey, B. Matuszewski, L. W. Kueper, J.-K. Xue and T. Fister, J. Am. Chem. Soc., 1993, 115, 6001.

108. S. Jinno, T. Okita and K. Inouye, Tetrahedron Lett., 1999, 9, 1029.

109. K. M. Dawood, W. Solodenko and A. Kirschning, Arkivoc, 2007, 104

110. G. W. Kabalka, L. L. Zhou, L. Wang and R. M. Pagni, Tetrahedron, 2006, 62, 857

111. D. Prukala, Tetrahedron Lett., 2006, 47, 9045.

112. S. Sahoo, T. Joseph and S. B. Halligudi, J. Mol. Catal. A. Chem, 2006, 244, 179.

113. E. Takahashi, H. Fujisawa and T. Mukaiyama, Chem. Lett., 2004, 33, 936.

114. E. F. Kleinmann, Comprehensive Organic Synthesis, Pergamon Press, New York, 1991.

115. R. G. Muller, H.; Waldmann, H., Angew. Chem. Int. Ed., 1999, 38, 184.

116. B. M. Reddy, M. K. Patil and B. T. Reddy, Catal Lett, 2008, 125, 97 
117. B. M. Reddy, P. M. Sreekanth, P. Lakshmanan and A. Khan, J Mol Catal aChem, 2006, 244, 1

118. B. Song, S. Yang, H. Zhong, L. Jin, D. Hu and G. Liu, J Fluorine Chem, 2005, 126, 87.

119. M. Xia and Y. D. Lu, J Fluorine Chem, 2006, 127, 1119

120. H. Zeng, H. L.i and H. Shao, Ultrason. Sonochem., 2009, 16, 758.

121. M. Kidwai, N. K. Mishra, V. Bansal, A. Kumar and S. Mozumdar, Tetrahedron Lett., 2009, 50, 1355

122. M. Ashok, B. S. Holla and N. S. Kumari, Eur. J. Med. Chem., 2007, 42, 380.

123. K. S. S. Atwai, B.N.; Unger, S.E.; Floyd, D.M.; Moreland, S.; Hedberg, A.; O”Reilly, B.C., J Med Chem, 1991, 34, 806.

124. A. D. Patil, N. V. Kumar, W. C. Kokke, M. F. Bean, A. J. Freyer, C. De Brosse, S. Mai, A. Truneh, D. J. Faulkner, B. Carte, A. L. Breen, R. P. Hertzberg, R. K. Johnson, J. W. Westley and B. C. M. Potts, J. Org. Chem., 1995, 60, 1182

125. T. U. Mayer, T. U. Kapoor, S. J. Haggarty, R. V. S. S. L. King and T. J. Mitchison, Science (Washington, D.C., 1883-), 1999, 286, 971

126. J. V. Grover, S. Bzwoezyk, D. E. McMullen, P. G. Normandin, S. Selph and J. Moreland, J.Cardiovasc.Pharma Col, 1995, 26289

127. C. O. Kappe, Tetrahedron, 1993, 496937

128. C. O. Kappe, Acc. Chem. Res., 2000, 33, 879

129. C. O. Kappe, J. Org. Chem., 1997, 62, 7201

130. J. Lu and M. H.R., Synlett, 2000, 63

131. Y. Ma, C. T. Qian, L. M. Wang and M. Yang, J Org Chem, 2000, 65, 3864

132. B. Ahmed, R. A. Khan, Habibullah and M. Keshari, Tetrahedron Lett., 2009, 50, 2889

133. M. A. Kolosov, V. D. Orlov, D. A. Beloborodov and V. V. Dotsenko, Mol Divers, 2009, 13, 5

134. J. Azizian, A. A. Mohammadi, A. R. Karimi and M. R. Mohammadizadeh, Appl.Catal., A, 2006, 300, 85

135. M. A. S. Chari, K., J. Mol.Cat.A Chem., 2004, 221, 137.

136. R. Fazaeli, S. Tangestaninejad, H. Aliyan and M. Moghadam, Appl. Catal. A:Gen., 2006, 309, 44

137. A. Hagedus, Z. Hell and I. Vigh, Synth. Comm., 2006, 129 
138. S. Martinez, M. Meseguer, L. Casas, E. Rodriguez, E. Molins, M. MorenoMañas, A. Roig, R. M. Sebastian and A. Vallribera, Tetrahedron, 2003, 59, 1553

139. B. J. Ahn, M. S. Gang, K. Chae, Y. Oh, J. Shin and W. Chang, J. Ind. Eng. Chem., 2008, 14, 401.

140. F. Bigi, S. Carloni, B. Frullanti, R. Maggi and G. Sartori, Tetrahedron Lett., 1999, 403465

141. V. R. Choudhary, V. H. Tillu, V. S. Narkhede, H. B. Borate and R. D. Wakharkar, Catal.Commun., 2003, 4, 449

142. S. L. Jain, J. K. Joseph, S. Singhal and B. Sain, J. Mol. Catal., 2007, 268, 134

143. J. K. Joseph, S. L. Jain and B. Sain, J. Mol. Catal.A: Chem., 2006, 247, 99

144. P. Salehi, M. Daviri, M. A. Zolfigol and M. A. B. Fard, Tetrahedron Lett., 2003, 44, 2889

145. I. Saxena, D. C. Borah and J. C. Sarna, Tetrahedron Lett., 2005, 46, 1159

146. V. Singh, V. Sapehiyia, V. Srivastava and S. Kaur, Catal Commun, 2006, 7, 571

147. A. Dondoni and A. Massi, Tetrahedron Lett., 2001, 42, 7975

148. M. S. y. m. Gopalakrishnan, Lett. Org.Chem., 2006, 3, 484.

149. M. Kidwai, P. Mothsra, V. Bansal, R. K. Somvanshi, A. S. Ethayathulla, S. Dey and T. P. Singh, Journal of Molecular Catalysis a-Chemical, 2007, 265, 177

150. M. G. Kulkarni, S. W. Chavhan, M. P. Shinde, D. D. Gaikwad, A. S. Borhade, A. P. Dhondge, Y. B. Shaikh, V. B. Ningdale, M. P. Desai and D. R. Birhade, Beilstein J Org Chem, 2009, 5,

151. V. R. Rani, N. Srinivas, M. R. Kishan, S. J. Kulkarni and K. V. Raghavan, Green Chem., 2001, 3, 305.

152. A. Shaabani, A. Sarvary, A. Rahmati and A. H. Rezayan, Lett. Org. Chem., 2007,

153. S. V. Sinde, W. N. Jadhav, M. K. Lande, L. S. Gadekar, B. R. Arbad, J. M. Kondre and N. N. Karade, Catalysis Lett., 2008, 125, 57

154. M. Tajbakhsh, B. Mohajerani, M. M. Heravi and A. N. Ahmadi, J Mol Catal A Chem, 2005, 236, 216

155. J. S. Yadav, B. V. S. Reddy, P. Sridhar, J. S. S. Reddy, K. Nagaiah, N. Lingaiah and P. S. Saiprasad, Eur.J.Org.Chem., 2004, 552

156. R. V. Yarapathi, S. Kurva and S. Tammishetti, Catal.Commun., 2004, 5, 511 
157. V. T. Kamble, D. B. Muley, S. T. Atkore and S. D. Dakore, Chin. J. Chem. , 2010, 28, 388

158. V. Singh, V. Sapehiyia, V. Srivastava and S. Kaur, Catal.Commun., 2006, 7, 571

159. L. Z. Gong, X. H. Chen and X. Y. Xu, Chem-Eur J, 2007, 13, 8920

160. K. S. Yamada N., Takhashi K., Umeza K., , Biochem. Pharmacol., 1992, 44, 1211.

161. R. W. Carling, P. D. Leeson, A. M. Moseley, J. D. Smith, K. Saywell, M. D. Trickelbank, J. A. Kemp, G. R. Marsahall, A. C. Foster and S. Grimwood, Biorg. Med. Chem. Lett., 1993, 3, 65.

162. T. P. Loh, K. S. V. Koh, K. Y. Sim and W. K. Leong, Tetrahedron Lett, 1999, 40, 8447

163. G. Sartori, F. Bigi, R. Maggi, A. Mazzacani and G. Oppici, Eur J Org Chem, 2001, 2513

164. S. Kobayashi and S. Nagayama, J. Am. Chem. Soc., 1996, 118, 8977

165. L. X. Shao and M. Shi, Adv Synth Catal, 2003, 345, 963

166. Y. Ma, C. T. Qian, M. H. Xie and J. Sun, J Org Chem, 1999, 64, 6462

167. B. R. Das, M.R.; Reddy, V.S.; et al Chem. Lett., 2004, 33, 1526.

168. R. S. N. Kumar, R.; Perumal, P.T., Synth., 2004, 949.

169. D. Mahajan, B. A. Ganai, R. L. Sharma and K. K. Kapoor, Tetrahedron Lett., 2006, 47, 7919

170. V. T. Kamble, B. S. Davane, S. A. Chavan, D. B. Muley and S. T. Atkore, Chinese Chem. Lett., 2010, 21, 265

171. K. V. N. S. Srinivas and B. Das, Synlett, 2004, 10, 1715.

172. J. S. R. Yadav, B.V.S.; Reddy, N., Chem. Lett., 2004, 33, 1436.

173. R. Filler, Y. Kobayashi and L. M. Yagupolskii, Organofluorine Compounds in Medicinal Chemistry and Biomedical Applications, Elsevier, Amsterdam, 1993.

174. G. Dyker, Angew Chem Int Edit, 1999, 38, 1699

175. S. K. De, Synth. Commun., 2005, 35, 653.

176. N. H. Khan, S. Agrawal, R. I. Kureshi, S. H. R. Abdi, S. Singh, E. Suresh and R. V. Jasra, Tetrahedron Lett., 2008, 49, 640.

177. E. Rafiee and A. Azad, Synth. Commun., 2007, 37, 1127.

178. J. S. R. Yadav, B.V.S.; Reddy, N., B. V. Subba Reddy, B. Eeshwaraiah and M. Srinivas, Tetrahedron, 2004, 60, 1767. 
179. A. Heydari, M. Pourayoubi and A. R. Mahjoub, Tetrahedron Lett., 2007, 48, 4059.

180. G. A. Olah, T. Mathew, C. Panja, K. Smidth and G. S. Surya Prakash, Catal Lett, 2007, 114, 2007.

181. A. Shaabani and A. Maleki, Appl. Catal. A Gen., 2007, 331, 149.

182. G. K. S. Prakash, T. E. Thomas, I. Bychinskaya and A. G. Prakash, Green Chem., 2008, 10, 1105.

183. s. kawahara, S. Tsuzuki and T. Uchimaru, Chem. Eur. J.. 2005, 11, 4458.

184. L. T. Vassilev, B. T. Vu, B. Graves, D. Carvajal, F. Podlaski, Z. Filipovic, N. Kong, U. Kammlott, C. Lukacs, C. Klein, N. Fotouhi and E. A. Liu, Science, 2004, 303, 844

185. T. Lindel, P. R. Jensen, W. Fenical, B. H. Long, A. M. Casazza, J. Carboni and C. R. Fairchild, J. Am. Chem. Soc., 1997, 119, 8744

186. S. L. Abrahams, R. J. Hazen, A. G. Batson and A. P. Phillips, J Pharmacol Exp Ther, 1989, 249, 359

187. T. Maier, R. Schmierer, K. Bauer, H. .Bieringer, H. Buerstell and B. Sachse, US Pat., 1989.

188. Y. F. Sun, W. Huang, C. G. Lu and Y. P. Cui, Dyes Pigments, 2009, 81, 10

189. M. Stahelin, D. M. Burland, M. Ebert, R. D. Miller, B. A. Smith, R. J. Twieg, W. Volksen and C. A. Walsh, Appl. Phys. Lett., 1992, 61, 1626

190. N. Fridman, M. Kaftory and S. Speiser, Sensor Actuat. B-Chem., 2007, 126, 107

191. J. Liu, J. Chem, J. Zhao, Y. Zhao, L. Li and H. Zhang, Synth., 2003, 2661.

192. M. M. Heravi, K. Bakhtiari, H. A. Oskooie and S. Taheri, J. Mol. Catal. A Chem., 2007, 263, 279

193. A. Parveen, A. Ahmed and S. K. Ahmed, J. Pharm. Biol. Chem. Sci., 2010, 1, 943

194. E. Chauveau, C. Marestin, F. Schiets and R. Mercier, Green Chem., 2010, 12, 1018

195. R. B. Sparks and A. P. Combs, Org. Lett., 2004, 6, 2473.

196. S. E. Wolkenberg, D. D. Wisnoski, W. H. Leister, Y. Wang, Z. J. Zhao and C. W. Lindsley, Org. Lett., 2004, 6, 1453

197. Y. Xu, L. F. Wan, H. Salchi, W. Deng and Q. X. Guo, Heterocycles, 2004, 63, 1613.

198. A. Y. Usyatinsky and Y. L. Khmelnitsky, Tetrahedron Lett., 2000, 41, 5031. 
199. S. Balalaie, A. Arabanian and M. S. Hashtroudi, Monatsh. Chem., 2000, 131, 945.

200. A. Shaabani and A. Rahmati, J. Mol. Catal. A Chem., 2006, 249, 246

201. L. Wang and C. Cai, Monatsh. Chem., 2009, 140, 541.

202. K. F. Shelke, S. B. Sapkal, G. K. Kakade, B. B. Shingate and M. S. Shingare, Green Chem. Lett. Rev., 2010, 3, 2727.

203. M. Dinakaran, P. Selvam, E. DeClercq and S. K. Sridhar, Biol Pharm Bull, 2003, 26, 1278

204. A. R. Desai and K. R. Desai, J. Heterocyclic Chem., 2005, 42, 995.

205. S. Kobayashi, M. Ueno, R. Suzuki and H. Ishitani, Tetrahedron Lett., 1999, 40, 2175

206. V. Niementowski, Beilstein, 1895, 24, 143.

207. M. A. Chari, D. Shobha and K. Mukkanti, Catal Commun, 2006, 7, 787.

208. B. V. Lingaiah, G. Ezikiel, T. Yakaiah, G. V. Reddy and P. S. Rao, Synlett., 2006, 2507.

209. D. W. Fry, A. J. Kraker, A. McMichael, L. A. Ambroso, J. M. Nelson, W. R. Leopold, R. W. Connors and A. J. Bridges, Science, 1994, 265, 1093.

210. N. S. Gifts, J. Moiler and E. B. Pedersen, Chem. Scripta, 1986, 26, 617.

211. M. Szczepankiewicz and J. Suwinski, Tetrahedron Lett., 1998, 369, 1785.

212. M. M. Heravi, S. Sadjadi, N. M. Haj, H. A. Oskooie, R. H. Shoar and F. F. Bamoharram, Tetrahedron Lett., 2009, 50, 943

213. M. Brands, Y. C. Grande, R. Endermann, R. Gahlmann, J. Kruger and S. Raddatz, Bioorg. Med. Chem. Lett., 2003, 13, 2641

214. U. Schmidt and J. Schmidt, Synthesis-Stuttgart, 1994, 300

215. R. A. Barrow, R. E. Moore, L. H. Li and M. A. Tius, Tetrahedron, 2000, 56, 3339

216. R. Bloch, Chem. Rev.

, 1998, 98, 1407

217. J. S. Yadav, B. V. S. Reddy, P. S. R. Reddy and M. S. Rao, Tetrahedron Lett., 2002, 43, 6245

218. C. Bellucci, P. G. Cozzi and A. Umanironchi, Tetrahedron Lett., 1995, 36, 7289

219. J. S. Yadav, B. V. S. Reddy and A. K. Raju, Synthesis-Stuttgart, 2003, 883

220. J. S. Yadav, B. V. S. Reddy, A. K. Raju and D. Gnaneshwar, Adv Synth Catal, 2002, 344, 938 
221. B. Das, B. Ravikanth, K. Laxminarayana and B. V. Rao, J Mol Catal a-Chem, 2006, 253, 92

222. J. S. Yadav, H. Ather, P. P. Rao, R. S. Rao, K. Nagaiah and A. R. Prasad, Catal Commun, 2006, 7, 797

223. L. Nagarapu, V. Paparaju, G. Pathuri, S. Kantevari, R. R. Pakkiru and R. Kamalla, J Mol Catal a-Chem, 2007, 267, 53

224. Y. Yin, G. Zhao and G. L. Li, Tetrahedron, 2005, 61, 12042.

225. H. C. Aspinall, J. S. Bissett, N. Greeves and D. Levin, Tetrahedron Lett., 2002, 43, 323

226. X. Zhengfeng, L. Guilong, Z. Gang and W. Jide, Chinese J. Chem., 2009, 27, 925.

227. T. Dingermann, D. Stinhilber and G. Folkers, Molecular Biology in Medicinal Chemistry, Wiley-VCH, Weinheim, 2004.

228. B. Das, K. Laxminarayana, B. Ravikanth and B. R. Rao, J. Mol. Catal. A Chem., 2007, 261, 180

229. N. P. Selvam and P. T. Perumal, Tetrahedron Lett., 2006, 47, 7481

230. M. M. Khodaei, A. R. Khosropour and H. Moghanian, Synlett, 2006, 916

231. H. R. Shaterian, A. Hosseinian, H. Yarahmadi and M. Ghashang, Lett. Org. Chem., 2008, 5, 290

232. A. Dorehgiraee, H. Khabazzadeh and K. Saidi, Arkivoc, 2009, 303

233. S. Kantevari, S. V. N. Vuppalapati and L. Nagarapu, Catal Commun, 2007, 8, 1857

234. L. Nagarapu, M. Baseeruddin, S. Apuri and S. Kantevari, Catal Commun, 2007, 8, 1729

235. J. C. Jun and O. S. Park, Synthetic Commun, 2007, 37, 1665

236. H. R. Shaterian and H. Yarahmadi, Tetrahedron Lett., 2008, 49, 1297

237. H. R. Shaterian, F. Khorami, A. Amirzadeh and M. Ghashang, Chinese J Chem, 2009, 27, 815

238. H. R. Shaterian, H. Yarahmadi and M. Ghashang, Tetrahedron, 2008, 64, 1263

239. H. R. Shaterian, A. Hosseinian and M. Ghashang, Tetrahedron Lett., 2008, 49, 5804

240. B. Das, D. N. Kumar, K. Laxminarayana and B. Ravikanth, Helv. Chim. Acta 2007, 90, 1330 
241. M. Kawase, A. Shah, H. Gaveriya, N. Motohashi, H. Sakagami, A. Varga and J. Molnar, Bioorgan. Med. Chem., 2002, 10, 1051

242. A. C. Gaudio, A. Korolkovas and Y. Takahata, J. Pharm. Sci., 1994, 83, 1110.

243. R. Shan, C. Velazquez and E. Knaus, J Med Chem, 2004, 47, 254.

244. R. G. Bretzel, C. C. Bollen, E. Maeser and K. F. Federlin, Drugs Future, 1992, 17, 465

245. T. Itoh, K. Nagata, M. Miyazaki, A. Ishikawa, A. Kurihara and A. Ohsawa, Tetrahedron, 2004, 60, 6649.

246. D. M. Stout and A. I. Meyers, Chem.Rev., 1982, 82, 223

247. L. Ohberg and J. Westman, Synlett, 2001, 1296

248. R. Alajarin, J. J. Vaquero, J. L. G. Navio and J. Alvarezbuilla, Synlett, 1992, 297

249. S. J. Ji, Z. Q. Jiang, J. Lu and T. P. Loh, Synlett, 2004, 831

250. L. M. Wang, J. Sheng, L. Zhang, J. W. Han, Z. Y. Fan, H. Tian and C. T. Qian, Tetrahedron, 2005, 61, 1539

251. R. Gupta, R. Gupta, S. Paul and A. Loupy, Synthesis-Stuttgart, 2007, 2835

252. M. Nikpassand, M. Mamaghani and K. Tabatabaeian, Molecules, 2009, 14, 1468

253. B. Das, K. Suneel, K. Venkateswarlu and B. Ravikanth, Chem. Pharm. Bull.

, 2008, 56, 366

254. G. Sabitha, G. S. K. Reddy, R. C. S. and Y. J. S.. Tetrahedron Lett., 2003, 44, 4129.

255. H. Adibi, H. A. Samimi and M. Beygzadeh, Catal Commun, 2007, 8, 2119.

256. S. R. Cherkupalli and R. Mekalan, Chem. Pharm. Bull., 2008, 56, 1002.

257. S. K. Singh and K. N. Singh, J. Heterocyclic. Chem., 2010, 47, 194

258. M. Maheswara, V. Siddaiah, G. Damu, L. V. and C. V. Rao, Arkivoc, 2006, 2, 201.

259. G. Song, B. Wang, X. Wu, Y. L. Kang and L. Yang, Synth. Commun., 2005, 35, 2875.

260. M. M. Heravi, K. Bakhtiari, N. M. Javadi, F. F. Bamoharram, M. Saeedi and H.

A. Oskooie, J Mol Catal a-Chem, 2007, 264, 50

261. B. Das, B. Ravikanth, R. Ramu and B. V. Rao, Chem. Pharm. Bull., 2006, 54, 1044

262. S. B. Sapkal, K. F. Shelke, B. B. Shingate and M. S. Shingare, Tetrahedron Lett., 2009, 50, 1754

263. K. N. Singh and S. K. Singh, Arkivoc, 2009, (xiii), 
264. C. A. Antonyraj and S. Kannan, Appl. Catal. A-Gen., 2008, 338, 121

265. M. J. Climent, A. Corma, S. Iborra and A. Velty, J. Catal., 2004, 221, 474

266. M. J. Climent, A. Corma, S. Iborra, K. Epping and A. Velty, J. Catal., 2004, 225, 316

267. J. G. K. Balasubramanian, Comprehensive Heterocyclic Chemistry II, Pergamon Press, London, 1996.

268. R. H. Bocker and F. P. Guengerich, J Med Chem, 1986, 29, 1596

269. J.-J. Vanden Eynde, R. D'oracio and H. Yves Van, Tetrahedron, 1994, 50, 2479.

270. J. R. Pfister, Synthesis, 1990, 689.

271. S. H. Mashraqui and M. A. Karnik, Tetrahedron Lett., 1998, 39, 12657.

272. M. Balogh, I. Hermecz, Z. Meszaros and P. Laszo, Helv. Chim. Acta, 1984, 2270

273. M. M. Heravi, H. A. Oskooie, R. Malakooti, B. Alimadadi, H. Alinejad and F. K. Behbahani, Catal Commun, 2009, 10, 819

274. O. De Paolis, J. Baffoe, S. M. Landge and B. Torok, Synthesis, 2008, 3423

275. M. M. Heravi, Y. S. Beheshtia, M. Khorshidi, B. Baghernejad and F. F. Bamoharram, Chinese J Chem, 2009, 27, 569

276. M. T. Cocco, C. Congiu, V. Lilliu and V. Onnis, Eur. J. Med. Chem., 2005, 40, 1365

277. H. Chen, W. Zhang, R. Tam and A. K. Raney, wo Pat., 2005058315, 2005.

278. N. M. Evdokimov, A. S. Kireev, A. A. Yakovenko, M. Y. Antipin, I. V. Magedov and A. Kornienko, J. Org. Chem., 2007, 72, 3443.

279. M. Movassaghi and M. D. Hill, J. Am. Chem. Soc., 2006, 128, 4592.

280. A. D. Thomas and C. V. Asokan, Tetrahedron Lett, 2002, 43, 2273

281. M. D. Fletcher, T. E. Hurst, T. J. Miles and C. J. Moody, Tetrahedron, 2006, 62, 5454

282. M. Komatsu, H. Ohgishi, S. Takamatsu, Y. Ohshiro and T. Agawa, Angewandte Chemie-International Edition in English, 1982, 21, 213

283. A. R. Renslo and R. L. Danheiser, J Org Chem, 1998, 63, 7840

284. N. M. Evdokimov, I. V. Magedov, A. S. Kireev and A. Kornienko, Org. Lett., 2006, 8, 899

285. K. Guo, M. J. Thompson, T. R. K. Reddy, R. Mutter and B. Chen, Tetrahedron, 2007, 63, 5300 
286. M. Sridhar, B. C. Ramanaiah, C. Narsaiah, B. Mahesh, M. Kumaraswamy, K. K. R. Mallu, V. M. Ankathi and P. S. Rao, Tetrahedron Lett., 2009, 50, 3897

287. B. C. Ranu, R. Jana and S. Sowmiah, J Org Chem, 2007, 72, 3152

288. S. Banerjee and G. Sereda, Tetrahedron Lett., 2009, 50, 6959

289. M. L. Kantam, K. Mahendar and S. Bhargava, J Chem Sci, 2010, 122, 63

290. R. Sens, G. Lamm and K. H. Etzbach, 1991.

291. A. R. Katritzky, S. Rachwal and T. P. Smith, J. Heterocyclic. Chem., 1995, 32, 1007

292. S. Balalaie, E. Kowsari and M. S. Hashtroudi, Monatsh. Chem., 2003, 134, 453

293. J. R. Casimir, C. Turetta, L. Ettouati and J. Paris, Tetrahedron Lett., 1995, 36, 4797

294. A. G. Godfrey, Brooks, D.A, L. A. Hay, M. Peters, J. R. McCarthy and D. Mitchell, J. Org. Chem., 2003, 682623

295. J. Barluenga, A. L. Viado, E. Aguilar, S. Fustero and B. Olano, J. Org. Chem., 1993, 58, 5972

296. K. Kobinata, M. Uramoto, M. Nishii, H. Kusakabe, G. Nakamura and K. Isono, Agricultural and Biological Chemistry, 1980, 44, 1709

297. H. D. Dakin and R. West, J. Biol. Chem., 1928, 78, 745

298. B. Bhatia, M. M. Reddy and J. Iqbal, J. Chem. Soc, Chem. Commun., 1994, 713

299. D. Bahulayan, S. K. Das and M. M. Iqbal, J. Org. Chem., 2003, 685735

300. I. F. Rao, E. N. Prabhakaran, S. K. Das and J. Iqbal, J. Org. Chem., 2003, 68, 4079

301. R. P. Bhat, V. P. Raje, V. M. Alexander, S. B. Patil and S. D. Samant, Tetrahedron Lett., 2005, 46, 4801

302. E. Rafiee, F. Tork and M. Joshaghani, Bioorg. Med. Chem. Lett., 2006, 16, 1221

303. M. M. Heravi, L. Ranjbar, F. Derikvand and F. F. Bamoharram, Catal.Commun., 2007, 8, 289

304. L. Nagarapu, S. Kantevari, V. N. Cheemalapati, S. Apuri and N. V. Kumari, J. Mol. Catal., 2007, 264, 22

305. T. Yakaiah, B. P. V. Lingaiah, G. V. Reddy, B. Narsaiah and P. S. Rao, ARKIVOC, 2007, 227

306. B. Das and K. R. Reddy, Helv. Chim. Act., 2006, 89, 3109

307. B. Das, M. Krishnaiah, K. Laxminarayana and K. R. Reddy, J. Mol. Catal., 2007, 270, 284 
308. M. M. Khodaei, A. R. Khosropour and P. Fattahpour, Tetrahedron Lett., 2005, 46, 2105

309. B. Das, R. A. Kumar, P. Thirupathi and Y. Srinivas, Synthetic Commun, 2009, 39, 3305

310. F. Couty and G. Evano, in Comprensive Heterocyclic Chemistry III, Elsevier, Oxford, 2008.

311. Y. Rival, G. Grassy, A. Taudaou and R. Ecalle, Eur. J. Med. Chem., 1991, 26, 13.

312. N. Hsua, S. K. Jha, T. Coleman and M. G. Frank, Behav. Brain Res., 2009, 223.

313. M. H. Wiegand, Drugs 2008, 68, 2411

314. A. Gueiffier, S. Mavel, M. Lhassani, A. Elhakmaoui, R. Snoeck, G. Andrei, O. Chavignon, J. C. Teulade, M. Witvrouw, J. Balzarini, E. De Clercq and J. P. Chapat, J Med Chem, 1998, 41, 5108

315. R. W. Tully and C. R. Gardner, J. Med. Chem., 1991, 34, 2060

316. S. Z. Langer, S. Arbilla, J. Benavides and B. Scatton, Adv. Biochem. Psychopharmacol., 1990, 46, 61.

317. A. R. Katritzky, X.-J. Xu and H. Tu, J. Org. Chem., 2003, 68, 4935.

318. H. Bienayme and K. Bouzid, Angew Chem Int Edit, 1998, 37, 2234

319. C. Blackburn, Tetrahedron Lett., 1998, 39, 5469

320. K. Groebke, L. Weber and F. Mehlin, Synlett, 1998, 661

321. A. L. Rousseau, P. Matlaba and C. J. Parkinson, Tetrahedron Lett., 2007, 48, 4079

322. A. Shaabani, F. Rezazadeh and E. Soleimani, Monatsh. Chem., 2008, 139, 931

323. V. Z. Parchinsky, O. Shuvalova, O. Ushakova, D. V. Kravchenko and M. Krasavin, Tetrahedron Lett., 2006, 47, 947

324. A. Shaabani, E. Soleimani, A. Maleki and J. Moghimi-Rad, Mol Divers, 2009, 13, 269

325. M. A. Mironov, M. I. Tokareva, M. N. Ivantsova and V. S. Mokrushin, Russian Chem. Bull. Int. Ed., 2006, 55, 1835

326. A. Shaabani, E. Soleimani and A. Maleki, Tetrahedron Lett., 2006, 47, 3031

327. R. S. Varma and D. Kumar, Tetrahedron Lett., 1999, 40, 7665

328. A. Shaabani, E. Soleimani and A. Maleki, Monatsh. Chem., 2007, 138, 73.

329. M. Gopalakrishnan, P. Sureshkumar, J. Thanusu and V. Kanagarajan, J Enzym Inhib Med Ch, 2008, 23, 87 
330. J. Xu, Bioorg. Med. Chem. Lett., 2005, 15, 2533.

331. R. W. Lamon, J. Org. Chem, 1969, 34, 756

332. N. B. Das, N. Ravindranath, B. Venkataiah and P. Madhusudhan, J. Chem. Res., 2000, 482.

333. V. Kanagarajan, P. Sureshkumar, J. Thanusu and G. Gopalakrishnan, Russian J. Org. Chem., 2009, 45 (11), 1707

334. P. Kafarski and B. Lejczak, Phosphorous Sulfur Silicon Relat. Elem., 1991, 63, 193.

335. E. Alonso, E. Alonso, A. Solis and C. del Pozo, Synlett., 2000, 698.

336. S. K. Chung and D. H. Kang, Tetrahedron Asymmetry, 1996, 7, 21.

337. D. Miliszkiewicz, P. Wieczorek, B. Lejczak, E. Kowalik and P. Kafarski, Pestic. Sci., 1992, 34, 349.

338. R. Gallardo-Macias and K. Nakayama, Synth., 2010, 1, 57.

339. N. S. Zefirov and E. D. Matveeva, Arkivoc, 2008, 1.

340. H. Firouzabadi, N. Iranpoor and S. Sobhani, Synth., 2004, 16, 2692.

341. S. Bhagat and A. K. Chakraborti, J. Org. Chem., 2008, 73, 6029.

342. K. S. Ambica, S. C. Taneja, M. S. Hundal and K. K. Kapoor, Tetrahedron Lett., 2008, 49, 2208.

343. B. Das, G. Satyalakshmi, K. Suneel and K. Damodar, J. Org. Chem., 2009, 74, 8400 .

344. J. S. Yadav, B. V. S. Reddy and P. Sreedhar, Green Chem., 2002, 436

345. A. K. Battacharya and K. C. Rana, Tetrahedron Lett., 2008, 2598.

346. M. Xia and Y. L.u, Ultrason. Sonochem., 2007, 14, 235.

347. S. D. P. Mitragotri, D. M.; Desai, U. V.; Wadgaonkar, P. P. , Catal Commun, 2008, 9, 1822

348. B. Kaboudin and R. Nazari, Tetrahedron Lett., 2001, 42, 8211

349. J. S. Yadav, B. V. S. Reddy and C. Mandan, Synlett, 2001, 7, 1131

350. Ambica, S. Kumar, S. C. Taneja, M. S. Hundal and K. K. Kapoor, Tetrahedron Lett., 2008, 49, 2208.

351. A. Vinu, P. Kalita, V. V. Balasubramanian, H. Oveisi, T. Selvan, A. Mano, M.

A. Chari and B. V. S. Reddy, Tetrahedron Lett, 2009, 50, 7132

352. A. Heydari, H. Hamadi and M. Pourayoubi, Catal. Commun., 2007, 8, 1224

353. M. T. Maghsoodiou, S. M. Habibi-Khorassani, R. H. Heydari, S. Nourollah and S. S.R.M., Chinese J. Chem., 2010, 28, 285 
354. J. V. Johnson, B. S. Rauckman, D. P. Baccanari and B. Roth, J Med Chem, 1989, 32, 1942

355. N. Yamada, S. Kadowaki, K. Takhashi and K. Umeza, Biochem. Pharmacol., 1992, 44, 1211.

356. X. Y. Xu, G. W. Qin, R. S. Xu and X. Z. Zhu, Tetrahedron, 1998, 54, 14179

357. M. Cushman and L. G. Chen, J. Org. Chem., 1987, 52, 1517.

358. M. Cushman, J. Gentry and F. W. Dekow, J. Org. Chem., 1977, 42, 1111.

359. N. F. Yu, L. Bourel, B. Deprez and J. C. Gesquiere, Tetrahedron Lett., 1998, 39, 829.

360. I. Vara, T. Bello, E. Aldaba, A. Arrieta, J. L. Pizarro, M. I. Arriortua, X. Lopez and F. P. Cossio, Org. Lett., 2008, 10, 4759.

361. N. F. Yu, R. Poulain and J. C. Gesquiere, Synlett, 2000, 355

362. J. S. Sadav, B. V. S. Reddy, K. S. Raj and A. R. Prasad, Tetrahedron, 2003, 59, 1805.

363. L. Wang, J. Liu, H. Tian, C. T. Qian and J. Sun, Adv Synth Catal, 2005, 347, 689.

364. J. Azizian, A. A. Mohammadi, A. R. Karimi and M. R. Mohammadizadeh, J. Org. Chem., 2005, 70, 350

365. J. Azizian, A. A. Mohammadi, E. Soleimani, A. R. Karimi and M. M. R., J. Heterocyclic Chem., 2006, 43, 187.

366. A. R. Karimi and R. Pashazadeh, Synth., 2010, 3, 437.

367. V. Michelet and J. P. Genett, Curr. Org. Chem., 2005, 9, 405.

368. P. O. Miranda, D. D. Diaz, J. I. Padron, M. A. Ramirez and V. S. Martin, J. Org. Chem., 2005, 70, 57.

369. J. S. Yadav, B. V. S. Reddy, S. Aravind, G. G. K. S. N. Kumar, C. Madhavi and A. C. Kunwar, Tetrahedron, 2008, 64, 3025.

370. A. A. W. Long, J. H. C. Nayler, H. Smith, T. Taylor and N. Ward, J. Chem. Soc. C, 1971, 1920

371. T. Ohashi, Takahashi, S., Nagamachi, T.; yoneda, K.; Yamada, H., Agric. Biol. Chem., 1981, 45, 831.

372. C. Cativiela, J. M. Fraile, J. I. Garcia, B. Lazaro, J. A. Mayoral and A. Pallares, Appl. Catal. A-Gen, 2002, 224, 153

373. R. P. Jain and J. C. Vederas, Bioorg. Med. Chem. Lett., 2004, 4, 1807. 
374. S. Grasso, G. Desarro, N. Micale, N. Zappala, G. Puia, M. Beraldi and C. Demicheli, J Med Chem, 2000, 43, 2851.

375. Y. Nomoto, H. Obase, H. Takai, M. Teranishi, J. Nakamura and K. Kubo, Chem. Pharm. Bull., 1990, 38, 2179.

376. N. Watanabe, Y. Kabasawa, Y. Takase, M. Matsukura, K. Miyazaki, H. Ishihara, K. Kodama and H. Adachi, J Med Chem, 1998, 41, 3367.

377. L. P. Liu, J. M. Lu and M. Shi, Org. Lett., 2007, 9, 1303.

378. M. Sayyafi, M. Seyyedhamzeh, H. R. Khavasi and A. Bazgir, Tetrahedron, 2008, 64, 2375.

379. H. R. Shaterian, M. Ghashang and M. Feyzi, Appl. Catal. A Gen, 2008, 345, 128.

380. L. Loy, G. Bonsignore, D. Secci and A. Calignano, Eur. J. Med. Chem., 1993, 28, 517.

381. L. Bonsignore, G. Loy, D. Secci and A. Calignano, Eur. J. Med. Chem., 1993, 28, 517

382. J. M. Quintela, C. Peinador and M. J. Moreira, Tetrahedron, 1995, 51, 5901

383. J. F. Zhou, S. J. Tu, Y. Gao and M. Ji, J. Org. Chem., 2001, 21, 742

384. Y. Peng and G. Song, Catal Commun, 2007, 8, 111

385. L. Fotouhi, M. M. Heravi, A. Fatehi and K. Bakhtiari, Tetrahedron Lett., 2007, 48, 5379

386. T. S. Jin, J. C. Xiao, S. J. Wang, T. S. Li and X. R. Song, Synlett, 2003, 2001

387. S. Balalaie, M. Bararjanian, A. M. Amani and B. Movassagh, Synlett, 2006, 263

388. N. S. Babu, N. Pasha, K. T. V. Rao, P. S. S. Prasad and N. Lingaiah, Tetrahedron Lett., 2008, 49, 2730

389. M. M. Heravi, S. Sadjadi, H. A. Oskoole, R. H. Shoar and F. F. Bamoharram, Catal Commun, 2008, 9, 470

390. S. Kamaljit, S. Jasbir and S. Harjit, Tetrahedron, 1996, 52, 14273

391. S. Abdolmohammadi and S. Balalaie, Tetrahedron Lett., 2007, 48, 3299

392. A. Shaabani, S. Samadi, Z. Badri and A. Rahmati, Catalysis Lett., 2005, 104, 39

393. M. Seifi and H. Sheibani, Catalysis Lett., 2008, 126, 275

394. M. Witvrouw, B. Van Maele, J. Vercammen, A. Hantson, Y. Engelborghs, E. De Clercq, C. Pannecouque and Z. Debyser, Curr. Drug Metab., 2004, 5, 291.

395. M. Kidwai, R. Goyal and K. Singhal, Indian J. Chem. B, 2007, 46, 1159 
396. M. M. Khafagy, A. H. F. Abd El-Wahab, F. A. Eid and A. M. El-Agrody, Farmaco, 2002, 57, 715

397. S. J. Mohr, M. A. Chirigos, F. S. Fuhrman and J. W. Pryor, Cancer Res, 1975, 35, 3750

398. D. R. Anderson, S. Hegde, E. Reinhard, L. Gomez, W. F. Vernier, L. Lee, S. Liu, A. Sambandam, P. A. Snider and L. Masih, Bioorg. Med. Chem. Lett., 2005, 15, 1587

399. G. Bianchi and A. Tava, Agr Biol Chem Tokyo, 1987, 51, 2001

400. F. Eiden and F. Denk, Arch Pharm, 1991, 324, 353

401. M. Kidwai, S. Saxena, M. K. R. Khan and S. S. Thukral, Bioorg. Med. Chem. Lett., 2005, 15, 4295

402. J. Bloxham, C. P. Dell and C. W. Smith, Heterocycles, 1994, 38, 399

403. X. S. Wang, D. Q. Shi, H. Z. Yu, G. F. Wang and S. J. Tu, Synthetic Commun., 2004, 34, 509

404. R. Maggi, R. Ballini, G. Sartori and R. Sartorio, Tetrahedron Lett., 2004, 45, 2297

405. D. Kumar, V. B. Reddy, B. G. Mishra, R. K. Rana, M. N. Nadagouda and R. S. Varma, Tetrahedron, 2007, 63, 3093

406. M. P. Surpur, S. Kshirsagar and S. D. Samant, Tetrahedron Lett., 2009, 50, 719

407. K. Gong, H. L. Wang, D. Fang and Z. L. Liu, Catal. Commun., 2008, 9, 650

408. M. Boronat, M. J. Climent, A. Corma, S. Iborra, R. Monton and M. J. Sabater, Chem. Eur. J., 2010, 16, 1221 
Table 1 Mannich reaction of different aldehydes amines and alkynes using Si-NHC$\mathrm{Cu}^{\mathrm{I}}$ catalyst.

\begin{tabular}{|c|c|c|c|}
\hline Alkyne & Aldehyde & Amine & Yield (\%) ${ }^{\mathrm{b}}$ \\
\hline $\mathrm{C}_{6} \mathrm{H}_{5} \mathrm{C} \equiv \mathrm{CH}$ & $\mathrm{CH}_{2} \mathrm{O}$ & & 95 \\
\hline $\mathrm{C}_{6} \mathrm{H}_{5} \mathrm{C} \equiv \mathrm{CH}$ & $\mathrm{CH}_{2} \mathrm{O}$ & & 94 \\
\hline $\mathrm{C}_{6} \mathrm{H}_{5} \mathrm{C} \equiv \mathrm{CH}$ & $\mathrm{CH}_{2} \mathrm{O}$ & & 94 \\
\hline $\mathrm{C}_{6} \mathrm{H}_{5} \mathrm{C} \equiv \mathrm{CH}$ & $\mathrm{CH}_{2} \mathrm{O}$ & & 96 \\
\hline $\mathrm{C}_{6} \mathrm{H}_{5} \mathrm{C} \equiv \mathrm{CH}$ & $\mathrm{C}_{6} \mathrm{H}_{5} \mathrm{CHO}$ & & $\begin{array}{c}79 \\
91^{\mathrm{c}}\end{array}$ \\
\hline $\mathrm{C}_{6} \mathrm{H}_{5} \mathrm{C} \equiv \mathrm{CH}$ & $\mathrm{C}_{6} \mathrm{H}_{5} \mathrm{CHO}$ & & $\begin{array}{c}71 \\
88^{\mathrm{c}}\end{array}$ \\
\hline $\mathrm{C}_{6} \mathrm{H}_{5} \mathrm{C} \equiv \mathrm{CH}$ & $\mathrm{m}^{-} \mathrm{ClC}_{6} \mathrm{H}_{4} \mathrm{CHO}$ & & $93^{c}$ \\
\hline $\mathrm{p}^{-} \mathrm{CH}_{3} \mathrm{C}_{6} \mathrm{H}_{5} \mathrm{C} \equiv \mathrm{CH}$ & $\mathrm{CH}_{2} \mathrm{O}$ & & 96 \\
\hline $\mathrm{n}^{-} \mathrm{C}_{8} \mathrm{H}_{17} \mathrm{C} \equiv \mathrm{CH}$ & $\mathrm{CH}_{2} \mathrm{O}$ & & $\begin{array}{c}78 \\
92^{\mathrm{c}}\end{array}$ \\
\hline EtOOCC $\equiv \mathrm{CCH}_{3}$ & $\mathrm{CH}_{2} \mathrm{O}$ & $\mathrm{HN}$ & $75^{\mathrm{c}}$ \\
\hline
\end{tabular}

a Reaction conditions: aldehyde (1.0 mmol), amine (1.1 mmol), alkyne (1.2 mmol), $\mathrm{SiO}_{2}-\mathrm{NHC}-\mathrm{Cu}^{\mathrm{I}}(2 \mathrm{~mol} \%)$, nitrogen, room temperature, $24 \mathrm{~h} .{ }^{\mathrm{b}}$ isolated yield. ${ }^{\mathrm{c}} 70{ }^{\circ} \mathrm{C}$ for $4 \mathrm{~h}$. 
Table 2 Results of the MCR between piperidine, benzaldehyde and phenylacetylene using different $\mathrm{Cu}^{\mathrm{I}}$ catalysts.

\begin{tabular}{ccccc}
\hline Catalyst & Solvent & $\mathrm{T}\left({ }^{\circ} \mathrm{C}\right)$ & Yield $^{\mathrm{a}}(\%)$ & $\begin{array}{c}\text { Acid sites } \\
(\mathrm{mmol} / \mathrm{g})\end{array}$ \\
\hline $\mathrm{Cu}^{1}$-USY & DMF & 60 & 40 & 4.39 \\
$\mathrm{Cu}^{1}$-USY & Toluene & 80 & 72 & 4.39 \\
$\mathrm{Cu}^{1}-$ USY & THF & 80 & 79 & 4.39 \\
$\mathrm{Cu}^{1}-$ USY & MeCN & 60 & 35 & 4.39 \\
$\mathrm{Cu}^{1}-$ USY & none & 80 & 95 & 4.39 \\
$\mathrm{Cu}^{1}-\mathrm{Y}$ & none & 80 & 92 & 6.67 \\
$\mathrm{Cu}^{1}-$ Beta & none & 80 & 90 & $0.91-1.23$ \\
$\mathrm{Cu}^{1}-$ ZSM-5 & none & 80 & 80 & 1.04 \\
$\mathrm{Cu}-$ Mor & none & 80 & 71 & 1.48 \\
$\mathrm{H}-$ USY & none & 80 & $-\mathrm{b}$ & 6.67 \\
$\mathrm{CuCl}$ & none & 80 & $40-90^{\mathrm{b}}$ & - \\
none & none & 80 & $-\mathrm{c}$ & - \\
\hline
\end{tabular}

Reaction conditions: $1 \mathrm{mmol}$ of each component for $15 \mathrm{~h}$ with a zeolite loading of 20 mg. ${ }^{a}$ Yields were evaluated by H-NMR analysis of the crude mixture. ${ }^{b}$ Upon mixing without solvent, intense heat was evolved leading to decomposition, whereas in solvent good yields were obtained. ${ }^{c}$ No transformation was observed. 
Table $3 \mathrm{~A}^{3}$ coupling of cyclohexanecarbaldehyde, morpholine and phenylacetylene using different Ni based catalysts. ${ }^{\text {a }}$

\begin{tabular}{|c|c|c|}
\hline Nickel source & Solvent & Yield(\%) \\
\hline $\mathrm{Ni}(\mathrm{OAc})_{2} 4 \mathrm{H}_{2} \mathrm{O}$ & DMF & $25^{c}$ \\
\hline $\mathrm{Ni}(\mathrm{OAc})_{2} 4 \mathrm{H}_{2} \mathrm{O}$ & toluene & $21^{\mathrm{c}}$ \\
\hline $\mathrm{Ni}(\mathrm{OAc})_{2} 4 \mathrm{H}_{2} \mathrm{O}$ & THF & $20^{c}$ \\
\hline $\mathrm{Ni}(\mathrm{OAc})_{2} 4 \mathrm{H}_{2} \mathrm{O}$ & $\mathrm{MeCN}$ & $26^{\mathrm{c}}$ \\
\hline $\mathrm{Ni}(\mathrm{OAc})_{2} 4 \mathrm{H}_{2} \mathrm{O}$ & none & 63 \\
\hline $\mathrm{NiCl}_{2} 6 \mathrm{H}_{2} \mathrm{O}$ & none & 53 \\
\hline $\mathrm{Ni}\left(\mathrm{SO}_{4}\right)_{2} 6 \mathrm{H}_{2} \mathrm{O}$ & none & 55 \\
\hline $\mathrm{Ni}\left(\mathrm{NO}_{3}\right)_{2} 6 \mathrm{H}_{2} \mathrm{O}$ & none & 36 \\
\hline $\mathrm{Ni} / \mathrm{Al}-\mathrm{HT}$ & none & 31 \\
\hline Ni-K10 clay & none & 64 \\
\hline Ni-Al-MCM-41 & none & 73 \\
\hline Ni-Y zeolite & none & 97 \\
\hline H-Y zeolite & none & 0 \\
\hline
\end{tabular}

a Cyclohexanecarbaldehyde (1.0 mmol), morpholine (1.2 mmol), phenylacetylene (1.2 mmol), Ni-Y (20 mg), $80{ }^{\circ} \mathrm{C}, 4$ h. ${ }^{\mathrm{b}}$ Yield of isolated product. ${ }^{\mathrm{c}} 100{ }^{\circ} \mathrm{C}$, for $15 \mathrm{~h}$. 
Table 4 Three-component coupling of benzaldehyde, piperidine, and phenylacetylene with supported gold catalyst. ${ }^{\text {a }}$

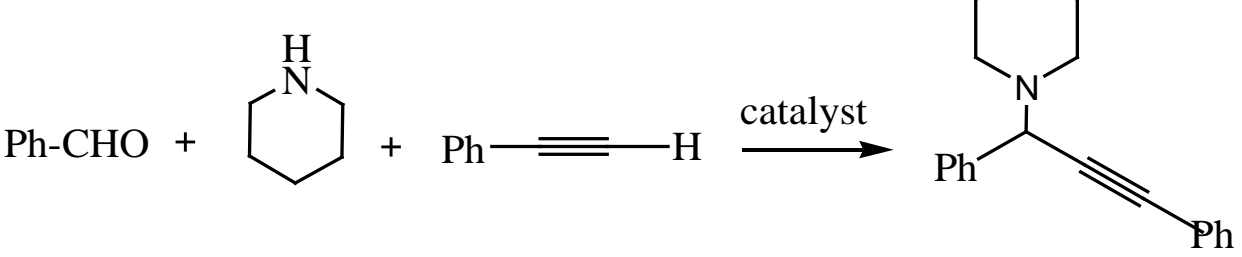

\begin{tabular}{lcccc}
\hline \multicolumn{1}{c}{ Catalyst $^{\mathrm{b}}$} & Gold (mol \%) & Conv. $(\%)^{\mathrm{c}}$ & $\begin{array}{c}\text { Yield } \\
\text { propargylamine(\%) }\end{array}$ & TON $^{\mathrm{d}}$ \\
\hline $0.2 \% \mathrm{Au} / \mathrm{SiO}_{2}$ & 0.013 & $<5$ & - & - \\
$3.0 \% \mathrm{Au} / \mathrm{C}$ & 0.081 & 13 & nd & 161 \\
$1.5 \% \mathrm{Au} / \mathrm{TiO}_{2}$ & 0.075 & 35 & nd & 464 \\
$4.5 \% \mathrm{Au} / \mathrm{Fe}_{2} \mathrm{O}_{3}$ & 0.247 & 40 & nd & 162 \\
$2.8 \% \mathrm{Au} / \mathrm{ZrO}_{2}$ & 0.142 & 95 & 93 & 668 \\
$2.5 \% \mathrm{Au} / \mathrm{CeO}_{2}$ & 0.127 & 100 & $>99$ & 788 \\
\hline
\end{tabular}

${ }^{a}$ Reaction conditions: benzaldehyde $(1.0 \mathrm{mmol})$, piperidine $(1.2 \mathrm{mmol})$, phenylacetilene $(1.3$ mmol), $\mathrm{H}_{2} \mathrm{O}$ (MiliQ, $1.0 \mathrm{~mL}$ ), $6 \mathrm{~h}, 100^{\circ} \mathrm{C}$. ${ }^{\mathrm{b}}$ The number (e.g. $0.2 \%$ ) is the mass weight of gold loaded on the support (e.g. $\mathrm{SiO}_{2}$ ). ${ }^{\mathrm{c}}$ Determined by GC analysis based on aldehyde. ${ }^{\mathrm{d}}$ Yields of isolated propargylamine based on benzaldehyde; n.d. not determined. ${ }^{\text {e }}$ Calculated on the basis of total weight of gold. 
Table $5 \mathrm{~A}^{3}$ coupling of benzaldehyde, piperidine, and phenylacetylene using different solid catalysts.

\begin{tabular}{|c|c|c|c|c|c|c|c|}
\hline Catalyst & $\begin{array}{l}\text { Yield } \\
(\%)\end{array}$ & Solvent & $\mathrm{T}^{\circ} \mathrm{C}$ & $\mathrm{t}(\mathrm{h})$ & $\begin{array}{l}\text { Catalyst } \\
\text { (mol\%) }\end{array}$ & $\begin{array}{r}\text { Molar } \\
\text { ratio }^{a}\end{array}$ & Ref. \\
\hline CuI-[bmim] $\mathrm{PF}_{6}{ }^{\mathrm{b}}$ & 85 & {$[\mathrm{bmim}] \mathrm{PF}_{6}$} & 120 & 2 & 2 & $1: 1.2: 1.5$ & 72 \\
\hline $\mathrm{Cu}-\mathrm{np}{ }^{\mathrm{b}}$ & 94 & $\mathrm{CH}_{3} \mathrm{CN}$ & 100 & 6 & 15 & $1: 1: 1.5^{f}$ & 92 \\
\hline $\mathrm{Cu}-\mathrm{HAP} \mathrm{P}^{\mathrm{b}}$ & 85 & $\mathrm{CH}_{3} \mathrm{CN}$ & reflux & 6 & $0.10^{\mathrm{d}}$ & $1: 1.2: 1.3$ & 88 \\
\hline Silica gel $\mathrm{CuCl}^{\mathrm{b}}$ & 86 & $\mathrm{H}_{2} \mathrm{O}$ & reflux & 10 & 0.05 & $1: 1.2: 1.5$ & 89 \\
\hline SiNHC-Cu ${ }^{1, b}$ & $79-91^{\mathrm{c}}$ & - & $\mathrm{rt}$ & 24 & 2 & $1: 1.2: 1.2$ & 91 \\
\hline SiCHDA- $\mathrm{Cu}^{1}$ & 92 & - & 80 & 12 & $0.04^{\mathrm{d}}$ & 1:1:1 & 102 \\
\hline USY- $\mathrm{Cu}^{1}$ & 95 & - & 80 & 15 & $0.02^{\mathrm{d}}$ & $1: 1: 1.2$ & 93 \\
\hline AgTPA $^{b}$ & 92 & $\mathrm{CH}_{3} \mathrm{CN}$ & 80 & 6 & $0.03^{d}$ & $1: 1.2: 1.3$ & 96 \\
\hline Au-np b & 94 & $\mathrm{CH}_{3} \mathrm{CN}$ & 80 & 5 & 10 & 1:1:1.5 & 99 \\
\hline Ag-NaY b & 81 & - & 100 & 15 & 5 & $5: 5: 5$ & 94 \\
\hline Zn dust ${ }^{b}$ & 90 & $\mathrm{CH}_{3} \mathrm{CN}$ & reflux & 9 & 15 & $1: 1.1: 1.2$ & 103 \\
\hline $\mathrm{Au} / \mathrm{MCN}^{\mathrm{b}}$ & 61 & Toluene & 100 & 24 & 0.05 & $1: 1.2: 1.3$ & 100 \\
\hline $\mathrm{Au} / \mathrm{CeO}_{2}{ }^{\mathrm{b}}$ & $>99$ & $\mathrm{H}_{2} \mathrm{O}$ & 100 & 6 & 0.127 & $1: 1.2: 1.3$ & 101 \\
\hline $\mathrm{LDH}-\mathrm{AuCl}_{4}$ & 92 & THF & reflux & 5 & $0.025^{d}$ & $1: 1.2: 1.5$ & 98 \\
\hline $\mathrm{Fe}_{3} \mathrm{O}_{4} \mathrm{np}^{\mathrm{b}}$ & 45 & THF & 80 & 24 & 5 & 0.5:0.6:0.7 & 104 \\
\hline $\mathrm{Ni}-\mathrm{HY}$ & 85 & - & 80 & 10 & $0.02^{d}$ & $1: 1.2: 1.2^{\mathrm{f}}$ & 95 \\
\hline
\end{tabular}

${ }^{a}$ mmol of benzaldehyde:piperidine:phenylacetylene, under $\mathrm{N}_{2}$. ${ }^{\mathrm{b}}$ catalyst was recovered and reused. ${ }^{\mathrm{c}}$ at $70^{\circ} \mathrm{C}$ for $4 \mathrm{~h}$. ${ }^{\mathrm{d}}$ grams of catalyst. ${ }^{\mathrm{e}} \mathrm{mmol}$ of benzaldehyde:morpholine : phenylacetylene. 
Table 6 Three component coupling and cyclization of an aldehyde, amine, and Nprotected ethynylaniline using gold supported catalysts.

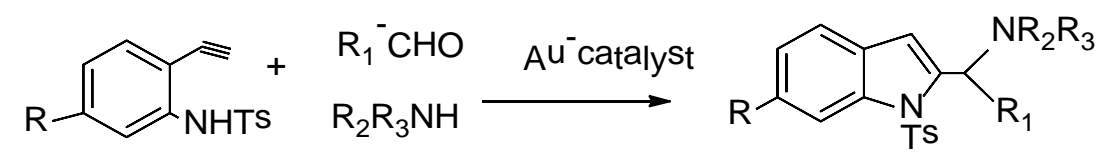

\begin{tabular}{|c|c|c|c|}
\hline Catalyst & $\mathrm{R}^{1}-\mathrm{CHO}$ & $\mathrm{R}^{2} \mathrm{R}^{3} \mathrm{NH}$ & Yield (\%) \\
\hline \multirow[t]{6}{*}{$\mathrm{Au} / \mathrm{ZrO}_{2}{ }^{[\mathrm{a}]}$} & $(\mathrm{HCOH}) n \mathrm{R}^{1}=\mathrm{H}$ & piperidine & 95 \\
\hline & Heptyl & piperidine & 97 \\
\hline & Cyclohexyl & piperidine & 75 \\
\hline & $(\mathrm{HCOH}) n \mathrm{R}^{1}=\mathrm{H}$ & pyrrolidine & 87 \\
\hline & $(\mathrm{HCOH}) n \mathrm{R}^{1}=\mathrm{H}$ & morpholine & 70 \\
\hline & $(\mathrm{HCOH}) n \mathrm{R}^{1}=\mathrm{H}$ & diethylamine & 90 \\
\hline \multirow[t]{5}{*}{ IRMOF-3-Si-Au ${ }^{[\mathrm{b}]}$} & $(\mathrm{HCOH}) n \mathrm{R}^{1}=\mathrm{H}$ & piperidine & $90(16 \mathrm{~h})$ \\
\hline & Heptyl & piperidine & 95(6 h) \\
\hline & Cyclohexyl $^{[\mathrm{c}]}$ & piperidine & $80(4 \mathrm{~h})$ \\
\hline & $(\mathrm{HCOH}) n \mathrm{R}^{1}=\mathrm{H}$ & $\mathrm{CA} 1^{\mathrm{d}}$ & $83(12 \mathrm{~h})$ \\
\hline & $(\mathrm{HCOH}) n \mathrm{R}^{1}=\mathrm{H}$ & $\mathrm{CA} 2^{\mathrm{d}}$ & $91(6 \mathrm{~h})$ \\
\hline
\end{tabular}

a Aldehyde $(0.2 \mathrm{mmol})$, aniline $(0.24 \mathrm{mmol})$ and N-protected ethynylaniline $(0.26$ mmol), gold $(0.0007 \mathrm{mmol})$ dioxane $(1.0 \mathrm{~mL}), \mathrm{h}$; Ts: toluene-4-sulfonyl. ${ }^{\mathrm{b}}$ Aldehyde $(0.40 \mathrm{mmol})$, aniline $(0.24 \mathrm{mmol})$ and $\mathrm{N}$-protected ethynylaniline $(0.20 \mathrm{mmol})$, gold $(14$ mg, $0.001 \mathrm{mmol})$ dioxane $(1.0 \mathrm{~mL}), 40{ }^{\circ} \mathrm{C}$. ${ }^{\mathrm{c}}$ At $80{ }^{\circ} \mathrm{C} .{ }^{\mathrm{d}}$ Chiral amines: CA1 (S)-(+)-2(metoxymethyl)-pyrrolidine and CA2 (S)-(+)-2-methylpiperidine. 
Table $7 \mathrm{~A}^{3}$ coupling of o-ethynylphenol with secondary anines and paraformaldehyde using cuprous iodide doped alumina as catalyst under microwave irradiation

\begin{tabular}{ccc}
\hline $\mathrm{R}$ & Yield (\%) \\
\hline $\mathrm{C}$ & 65 \\
\hline
\end{tabular}

a Reaction conditions: paraformaldehyde (3 mmol), o-ethynylphenol (1 mmol), secondary amine (1 mmol), cuprous iodide (3 mmol) $\mathrm{Al}_{2} \mathrm{O}_{3}(1 \mathrm{~g})$ irradiated at $300 \mathrm{~W}$ for $10 \mathrm{~min} .{ }^{\mathrm{b}}$ Isolated yields. 
Table 8 Mannich reaction of ketones, aromatic aldehydes and aromatic amines in the presence of $\mathrm{Cu}-\mathrm{np}^{\mathrm{a}}$

\begin{tabular}{|c|c|c|c|c|}
\hline Ketone & R-CHO & $\mathrm{R}-\mathrm{NH}_{2}$ & $\begin{array}{l}\text { Time } \\
\text { (h) }\end{array}$ & Yield (\%) \\
\hline Acetophenone & $\mathrm{Ph}$ & $\mathrm{Ph}$ & 4 & 93 \\
\hline Acetophenone & $\mathrm{Ph}$ & $4-\mathrm{CH}_{3} \mathrm{C}_{6} \mathrm{H}_{4}$ & 9 & 97 \\
\hline Acetophenone & $\mathrm{Ph}$ & $3,4-\left(\mathrm{CH}_{3}\right)_{2} \mathrm{C}_{6} \mathrm{H}_{3}$ & 10.5 & 92 \\
\hline Acetophenone & $\mathrm{Ph}$ & $4-\mathrm{ClC}_{6} \mathrm{H}_{4}$ & 9 & 95 \\
\hline Acetophenone & $4-\mathrm{CH}_{3} \mathrm{C}_{6} \mathrm{H}_{4}$ & $\mathrm{Ph}$ & 8 & 97 \\
\hline Acetophenone & $\mathrm{Ph}$ & $4-\mathrm{OCH}_{3} \mathrm{C}_{6} \mathrm{H}_{4}$ & 10 & 91 \\
\hline Acetophenone & $\mathrm{Ph}$ & $4-\mathrm{NO}_{2} \mathrm{C}_{6} \mathrm{H}_{4}$ & 12 & 73 \\
\hline Acetophenone & $4-\mathrm{OCH}_{3} \mathrm{C}_{6} \mathrm{H}_{4}$ & $\mathrm{Ph}$ & 9 & 91 \\
\hline Acetophenone & $4-\mathrm{NO}_{2} \mathrm{C}_{6} \mathrm{H}_{4}$ & $\mathrm{Ph}$ & 12 & 74 \\
\hline p-methylacetophenone & $\mathrm{Ph}$ & $\mathrm{Ph}$ & 10 & 85 \\
\hline p-nitroacetophenone & $\mathrm{Ph}$ & $\mathrm{Ph}$ & 10 & 87 \\
\hline cyclohexanone & $\mathrm{Ph}$ & $\mathrm{Ph}$ & 9 & 88 \\
\hline cyclohexanone & $\mathrm{Ph}$ & $4-\mathrm{CH}_{3} \mathrm{C}_{6} \mathrm{H}_{4}$ & 11 & 90 \\
\hline cyclohexanone & $\mathrm{Ph}$ & $4-\mathrm{ClC}_{6} \mathrm{H}_{4}$ & 12 & 91 \\
\hline cyclohexanone & $4-\mathrm{OCH}_{3} \mathrm{C}_{6} \mathrm{H}_{4}$ & $\mathrm{Ph}$ & 12 & 83 \\
\hline
\end{tabular}

${ }^{\text {a }}$ Reaction conditions: acetophenone or cyclohexanone $(1 \mathrm{mmol})$, aromatic aldehyde (1 mmol), aromatic amine (1 mmol), $10 \mathrm{~mol} \% \mathrm{Cu}-\mathrm{np}(18+/-2 \mathrm{~nm})$ methanol as solvent, room temperature, nitrogen atmosphere. ${ }^{\mathrm{b}}$ isolated yields. 
Table 9 Comparison of different catalysts used in the Biginelli reaction for the synthesis of 5-(ethoxycarbonyl)-6-methyl-4-phenyl-3,4-dihydropyrimidin-2(H)-one.

\begin{tabular}{|c|c|c|c|c|c|c|c|}
\hline Catalysts & $\mathrm{B}: \mathrm{E}: \mathrm{U}^{\mathrm{a}}$ & Solvent & $\mathrm{T}^{\circ} \mathrm{C}$ & $\begin{array}{l}\text { Catalyst } \\
\text { (g) }\end{array}$ & $\mathrm{t}(\mathrm{h})$ & $\begin{array}{c}\text { Yield } \\
\text { DHPM }\end{array}$ & Ref. \\
\hline $\mathrm{I}_{2}-\mathrm{Al}_{2} \mathrm{O}_{3}$ & $2: 2: 2$ & - & MW & $0.2^{\mathrm{C}}$ & 0.02 & 90 & 145 \\
\hline $\mathrm{SiO}_{2}-\mathrm{NaHSO}_{4}$ & $1: 1.2: 1.2$ & $\mathrm{CH}_{3} \mathrm{CN}$ & reflux & $10^{\mathrm{b}}$ & 1.5 & 93 & 135 \\
\hline Alum-SiO 2 & 5:5:6 & - & 80 & 0.16 & 4 & 92 & 134 \\
\hline $\begin{array}{l}\text { Ferrihydrite in a } \\
\text { silica aerogel }\end{array}$ & $50: 62: 75$ & $\mathrm{EtOH}$ & reflux & $\begin{array}{c}1.77(4 \mathrm{~mm} \\
\text { ol of } \mathrm{Fe})\end{array}$ & 84 & 65 & 138 \\
\hline $\begin{array}{l}\text { Silica sulphuric } \\
\text { acid }\end{array}$ & $2: 2: 3$ & $\mathrm{EtOH}$ & reflux & 0.23 & 6 & 91 & 144 \\
\hline $\mathrm{FeCl}_{3}-\mathrm{SiMCM}-41$ & 1:1:1.3 & - & $(\mathrm{MW})$ & $10^{\mathrm{d}}$ & 0.08 & 89 & 141 \\
\hline $\begin{array}{l}\mathrm{FeCl}_{3} \text {-Nanopore } \\
\text { Silica }\end{array}$ & $1: 1: 1.2$ & - & (MW) & $10^{\mathrm{d}}$ & 0.25 & 55 & 139 \\
\hline Montmorillonite & 10:10:15 & - & 130 & 0.5 & 48 & 82 & 140 \\
\hline $\mathrm{ZrO}_{2}$-pillared clay & $2.5: 2.5: 3.7$ & - & $(\mathrm{MW})$ & 0.25 & 0.08 & 92 & 158 \\
\hline Nafion-NR-50 & $5: 5: 5$ & $\mathrm{CH}_{3} \mathrm{CN}$ & reflux & 0.25 & 3 & 96 & 143 \\
\hline Amberlyst-15 & $5: 5: 5$ & $\mathrm{CH}_{3} \mathrm{CN}$ & reflux & 0.25 & 5.5 & 85 & 143 \\
\hline $\begin{array}{l}\text { Yb(III)-resin and } \\
\text { Polymer-supported } \\
\text { scavengers }\end{array}$ & $0.5: 0.5: 1.5$ & - & 120 & 0.17 & 48 & 80 & 147 \\
\hline $\mathrm{Ag}_{3} \mathrm{PW}_{12} \mathrm{O}_{40}$ & 5: 5:10 & $\mathrm{H}_{2} \mathrm{O}$ & 80 & $10^{\mathrm{d}}$ & 4 & 92 & 155 \\
\hline (PVP)-Cu complex & 1:1:1.3 & $\mathrm{MeOH}$ & reflux & $20^{\mathrm{e}}$ & 24 & 70 & 156 \\
\hline Scolecite & $5: 5: 6$ & $\mathrm{CH}_{3} \mathrm{CN}$ & reflux & $2^{\mathrm{d}}$ & 0.5 & 83 & 153 \\
\hline $\mathrm{ZrO}_{2} / \mathrm{SO}_{4}{ }^{2-}$ & $10: 10: 10$ & - & $(\mathrm{MW})$ & 0.1 & 0.5 & 98 & 148 \\
\hline Heulandite & $6: 6: 7.2$ & $\begin{array}{l}\text { Acetic } \\
\text { acid }\end{array}$ & 100 & 0.2 & 5 & 75 & 154 \\
\hline HY & 10:8:10 & Toluene & reflux & 0.5 & 12 & 21 & 151 \\
\hline HZSM-5 & 10:8:10 & Toluene & reflux & 0.5 & 12 & 80 & 151 \\
\hline Ersorb-4 & 5:5:6 & $\mathrm{EtOH}$ & 80 & 1 & 8 & 93 & 137 \\
\hline Co(II)phthalocyanine & $5: 5: 5$ & $\mathrm{CH}_{3} \mathrm{CN}$ & reflux & $2^{b}$ & 1 & 98 & 142 \\
\hline TS-1 & $4.7: 4.7: 7$ & - & 50 & 0.01 & 0.16 & 98 & 150 \\
\hline $\mathrm{HBF}_{4}-\mathrm{SiO}_{2}$ & 1:1:1.5 & Ethanol & r.t. & $5^{b}$ & 2 & 94 & 157 \\
\hline
\end{tabular}

${ }^{\mathrm{a}} \mathrm{B}: \mathrm{E}: \mathrm{U}$ mmol of benzaldehyde: ethyl acetoacetate: urea. ${ }^{\mathrm{b}} \mathrm{mol} \mathrm{\% .}{ }^{\mathrm{c}} 0.2 \mathrm{mmol}$ of iodine adsorbed on $0.5 \mathrm{~g}$ of neutral alumina. ${ }^{\mathrm{d}}$ wt\% based on total weight. ${ }^{\mathrm{e}} \mathrm{wt} \%$ based on $\beta$ ketoester. ${ }^{\mathrm{f}} \mathrm{wt} \%$ based on aldehyde. ${ }^{\mathrm{g}}$ Alum-SiO $2: \mathrm{KAl}\left(\mathrm{SO}_{4}\right)_{2} 12 \mathrm{H}_{2} \mathrm{O}$ supported on silica gel. ${ }^{\text {h }}$ PVP-Cu complex: Poly(4-vinylpyridine-divinylbenzene)-Cu(II) complex. 
Table 11 Synthesis of $\alpha$-amino nitriles by the three component coupling reaction.
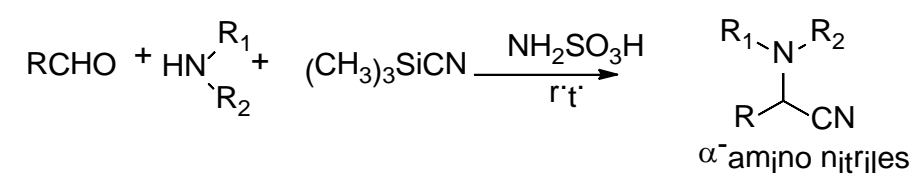

\begin{tabular}{|c|c|c|c|}
\hline $\mathrm{R}$ & $\mathrm{R}^{1}$ & $\mathrm{R}^{2}$ & Yield (\%) \\
\hline Phenyl & $\mathrm{H}$ & Phenyl & 98 \\
\hline n-butyl & $\mathrm{H}$ & Phenyl & 90 \\
\hline 4- $\mathrm{CH}_{3}$ Phenyl & $\mathrm{H}$ & Phenyl & 97 \\
\hline 2-Furyl & $\mathrm{H}$ & Phenyl & 95 \\
\hline Cinnamyl & $\mathrm{H}$ & Phenyl & 98 \\
\hline n-butyl & Ethyl & Ethyl & 82 \\
\hline Phenyl & Ethyl & Ethyl & 90 \\
\hline 4- $\mathrm{CH}_{3}$ Phenyl & Ethyl & Ethyl & 85 \\
\hline 2-Furyl & Ethyl & Ethyl & 80 \\
\hline Cinnamyl & Ethyl & Ethyl & 88 \\
\hline 4- $\mathrm{CH}_{3} \mathrm{OPhenyl}$ & Ethyl & Ethyl & 91 \\
\hline Phenyl & Benzyl & Benzyl & 94 \\
\hline i-Propyl & Benzyl & Benzyl & 94 \\
\hline 4- $\mathrm{CH}_{3}$ Phenyl & tert-butyl & $\mathrm{H}$ & 84 \\
\hline Cinnamyl & tert-butyl & $\mathrm{H}$ & 88 \\
\hline
\end{tabular}

Reaction conditions: aldehyde (3 mmol), amine (3.2 mmol), trimethylsilyl cyanide (3 mmol) and sulfamic acid (5 mol\%) at room temperature. 
Table 12 MCR of benzyl (or benzoin), benzaldehyde and ammonium acetate using different solid acid catalysts.<smiles>O=C(C(=O)c1ccccc1)c1ccccc1</smiles>

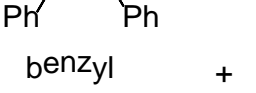

or<smiles>O=C(c1ccccc1)C(O)c1ccccc1</smiles>

Benzoin<smiles></smiles><smiles>c1ccc(-c2nc(-c3ccccc3)c(-c3ccccc3)[nH]2)cc1</smiles>

\begin{tabular}{lccclccc} 
Catalyst & B:PhCHO:AA & Solvent & $\begin{array}{c}\text { Catal. } \\
(\mathrm{g})\end{array}$ & \multicolumn{1}{c}{$\left(^{\circ} \mathrm{C}\right)$} & $\begin{array}{c}\text { Time } \\
(\mathrm{min})\end{array}$ & $\begin{array}{c}\text { Yield } \\
(\%)\end{array}$ & Ref \\
\hline $\mathrm{Al}_{2} \mathrm{O}_{3}$ & $0.5: 0.5: 57$ & $\mathrm{Et}_{2} \mathrm{O}$ & $2.5^{\mathrm{b}}$ & $\mathrm{MW}(130 \mathrm{~W})$ & 20 & 76 & 198 \\
$\mathrm{SiO}_{2}{ }^{\mathrm{c}}$ & $5.0: 5.0: 100$ & $\mathrm{CH}_{2} \mathrm{Cl}_{2}$ & 15.4 & $\mathrm{MW}(160 \mathrm{~W})$ & 20 & 70 & 197 \\
$\mathrm{Al}_{2} \mathrm{O}_{3}{ }^{\mathrm{c}}$ & $5.0: 5.0: 100$ & $\mathrm{CH}_{2} \mathrm{Cl}_{2}$ & 17 & $\mathrm{MW}(160 \mathrm{~W})$ & 20 & 67 & 197 \\
$\mathrm{SSA}$ & $1.0: 1.0: 6.0$ & - & 0.2 & $\mathrm{MW}(160 \mathrm{~W})$ & 10 & 85 & 200 \\
$\mathrm{SSA}$ & $1.0: 1.0: 6.0$ & - & 0.2 & 130 & 50 & 83 & 200 \\
$\mathrm{HY}$ & $4.0: 4.0: 8.0$ & - & 4 & $\mathrm{MW}$ & 6 & 81 & 199 \\
$\mathrm{PSZC}$ & $1.0: 1.0: 2.5$ & $\mathrm{EtOH}$ & $15^{\mathrm{d}}$ & $\mathrm{MW}$ & 90 & 96 & 201 \\
$\mathrm{CSA}$ & $1.0: 1.0: 2.5$ & - & 0.1 & $\mathrm{MW}(180)$ & 1 & 98 & 202
\end{tabular}

a mmol of benzyl:benzaldehyde: ammonium acetate. ${ }^{\mathrm{b}} 9.3 \mathrm{~g}$ of alumina impregnated with $4.4 \mathrm{~g}$ of ammonium acetate. ${ }^{\mathrm{c}}$ benzoin was used instead of benzyl. ${ }^{\mathrm{d}}$ mol\%. 
Table 13 Montmorillonite clay as catalyst in the synthesis of homoallylic amines. ${ }^{\mathrm{a}}$

Time (h) Yield (\%)

a Reaction conditions: Aldehyde (5 mmol), amine (5 mmol), allyltributylstannane (5mmol), Montmorillonite $\mathrm{KSF}(1 \mathrm{~g})$, in $\mathrm{CH}_{3} \mathrm{CN}(10 \mathrm{ml})$ at room temperature. 
Table 14 Three component coupling reaction of benzaldehyde, aniline and allyltributylstannane using different acid catalysts at room temperature.

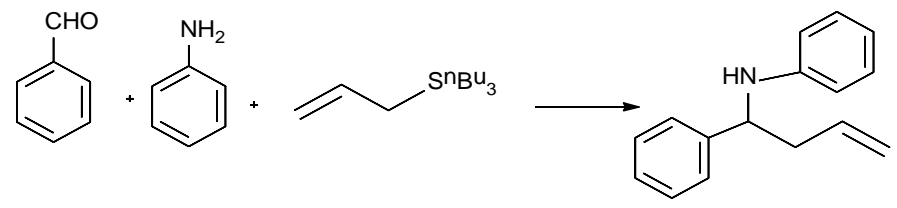

\begin{tabular}{ccccccc}
\hline Catalyst & $\begin{array}{c}\text { Yield } \\
(\%)\end{array}$ & $\mathrm{t}(\mathrm{h})$ & $\mathrm{B}: \mathrm{A}: \mathrm{AS}$ & $\begin{array}{c}\text { Catalyst } \\
\text { amount }(\mathrm{g})\end{array}$ & Solvent & Ref. \\
\hline [bmim]BF 4 & 92 & 4.5 & $2: 5: 2$ & $2^{\mathrm{c}}$ & - & \\
Mont KSF & 90 & 4 & $5: 5: 5.1$ & 1.00 & $\mathrm{CH}_{3} \mathrm{CN}$ & 220 \\
$\mathrm{NaHSO}_{4} \mathrm{SiO}_{2}$ & 90 & 1.5 & $1: 1: 1.2$ & 0.20 & $\mathrm{CH}_{3} \mathrm{CN}$ & 221 \\
$\mathrm{NH}_{2} \mathrm{SO}_{3} \mathrm{H}$ & 90 & 1 & $5: 5: 5$ & $5,00^{\mathrm{a}}$ & - & 222 \\
$\mathrm{HClO}_{4}-\mathrm{SiO}_{2}$ & 89 & 3 & $2: 2: 2.4$ & $0.01^{\mathrm{a}}$ & $\mathrm{CH}_{3} \mathrm{CN}$ & 223 \\
$\mathrm{Yb} \mathrm{PS}_{2}-\mathrm{Rf}_{6}$ & 95 & 5 & $10: 10: 3.3$ & $0.1^{\mathrm{b}}$ & $\mathrm{CH}_{3} \mathrm{CN}$ & 224 \\
$\mathrm{PMA}^{\mathrm{PMA}}$ & 97 & 24 & $0.2: 0.2: 0.2$ & 0.04 & $\mathrm{H}_{2} \mathrm{O}$ & 226 \\
\hline
\end{tabular}

B:A:AS mmol of benzaldehyde(B), aniline (A) and allyltributylstannane (AS)

${ }^{\mathrm{a}}$ mmol. ${ }^{\mathrm{b}} 10 \mathrm{mmol}$ benzoic acid, $0.1 \mathrm{~mol} \%$ of catalyst. ${ }^{\mathrm{C}} 2 \mathrm{~mL}$. 
Table 15 MC synthesis of N-[phenyl-(2-hydroxynaphthalen-1-yl)-methyl]-acetamide using different acid catalysts.

\begin{tabular}{|c|c|c|c|c|c|}
\hline \multirow[b]{2}{*}{ Catalyst } & \multicolumn{5}{|c|}{ 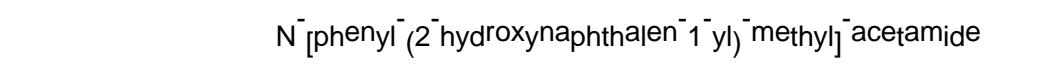 } \\
\hline & $\begin{array}{l}\text { Catalyst amount } \\
\text { mol \% or (g) }\end{array}$ & $\mathrm{T}\left({ }^{\circ} \mathrm{C}\right)$ & Time(h) & $\begin{array}{c}\text { Yield } \\
(\%)\end{array}$ & Ref. \\
\hline Iodine & 5 & 125, Meth B & 5.5 & 86 & 228 \\
\hline $\mathrm{Ce}\left(\mathrm{SO}_{4}\right)_{2}$ & 100 & Reflux & 36 & 72 & 229 \\
\hline p-TSA & 10 & 125, Meth B & 0.6 & 89 & 230 \\
\hline Montm K-10 & $(0.1)$ & 125, Meth B & 1.5 & 89 & 233 \\
\hline Amberlyst-15 & $(0.25)$ & 110, Meth B & 0.2 & 86 & 235 \\
\hline $\mathrm{K}_{5} \mathrm{CoW}_{12} \mathrm{O}_{40} 3 \mathrm{H}_{2} \mathrm{O}$ & 1 & 125, Meth B & 2 & 90 & 234 \\
\hline $\mathrm{H}_{3} \mathrm{PW}_{12} \mathrm{O}_{40}$ & 2 & 100, Meth $B^{a}$ & 1.4 & 90 & 232 \\
\hline $\mathrm{FeCl}_{3-} \mathrm{SiO}_{2}$ & $(0.025)$ & reflux, Meth A & 20 & 80 & 236 \\
\hline $\mathrm{FeCl}_{3-} \mathrm{SiO}_{2}$ & $(0.025)$ & 125, Meth B & 0.18 & 86 & 236 \\
\hline $\mathrm{Al}_{2} \mathrm{O}_{3}-\mathrm{SO}_{3} \mathrm{H}$ & 20 & reflux, Meth A & 20 & 85 & 231 \\
\hline $\mathrm{Al}_{2} \mathrm{O}_{3}-\mathrm{SO}_{3} \mathrm{H}$ & 20 & 125, Meth B & 0.06 & 83 & 231 \\
\hline $\mathrm{Al}_{2} \mathrm{O}_{3}-\mathrm{SO}_{3} \mathrm{H}$ & 20 & MW, Meth C & 0.06 & 87 & 231 \\
\hline $\mathrm{HClO}_{4}-\mathrm{SiO}_{2}$ & 0.6 & reflux, Meth A & 20 & 74 & 238 \\
\hline $\mathrm{HClO}_{4}-\mathrm{SiO}_{2}$ & 0.6 & 110, Meth B & 0.66 & 89 & 238 \\
\hline $\mathrm{HClO}_{4}-\mathrm{SiO}_{2}$ & 0.6 & MW, Meth C & 0.25 & 86 & 238 \\
\hline $\mathrm{Al}_{2} \mathrm{O}_{3}-\mathrm{HClO}_{4}$ & 5 & 125, Meth B & 0.5 & 90 & 237 \\
\hline
\end{tabular}

Benzaldehyde: 2-Naphthol molar ratio=1, Method A: acetonitrile (Ritter type reaction) Method B: acetamide (thermal and solvent free conditions). Method C: acetamide 
(microwave and solvent free conditions). ${ }^{a}$ tetraethyl ammonium chloride (1 mmol) was also added.

Table 16 Results of the synthesis of 1,4-DHP using different supported sulfonic acid as catalysts

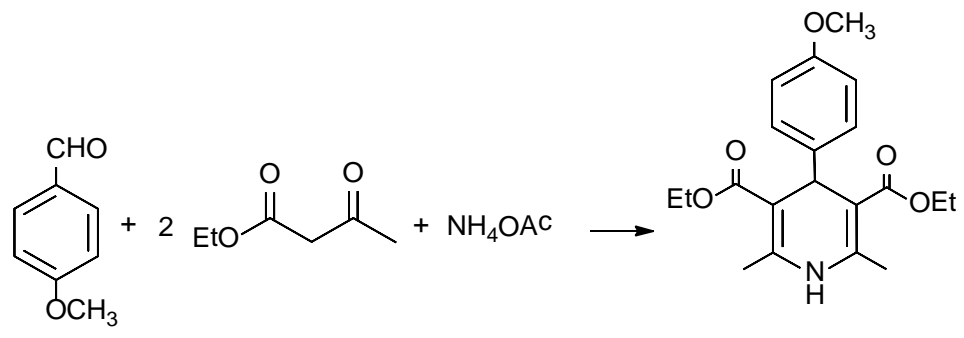

\begin{tabular}{|c|c|c|}
\hline Catalyst & Time (h) & Yield (\%) \\
\hline $\mathrm{SiO}_{2}-\mathrm{SO}_{3} \mathrm{H}$ & 5.00 & 95 \\
\hline Polystyrene- $\mathrm{SO}_{3} \mathrm{H}$ & 6.50 & 82 \\
\hline $\mathrm{PEG}-\mathrm{SO}_{3} \mathrm{H}$ & 6.25 & 85 \\
\hline
\end{tabular}

Reaction conditions: 4-methoxybenzaldehyde (1mmol), ethyl acetoacetate (2 mmol), ammonium acetate $(1.5 \mathrm{mmol})$ catalyst $(0.2 \mathrm{~g})$, at $60^{\circ} \mathrm{C}$ 
Table 17 Results in the synthesis of ethyl 2,7,7-trimethyl-5-oxo-4-phenyl-1,4,5,6,7,8hexahydroquinoline-3-ethylcarboxylate using different catalysts.

\begin{tabular}{|c|c|c|c|c|c|c|}
\hline Catalyst & $\begin{array}{l}\text { Cat.amount } \\
\text { mol\% (g) }\end{array}$ & Solvent / T $\left({ }^{\circ} \mathrm{C}\right)$ & $\begin{array}{l}\text { Time } \\
\text { (min) }\end{array}$ & $\begin{array}{l}\text { Yield } \\
\text { (\%) }\end{array}$ & $\begin{array}{l}\text { B:D:E:A } \\
(\mathrm{mmol})\end{array}$ & Ref. \\
\hline Montmorillonite & $(0.2)$ & $\mathrm{CH}_{3} \mathrm{CH}_{2} \mathrm{OH} / 80$ & 50 & 98 & $2: 2: 2: 3$ & 259 \\
\hline HY & $(0.1)$ & $\mathrm{CH}_{3} \mathrm{CN} / \mathrm{rt}$ & 120 & 93 & $1: 1: 1: 1.5$ & 261 \\
\hline $\mathrm{K}_{7}\left[\mathrm{PW}_{11} \mathrm{CoO}_{40}\right]$ & 1 & $\mathrm{CH}_{3} \mathrm{CN} /$ reflux & 30 & 85 & 1:1:1:1 & 260 \\
\hline Glycine & 10 & MW & 1 & 95 & $1: 1: 1: 1.2$ & 263 \\
\hline Ni np & 10 & MW & 1 & 95 & $1: 1: 1: 1.5$ & 262 \\
\hline
\end{tabular}

${ }^{\mathrm{a}} \mathrm{B}: \mathrm{D}: \mathrm{E}: \mathrm{A}$ : Molar ratio Benzaldehyde:Dimedone:Ethyl acetoacetate:Ammonium acetate 
Table 18 Main characteristic and yields of DHP obtained for various Hydrotalcites as catalyst.

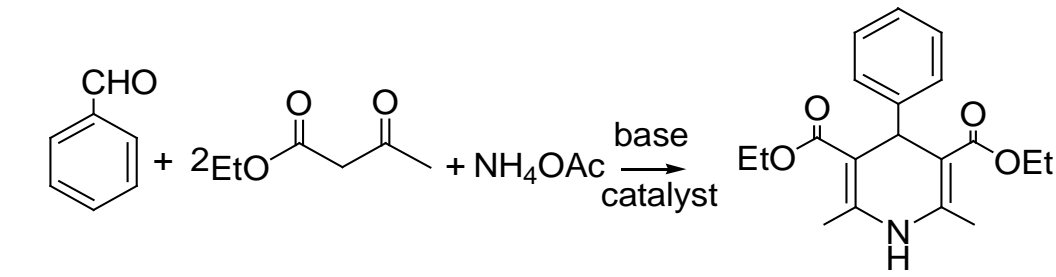

\begin{tabular}{lcccc}
\hline Catalyst & $\mathrm{M}(\mathrm{II}) / \mathrm{Al}$ & $\begin{array}{l}\text { Surf. Area } \\
\left(\mathrm{m}^{2} / \mathrm{g}\right)\end{array}$ & Yield (\%) $^{\mathrm{a}}$ & Yield (\%) $^{\mathrm{b}}$ \\
\hline $\mathrm{MgAl}_{2}$-HT & 2.10 & 118 & 45 & 61 \\
$\mathrm{MgAl}_{3}$-HT & 2.87 & 100 & 29 & 35 \\
$\mathrm{MgAl}_{4}$ HT & 4.36 & 92 & 25 & 30 \\
$\mathrm{NiAl}_{3}$-HT & 2.95 & 145 & 20 & 22 \\
$\mathrm{CoAl}_{3}$-HT & 2.53 & 10 & 20 & 35 \\
$\mathrm{MgAl}_{2}$-CHT & 2.10 & $\mathrm{Nd}^{\mathrm{e}}$ & - & 15 \\
MgAl$_{4}$-RHT & 4.36 & $\mathrm{Nd}$ & - & 32 \\
Blank & - & - & 18 & 9 \\
\hline
\end{tabular}

Experimental conditions: Benzaldehyde $(0.0039 \mathrm{M})$, ethyl acetoacetate $(0.0078 \mathrm{M})$ ammonium acetate $(0.0039 \mathrm{M})$, room temperature. ${ }^{\mathrm{a}} 25 \mathrm{mg}$ of catalyst, time $1 \mathrm{~h}, 10 \mathrm{~mL}$ $\mathrm{EtOH},{ }^{\mathrm{b}} 50 \mathrm{mg}$ catalyst time $6.5 \mathrm{~h}, 10 \mathrm{~mL} \mathrm{MeCN},{ }^{\mathrm{c}}$ Calcined at $450{ }^{\circ} \mathrm{C}$ for $5 \mathrm{~h}{ }^{\mathrm{e}} \mathrm{Nd}$ : Not determined 
Table 19 MC Pyridine derivatives synthesis using bifunctional metal-acid heterogeneous catalysts.

\begin{tabular}{lcccc}
\multicolumn{1}{c}{$\mathrm{PhCHO}^{+}+2$} & & & & \\
\hline Catalysts & Method & $\left.{ }^{\circ} \mathrm{C}\right)$ & Time(h) & Yield (\%) \\
\hline $\mathrm{Pt} / \mathrm{Al}_{2} \mathrm{O}_{3} / \mathrm{K} 10$ & $\mathrm{MW}$ & 130 & 1.5 & 15 \\
$\mathrm{Pd} / \mathrm{Al}_{2} \mathrm{O}_{3} / \mathrm{K} 10$ & $\mathrm{MW}$ & 130 & 1.5 & 20 \\
$\mathrm{Pd} / \mathrm{C} / \mathrm{K} 10$ & $\mathrm{MW}$ & 130 & 1.5 & 78 \\
$\mathrm{Pd} / \mathrm{C}$ & $\mathrm{MW}$ & 130 & 1.0 & 51 \\
$\mathrm{~K} 10$ & $\mathrm{MW}$ & 130 & 1.5 & 0 \\
$\mathrm{Pd} / \mathrm{C} / \mathrm{K} 10$ & $\mathrm{CH}$ & 140 & 29 & 88 \\
$\mathrm{Pd} / \mathrm{C} / \mathrm{K} 10$ & $\mathrm{CH}$ & 100 & 28 & 11 \\
$\mathrm{Pd} / \mathrm{C} / \mathrm{TfOH}$ & $\mathrm{CH}$ & 130 & 14 & 50 \\
$\mathrm{Pd} / \mathrm{C} / \mathrm{HOAc}$ & $\mathrm{CH}$ & 110 & 24 & 10
\end{tabular}

Reaction Conditions: benzaldehyde (1 mmol), methyl acetoacetate (2 mmol) and ammonium acetate $(1 \mathrm{mmol})$. (toluene, pressure tube for conventional heating $(\mathrm{CH})$. 
Table 20 Results obtained in the MCR of benzaldehyde, acetophenone, acetyl chloride and acetonitrile in presence of different solid acid catalyst.

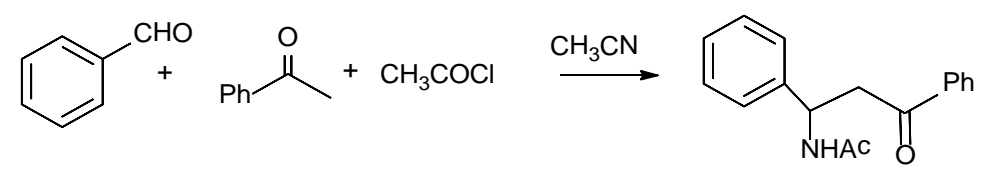

$\mathrm{N}^{-} 3^{-}{ }^{-} \mathrm{oxo}^{-} 13^{-}$diphenyl propyl) acetamide.

\begin{tabular}{|c|c|c|c|c|}
\hline $\begin{array}{l}\text { Catalyst } \\
\text { (amount) }\end{array}$ & $\begin{array}{c}\mathrm{T} \\
\left({ }^{\circ} \mathrm{C}\right)\end{array}$ & $\begin{array}{l}\text { Time } \\
\text { (h) }\end{array}$ & Yield $(\%)^{\mathrm{a}}$ & Ref. \\
\hline $\mathrm{K}_{5} \mathrm{CoW}_{12} \mathrm{O}_{40} 3 \mathrm{H}_{2} \mathrm{O}(0.01 \% \mathrm{~mol})$ & $\mathrm{rt}$ & 1 & 86 & 304 \\
\hline $\mathrm{H}_{6} \mathrm{P}_{2} \mathrm{~W}_{18} \mathrm{O}_{62}(0.7 \% \mathrm{~mol})$ & 80 & 0.4 & 86 & 303 \\
\hline $\mathrm{H}_{3} \mathrm{PW}_{12} \mathrm{O}_{40}(0.05 \% \mathrm{~mol})$ & $\mathrm{rt}$ & 0.8 & 95 & 302 \\
\hline $\mathrm{H}_{3} \mathrm{PMo}_{12} \mathrm{O}_{40}(0.08 \% \mathrm{~mol})$ & $\mathrm{rt}$ & 0.5 & 90 & 302 \\
\hline $\mathrm{H}_{3} \mathrm{SiW}_{12} \mathrm{O}_{40}(0.08 \% \mathrm{~mol})$ & rt & 0.5 & 92 & 302 \\
\hline Amberlyst-15 (200 mg) & $\mathrm{rt}$ & 6 & 89 & 306 \\
\hline HBeta & $\mathrm{rt}$ & 8 & 89 & 301 \\
\hline Nafion (500 mg) & $\mathrm{rt}$ & 4 & 96 & 305 \\
\hline Sulfated zirconiab & $\mathrm{rt}$ & $1-3$ & 95 & 307 \\
\hline $\begin{array}{l}\text { Silica sulfuric acid (300 mg, } 0.78 \\
\text { mmol H+) }\end{array}$ & 80 & $1-2$ & 91 & 308 \\
\hline $\begin{array}{l}\mathrm{PMA} / \mathrm{SiO}_{2}(0.005 \mathrm{~mol} \text { based on } \\
\text { PMA) }\end{array}$ & rt & 6 & 94 & 309 \\
\hline
\end{tabular}

${ }^{a}$ Reactions are performed using $1 \mathrm{mmol}$ benzaldehyde and $1 \mathrm{mmol}$ acetophenone. ${ }^{\mathrm{b}}$ No data about the amount of catalyst is reported. 
Table 21 Reaction conditions and yields of Diethyl(Phenyl)( $N$ phenylamino)methylphosphonate prepared by coupling benzaldehyde aniline and diethyl phosphonate using different catalysts.

\begin{tabular}{|c|c|c|c|c|}
\hline $\mathrm{Ph}^{-} \mathrm{CHO}+\mathrm{Ph}^{-} \mathrm{NH}_{2}$ & $\begin{array}{c}\mathrm{O} \\
+\quad \mathrm{H}^{-\Lambda \mathrm{P}^{-}}(\mathrm{OEt})_{2}\end{array}$ & $\underset{\text { catalyst }}{\stackrel{\text { acid }}{\longrightarrow}}$ & $\begin{array}{c}\mathrm{Ph}^{-} \mathrm{CH}^{-}{ }^{\mathrm{O}} \\
\mathrm{NHPh}^{-}\end{array}$ & \\
\hline Catalyst(amount) & $\begin{array}{l}\text { Solvent/ } \\
\mathrm{T}\left({ }^{\circ} \mathrm{C}\right)\end{array}$ & $\begin{array}{l}\text { Time } \\
\text { (min) }\end{array}$ & $\begin{array}{l}\text { Yield } \\
(\%)^{\mathrm{a}}\end{array}$ & Ref \\
\hline Amberlyst-IR 120(0.10 g) & $-/ \mathrm{MW}$ & 2 & 90 & 345 \\
\hline $\mathrm{Al}_{2} \mathrm{O}_{3}$ acidic(5,75g) & $-/ \mathrm{MW}$ & 6 & 87 & 348 \\
\hline $\mathrm{SbCl}_{3} / \mathrm{Al}_{2} \mathrm{O}_{3}(5 \mathrm{~mol} \%)$ & $\mathrm{CH}_{3} \mathrm{CN} / \mathrm{rt}$ & 180 & 90 & 350 \\
\hline ALKIT-5 (0.02 g) & $\mathrm{CH}_{3} \mathrm{CN} / 80$ & 240 & 86 & 351 \\
\hline $\mathrm{H}_{3} \mathrm{PW}_{12} \mathrm{O}_{40}(0.50 \mathrm{~mol} \%)$ & $\mathrm{CH}_{2} \mathrm{Cl}_{2} / \mathrm{rt}$ & 10 & 94 & 352 \\
\hline $\mathrm{Al}\left(\mathrm{H}_{2} \mathrm{PO}_{4}\right)_{3}(0.06 \mathrm{~g})$ & $-/ 100$ & 90 & 93 & 353 \\
\hline
\end{tabular}


Table 22 Yield of 4H-pyran derivative using different solid base catalysts

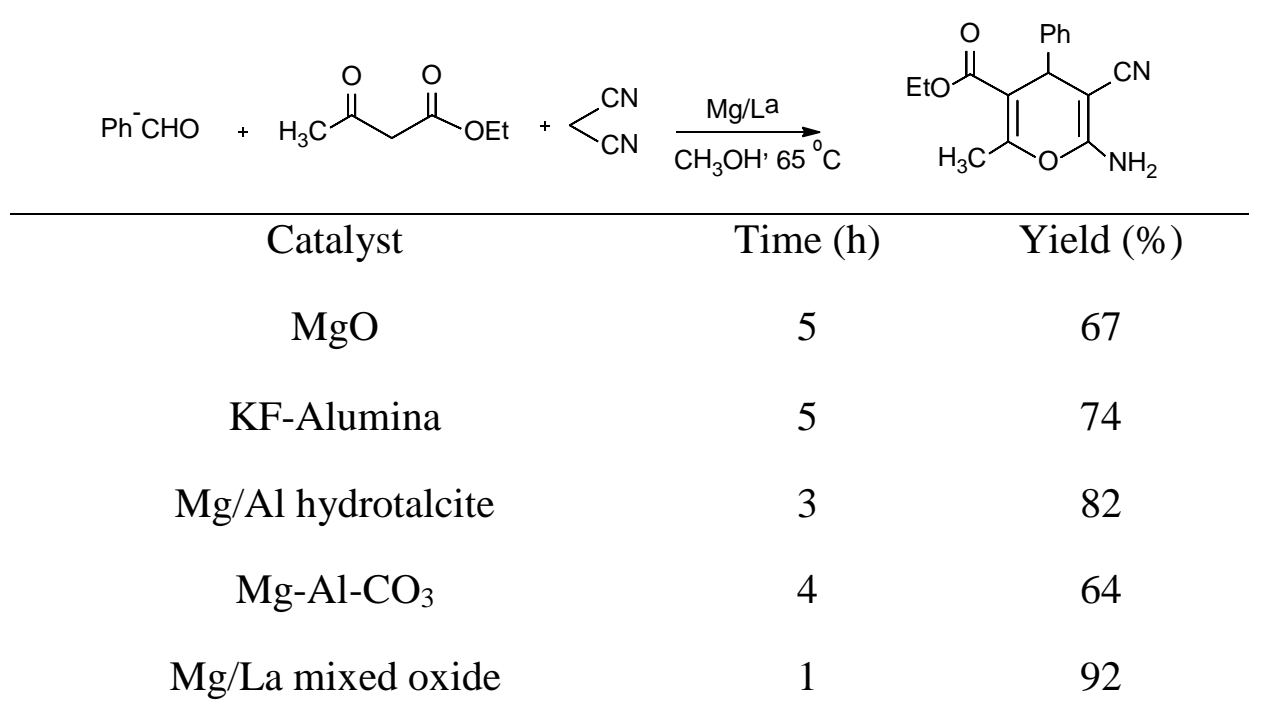

Reaction conditions: 4-chlorobenzaldehyde (1 mmol), malononitrile (1.1 mmol), ethyl acetoacetate $(1.1 \mathrm{mmol})$ in $\mathrm{MeOH}$ at $65^{\circ} \mathrm{C}$. 
Table 23 Synthesis of 2-amino-4-(4-bromophenyl)-3-cyano-4H,5H-pyrano[3,2c]chromene-5-one from the condensation of 4-hydroxycoumarin, 4-bromobenzaldehyde and malononitrile.

\begin{tabular}{lccc} 
Catalyst (mmol \%) & Solvent & Time(min) & Yield (\%) \\
\hline $\mathrm{H}_{6} \mathrm{P}_{2} \mathrm{~W}_{18} \mathrm{O}_{62.18 \mathrm{H}_{2} \mathrm{O}(1)}$ & $\mathrm{EtOH}$ & 120 & 72 \\
$\mathrm{H}_{6} \mathrm{P}_{2} \mathrm{~W}_{18} \mathrm{O}_{62} .18 \mathrm{H}_{2} \mathrm{O}(1)$ & $\mathrm{H} 2 \mathrm{O}$ & 140 & 82 \\
$\mathrm{H}_{6} \mathrm{P}_{2} \mathrm{~W}_{18} \mathrm{O}_{62} .18 \mathrm{H}_{2} \mathrm{O}(1)$ & $\mathrm{EtOH}: \mathrm{H}_{2} \mathrm{O}$ & 60 & 87 \\
$\mathrm{NH}_{2} \mathrm{SO}_{3}(10)$ & $\mathrm{EtOH}: \mathrm{H}_{2} \mathrm{O}$ & 100 & 76 \\
$\mathrm{H}_{14} \mathrm{NaP}_{5} \mathrm{~W}_{30} \mathrm{O}_{110}(1)$ & $\mathrm{EtOH}: \mathrm{H}_{2} \mathrm{O}$ & 90 & 74 \\
\hline $\mathrm{E}_{2} \mathrm{OH}: \mathrm{H}_{2} \mathrm{O}(50.50)$ &
\end{tabular}

EtOH: $\mathrm{H}_{2} \mathrm{O}$ (50:50) under refluxing conditions. 
Table 24 Yields of 2-amino-chromene in the presence of different solid catalysts

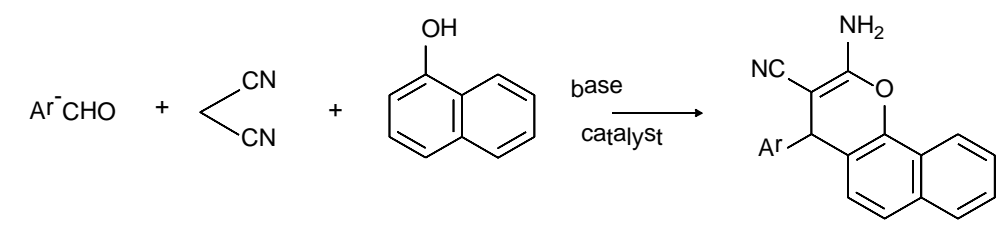

\begin{tabular}{lcc}
\hline Catalyst & Yield(\%) BM & Yield(\%)chromene \\
\hline$\gamma$-Alumina & 13 & 84 \\
Silica gel & 35 & 61 \\
Montmorillonite KSF & 48 & 50 \\
Hydrotalcite Pural MG30 & 72 & 24
\end{tabular}

BM: benzylidenemalononitrile. Experimental conditions: Benzaldehyde (10 mmol), malononitrile (10 mmol),1-naphthol (10 mmol), catalysts $(0.50 \mathrm{~g}), 10$ $\mathrm{mL}$ water at refluxing conditions after $2 \mathrm{~h}$ of reaction. 
Table 25 Yield of 2-aminochromenes from benzaldehyde, malononitrile and 1naphthol in the presence of different catalysts.

\begin{tabular}{|c|c|c|c|c|c|}
\hline Catalyst & B:M:N & $\begin{array}{l}\text { Time } \\
\text { (h) }\end{array}$ & $\begin{array}{c}\text { Solvent /T } \\
\left({ }^{\circ} \mathrm{C}\right)\end{array}$ & $\begin{array}{l}\text { Yield } \\
\text { (\%) }\end{array}$ & Ref \\
\hline $\mathrm{KF}-\mathrm{Al}_{2} \mathrm{O}_{3}(0.5 \mathrm{~g})$ & $5: 5: 5$ & 5 & $\mathrm{EtOH} / 80$ & 83 & 403 \\
\hline $\mathrm{Al}_{2} \mathrm{O}_{3}(0.5 \mathrm{~g})$ & 0.01:0.01:0.01 & 3 & $\mathrm{H}_{2} \mathrm{O} /$ reflux & 96 & 404 \\
\hline $\mathrm{MgO}(0.05 \mathrm{~g})$ & $2: 2: 2$ & 1 & $\mathrm{H}_{2} \mathrm{O} /$ reflux & 86 & 405 \\
\hline $\mathrm{MgO}(0.05 g)$ & $2: 2: 2$ & 0.25 & $\mathrm{H}_{2} \mathrm{O}: \mathrm{PEG} / \mathrm{rt}$ & 96 & 405 \\
\hline $\mathrm{Mg} / \mathrm{Al} \mathrm{HT}{ }^{\mathrm{a}}$ & $1: 1: 1$ & 0.12 & MW/140 & 84 & 406 \\
\hline$[\mathrm{Bmim}] \mathrm{BF}_{4}{ }^{\mathrm{b}}$ & $5: 5: 5$ & 1 & $\mathrm{H}_{2} \mathrm{O} /$ reflux & 81 & 407 \\
\hline$[\mathrm{Bmim}] \mathrm{OH}^{\mathrm{b}}$ & $5: 5: 5$ & 0.16 & $\mathrm{H}_{2} \mathrm{O} /$ reflux & 91 & 407 \\
\hline
\end{tabular}

B:M:N: mmol of Benzaldehyde:Malononitrile;1-Naphthol.

${ }^{\mathrm{a}} 50 \mathrm{wt} \%$ respect naphthol; ${ }^{\mathrm{b}} 0.5 \mathrm{mmol}$. 